Rhode Island College

Digital Commons @ RIC

Master's Theses, Dissertations, Graduate

Master's Theses, Dissertations, Graduate

Research and Major Papers Overview

Research and Major Papers

2017

\title{
Teachers' Experiences of Induction: A Narrative Retrospective Inquiry
}

Jodi L. Clark

Rhode Island College

Follow this and additional works at: https://digitalcommons.ric.edu/etd

Part of the Higher Education Commons, and the Secondary Education Commons

\section{Recommended Citation}

Clark, Jodi L., "Teachers' Experiences of Induction: A Narrative Retrospective Inquiry" (2017). Master's Theses, Dissertations, Graduate Research and Major Papers Overview. 177.

https://digitalcommons.ric.edu/etd/177

This Dissertation is brought to you for free and open access by the Master's Theses, Dissertations, Graduate Research and Major Papers at Digital Commons @ RIC. It has been accepted for inclusion in Master's Theses, Dissertations, Graduate Research and Major Papers Overview by an authorized administrator of Digital Commons @ RIC. For more information, please contact digitalcommons@ric.edu. 
TEACHERS' EXPERIENCES OF INDUCTION COACHING:

A NARRATIVE RETROSPECTIVE INQUIRY

BY

JODI L. CLARK

A DISSERTATION SUBMITTED IN PARTIAL FULFILLMENT OF THE

REQUIREMENTS FOR THE DEGREE OF

DOCTOR OF PHILOSOPHY

IN

EDUCATION

UNIVERSITY OF RHODE ISLAND

AND

RHODE ISLAND COLLEGE

2017 


\title{
DOCTOR OF PHILOSOPHY DISSERTATION
}

\author{
$\mathrm{OF}$
}

Jodi L. Clark

\section{APPROVED: \\ Dissertation Committee \\ Major Professor:}

\author{
Theresa Deeney \\ Kathy Peno \\ Anne Goodrow \\ Corinne McKamey
}

RIC:

Donald Halquist, Dean, Feinstein School of Education - RIC

URI:

Nasser H. Zawia, Dean, The Graduate School - URI

UNIVERSITY OF RHODE ISLAND

AND

RHODE ISLAND COLLEGE

2017 


\begin{abstract}
It is well established that beginning teachers need support to bridge the gap from college teacher preparation to the classroom setting (Fletcher \& Strong, 2009; Wong, 2003). In fact, lack of support in this transition has been identified as a leading factor that causes beginning teachers to leave the profession at high rates early in their careers (Andrews, Gilbert \& Martin, 2006). Research suggests that coaching is an effective way to support beginning teacher's learning (Ingersoll \& Strong, 2011). The purpose of this qualitative research is to tell the lived experiences of nine teachers who took part of in a statewide induction coaching program. Using narrative inquiry methodology with semi-structured interviews, the study sought to gain the individual stories of past beginning teachers who worked with an induction coach, identify common themes across beginning teachers' narratives, and to understand what their retrospective stories tell us about working with their induction coach. Four main implications of the findings include the needs of beginning teachers in the field, phases of coaching in reaction to the needs of beginning teachers, qualities of an induction coach, and the need for coaches to mediate the identities of the beginning teacher.
\end{abstract}




\section{ACKNOWLEDGMENTS}

I would like to acknowledge my Major Professor, Dr. Theresa Deeney, for continually pushing me to tell the stories of these nine beginning teachers. Through numerous revisions, meetings, and endless forms you were there by my side. Your guidance and patience along this journey has been invaluable.

Thank you to my other committee members for your time and commitment: Dr. Anne Goodrow, Dr. Corinne McKamey, Dr. Kathy Peno, Dr. Christine Kunkel, and my Outside Committee Chair, Dr. Richard Rhodes.

Thank you to the nine brave teachers who shared with me the story of their first year(s) teaching. These dedicated professionals met with me on Saturdays, during school vacation, and even in the evening after a long school day. I hope your stories encourage other professionals to value the needs of beginning teachers.

I also want to thank my fellow sixteen pioneers in the Rhode Island Induction Program who inspired me through their hard work and dedication. Our bi-monthly gatherings provided me with a realistic picture of a first year teacher's challenges and successes, which prompted me to further research teacher induction. This work could not have been done without the expertise, support, and training from our fearless leaders: Fred Williams and Jan Miles from the New Teacher Center, as well as Hilda Potrzeba and Donna Vallese at the Rhode Island Department of Education.

My appreciation also extends to the $2010 \mathrm{PhD}$ Cohort: Mary Moen, Shima Younes, Erin Papa, Mary Slattery, and Rachael Clemons. We did this together, and without your support, I would not have completed this journey. Rachael and Mary M., 
thank you for the additional time you spent acting as peer reviewers. Thank you to Erin and Nicole L'Etoile for working alongside me at the library and coffee shops to get the work done.

I would like to acknowledge the generous Enhancement of Graduate Research Award that I received from The University of Rhode Island's Graduate School. This grant provided me the funding to present my research at the New Teacher Center International Symposium in San Francisco, as well as at the New England Educational Research Organization Annual Conference in New Hampshire.

Thank you to Donna Sherman and my mom, Beverly Clark, for their editing expertise. No words can express my appreciation for the endless hours you have spent reading, editing, and revising.

Finally, to my mom and dad, my entire family, friends, and colleagues who have cheered me on along the way. I could not have completed this seven-year journey without your love, words of encouragement, shoulders to lean on, distractions from the stress of writing, and your understanding of my absence when I needed to escape and seek solitude at the library to work on my research. 


\section{DEDICATION}

This dissertation is dedicated to my family and friends who have supported me in this journey, and to all the teachers along the way who instilled in me a love of learning.

The three most powerful teachers in my life have been the three strongest women I know: my mother, my grandmother, and my great grandmother. First and foremost, my mom, Beverly Clark, has been my greatest influence. She has been my editor-in-chief throughout my life, and I cannot thank her enough for the countless hours she has spent reading my papers, providing feedback, and words of encouragement. I could not have done this without her! My grandmother, Doris Colburn, was a brilliant and witty woman who loved learning and could tackle any challenging crossword puzzle. From her I learned the art of telling a story, as well as the importance to see past the hard times and focus on the precious moments in life. My great grandmother, Alice Parker, spent hours with me as a child patiently teaching me her crafts and the art of making tea. Her strong will and independence taught me how to face any obstacle. 


\section{TABLE OF CONTENTS}

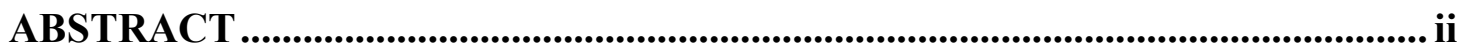

ACKNOWLEDGMENTS ..............................................................................................ii

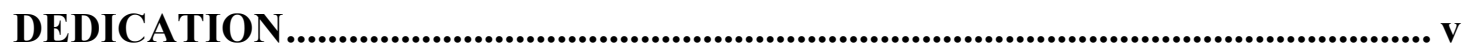

TABLE OF CONTENTS.............................................................................................. vi

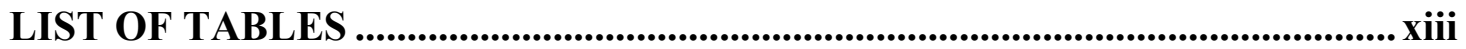

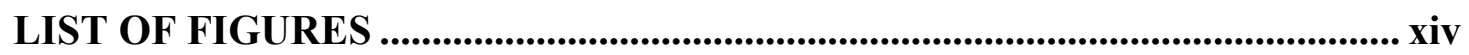

CHAPTER 1 Introduction ................................................................................................ 1

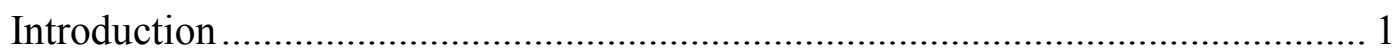

My Narrative ................................................................

Statement of the Problem......................................................

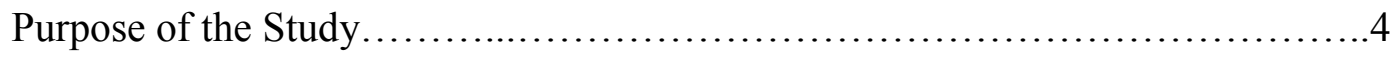

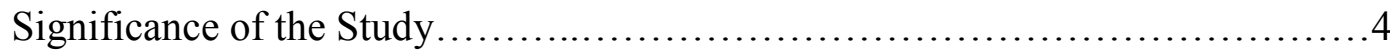

Research Puzzles........................................................6

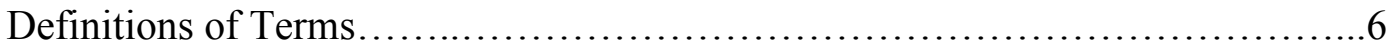

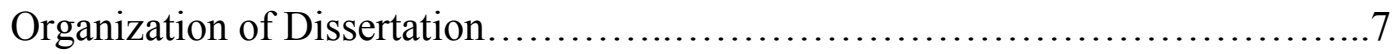

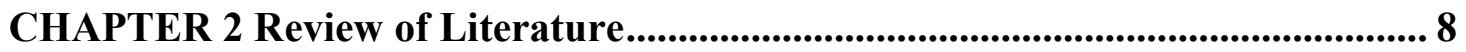

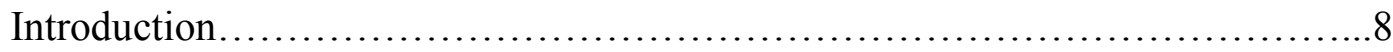

Theoretical Framework......................................................... 8

Sociocultural Learning Theory ………………………................................... 8

Adult Learning Theory.................................................. 13

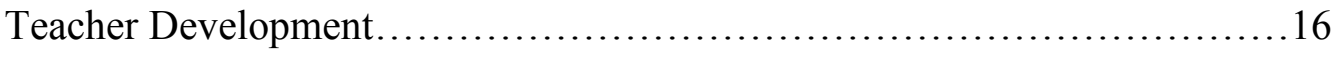

Supporting Beginning Teacher Development................................19 


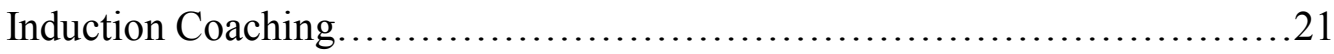

Impact of Coaching on Teacher Efficacy...............................26

Chapter Summary..................................................27

CHAPTER 3 Methodology ...................................................................................... 28

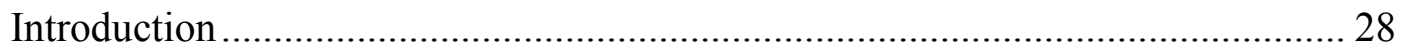

Research Design.....................................................28

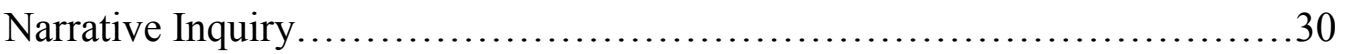

Thematic Analysis........................................... 31

Structural Analysis..........................................32

Interactional Analysis......................................33

Performative Analysis............................................33

Context of the Study................................................ 35

The Role of the Researcher............................................ 36

Methods and Procedures.................................................. 36

Participants.................................................... 36

Purposeful Sampling............................................. 38

Participant Consent..............................................40

Data Collection........................................................40

Interviews...................................................40

Field Notes.................................................. 42

Narrative Sketch.................................................43

Data Analysis....................................................45

Data Preparation....................................................45 
Analysis 46

Stage 1: Initial Coding.....................................47

Coding Small Stories...............................47

Coding Big Stories...................................48

Stage 2: Secondary Coding..................................48

Stage 3: Cross-Case Analysis................................50

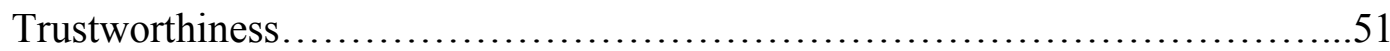

Reflexivity Journal.............................................53

Peer Review...................................................54

Member Checking................................................55

Chapter Summary........................................................56

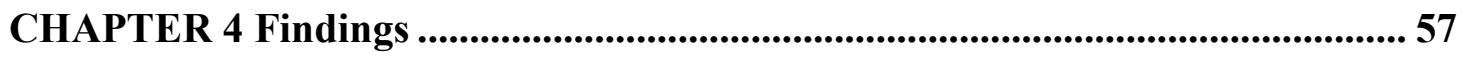

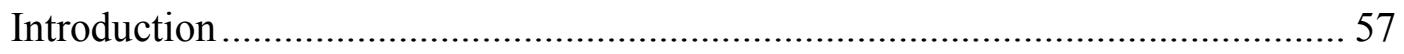

Individual, Small Story Thematic Analysis Findings.........................58

Profile \#1: Rachael..............................................59

Memo: Rachael Overview.....................................59

Profile \#2: Beth...............................................60

Memo: Beth Overview.......................................60

Profile \#3: Shelly...............................................61

Memo: Shelly Overview.....................................61

Profile \#4: Charlotte.................................................62

Memo: Charlotte Overview...................................63

Profile \#6: Sarah..................................................63 
Memo: Sarah Overview...........................................64

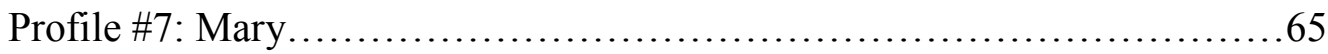

Memo: Mary Overview..........................................65

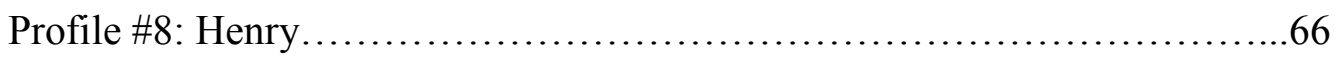

Memo: Henry Overview..........................................66

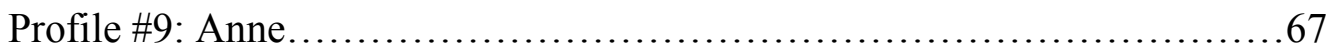

Memo: Anne Overview.............................................67

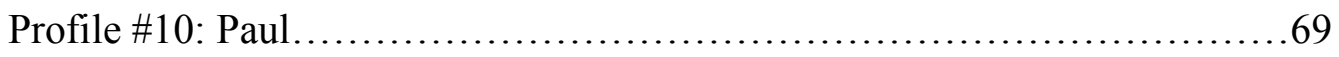

Memo: Paul Overview.............................................69

Performative Analysis Findings............................................ 70

Cross-Case, Small Story, Thematic Findings..................................74

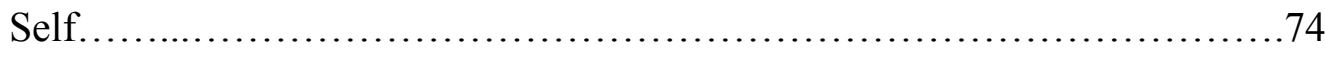

Isolated......................................................... 75

Defeated...................................................... 77

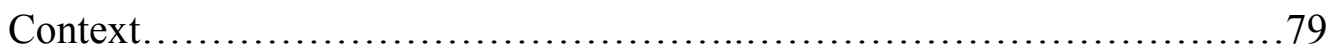

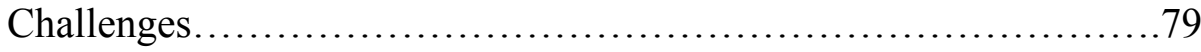

Support............................................................ 83

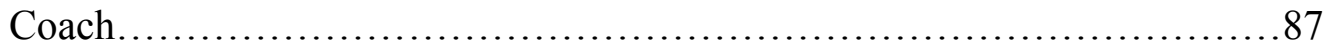

First Impressions............................................... 87

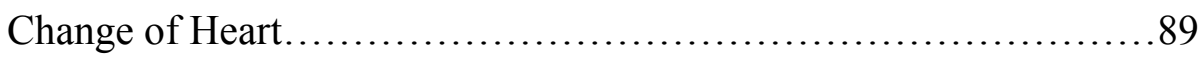

Emotional Support........................................... 93

A Second Set of Eyes........................................... 96

Confidential Outsider............................................... 99 
Want Back/Regret.......................................103

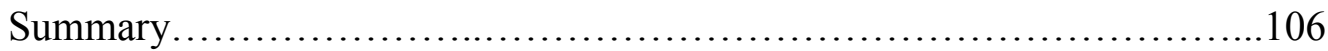

Types of Coaching Support Findings................................... 106

Big Story, Structural Findings........................................ 111

Big Narrative \#1: Henry's Story......................................111

Big Narrative \#2: Charlotte's Story.................................... 117

Big Narrative \#3: Mary's Story...................................... 121

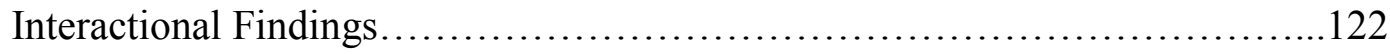

Chapter Summary................................................. 127

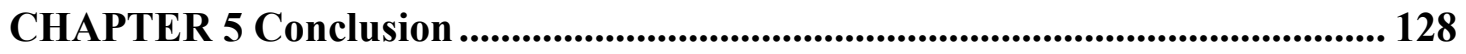

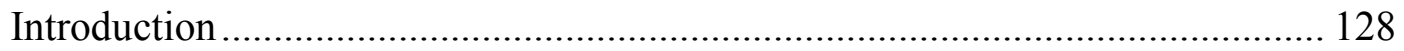

Summary of Findings.............................................. 128

Limitations....................................................... 131

Generalizability.................................................... 131

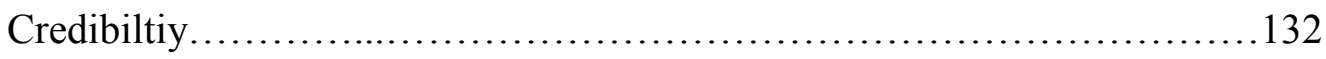

Dependability..................................................... 132

Researcher Bias................................................. 133

Implications..................................................... 133

Needs of Beginning Teachers......................................133

More Knowledgeable Other................................133

Reflection..................................................134

Emotional Support....................................... 134

Pedagogical Support.......................................135 
Classroom Management.........................................135

Multiple Years of Support.......................................136

Phases of Induction Coach Support.....................................136

Phase One: Trepidation.......................................... 138

Phase Two: Change of Heart....................................... 138

Phase Three: Emotional Support.................................139

Phase Four: Classroom Management Support......................140

Phase Five: Pedagogical Support.................................140

Phase Six: Reflection Support.....................................141

Phase Seven: Want Back/Regret................................141

Qualities of Induction coaches....................................... 144

Flexible.......................................................... 144

Confidential................................................. 145

Knowledgeable.................................................. 145

Resourceful................................................. 146

Role of the Coach in Mediating Identities................................147

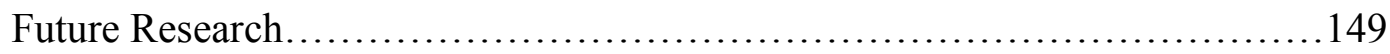

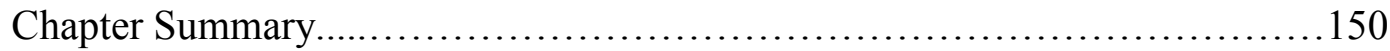

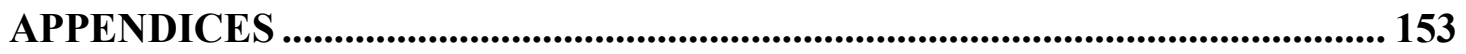

Appendix A: Internal Review Board Approval.............................153

Appendix B: Rhode Island Department of Education Approval...................155

Appendix C: Email to Induction Coaches.................................156

Appendix D: Email to Beginning Teachers.................................157 
Appendix E: Signed Consent Form...................................158

Appendix F: SurveyMonkey Questions.................................161

Appendix G: Implied Consent Statement................................ 162

Appendix H: Interview Guide.......................................... 164

Appendix I: Member Check Email........................................ 165

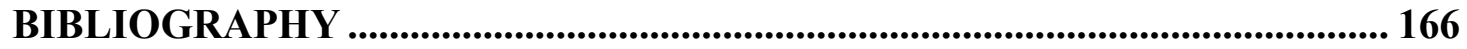




\section{LIST OF TABLES}

TABLE

PAGE

Table 3.1 Purposeful Sampling of Participants...................................................... 39

Table 3.2 Notational System for Transcription...................................................... 45

Table 3.3 Notes from Reflexivity Journal ........................................................ 50

Table 3.4 Strategies for Promoting Validity and Reliability................................... 52

Table 4.1 Participants' Identities.................................................................... 71

Table 4.2 Types of Coaching Support.......................................110 


\section{LIST OF FIGURES}

FIGURE

PAGE

Figure 2.1 Overview of Theoretical Framework................................................... 9

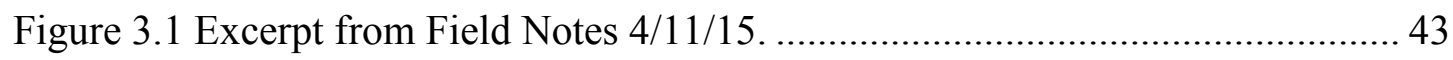

Figure 3.2 Memo for Sarah ............................................................................ 44

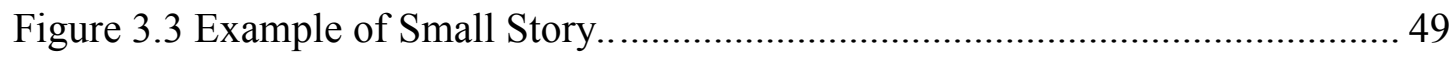

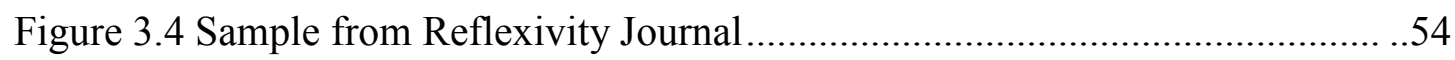

Figure 4.1 Overview of Analysis......................................... 57

Figure 4.2 Overview of Cross-Case, Small Story Thematic Findings.................75

Figure 4.3 Overview of Cross-Case, Small Story Coaching Support Findings........106

Figure 5.1 Phases of First-Year Teachers' Attitude Toward Coaching...............137

Figure 5.2 Phases of Induction Coach Support............................. 138

Figure 5.3 Overlap of Phases........................................... 143

Figure 5.4 Role of Coach in Mediating Identities...............................148 


\section{CHAPTER 1}

\section{INTRODUCTION}

This study is a narrative inquiry into beginning teachers' experiences working with an induction coach. To remain true to the methodology that I have chosen for conducting the research, narrative inquiry, I will start this journey by reflecting on my own story: "Narrative inquirers need to begin with personal justifications, that is, by justifying the inquiry in the context of their own life experiences, tensions, and personal inquiry puzzles" (Clandinin, 2013, p. 36). This is my story of induction in the teaching profession.

\section{My Narrative}

I remember my first day of teaching as if it was yesterday. I had mapped out the journey from my house to the school with meticulous detail, knowing exactly how long it took and where I might hit traffic. I was ready for the first day, my outfit selected and ironed, and my lunch was packed. I went to bed nice and early to be ready. Sometime in the middle of the night, amidst the teacher dreams and tossing and turning, I had turned off my alarm clock. I rolled over and glanced at the clock and it glowed the time I wanted to be leaving my house. I raced around frantically and arrived at school as the students were walking in. My new colleagues were most likely looking at me with disgust, "Who is the brand new teacher who saunters in with the students?" 
This was just the beginning of what would be a tumultuous first year. Sure, I had support from the team of teachers I was working with, but for that year, I felt like I was constantly running late, and the frantic feeling of that first day never left.

Why wasn't I prepared? What had I done wrong in my training? My $4^{\text {th }}$ grade student teaching placement had been a great learning experience. And now I was teaching both $5^{\text {th }}$ and $6^{\text {th }}$ grade in a middle school. I was not ready for this! Yes, I had aced all my classes, written perfect lesson plans, and read every teacher prep book I could find. But nothing could prepare me for that first year, just a classroom full of students, and me with no curriculum, and no guide.

Throughout the year, I caught every illness that passed through my classes and made multiple trips to the walk-in clinic. I was afraid to be out sick. How would I write lesson plans for a substitute when I did not know what I was doing day-to-day? I had an assigned mentor, and we met once a week after school and talked about basic things - when the quarter ended, whom to ask for copy paper, and how to fill-out report cards. However, we did not talk about students, curriculum, assessments, or data. Yes, it was helpful to meet with her, but she did not know my students and what I faced each day. The other teachers on my team tried to be helpful. They gave me copies of worksheets and projects they used, and I felt obliged to follow their path. What did I know? I felt like an imposter teaching someone else's lessons. It wasn't me; I had no ownership in what I was teaching (or assigning). I struggled with behavior management on a daily basis. I tried to mimic what the teachers on my team did with the "difficult" students. One was very strict and yelled a lot and the other had 
a great sense of humor that lured the students in. I did not really feel comfortable in either role.

Even though I was assigned a mentor to work with that first year, she taught in another grade level and was busy with her own classroom needs. She did not know my students and the dynamics of the two teams I was working on. Somehow, I made it through and found other beginning teachers to commiserate with as well as a veteran teacher on one of my teams who took me under her wing and showed me the ropes. But that first year was difficult. There were many times I questioned my career choice and if I had what it took to make it as a teacher. I know now that I have chosen the greatest profession out there and that with a lot of hard work and dedication I can inspire students in the classroom. However, after sixteen years in public education, working with many beginning teachers as well as student teachers, I am left wondering why our profession does not provide more support for teachers early in their careers.

\section{Statement of the Problem}

Like my own personal story of induction into the profession, it is well established that beginning teachers need support to bridge the gap from college teacher preparation to the classroom setting (Fletcher \& Strong, 2009; Wong, 2003). In fact, lack of support in this transition has been identified as a leading factor that causes beginning teachers to leave the profession at high rates early in their careers (Andrews, Gilbert, \& Martin, 2006). Wilkins and Clift (2006) report that the teacher attrition problem is epidemic as districts across the county invest significant time and money to recruit and train over 500,000 new teachers every year, only to lose $30 \%$ - 
$50 \%$ of them within the first five years. Attrition is not the only problem to consider. If we know from research in teacher development that teachers do not have all the skills they need when they finish a teacher preparation program, then why would we send them out into the workforce to go it alone? For the sake of the students and beginning teachers like me, we need to change this pattern in our profession. To provide needed support, many states and school districts have developed formal coaching or mentoring programs for beginning teachers. Quality induction programs can be effective in raising student achievement (Fletcher, Strong \& Villar, 2008; Wong, 2005). Although research does suggest benefits of induction programs, few studies glean insight from first- and second-year teachers regarding their initial teaching experience and the support they gained from an induction program.

\section{Purpose of the Study}

The purpose of my qualitative study is to capture the stories of beginning teachers in Rhode Island who participated in a statewide induction program to support them during this critical time in their careers. Specifically, my goal is to understand the beginning teachers' experiences working with an induction coach, and how working with an induction coach supported them with the transition from being students themselves to becoming teachers of students.

\section{Significance of the Study}

To understand the impact of the Rhode Island Induction Program, The New Teacher Center conducted a survey of 262 beginning teachers who took part in the first year of the program. Beginning teachers reported that the focus of their work with induction coaches included observing instruction, discussing classroom management, 
debriefing the observation, and setting goals (Rhode Island Department of Education, 2012). Beginning teachers reported that help with classroom management and differentiating instruction supports had the most positive impact on student learning. Ninety-one percent of the beginning teachers who responded to the survey felt that their work with their induction coach positively influenced their teaching practice and increased student learning. While this data is informative and provides a basic understanding of the teachers' perceptions of the program, my goal is to gain a deeper understanding of the beginning teachers experience by capturing their stories of teaching in the first year(s).

Although some research has been conducted on induction and new teacher mentoring, Unruh and Holt (2010) suggest the impact of beginning teacher induction programs on teachers' perceived efficacy is an area not extensively researched. My research addressed narrative descriptions of teachers' perceptions of their first year in terms of self-identity and the relationship they built with their induction coach, as well as the perceived effects coaching had on their growth and development as educators.

When investigating beginning teachers' experiences in an induction program designed to support them in developing and honing the craft of teaching, I draw from theory and research in social learning, adult learning, how novice teachers acquire the skills needed to be successful in the classroom, and how school systems support teachers during their initial years in the profession. In order to fully understand the narratives of beginning teachers, I must highlight the situational identities they find themselves in as a novice in the field of education. This identity as a beginner teacher 
is also rooted in the context of their surroundings - the school climate, physical working conditions, colleague support, and leadership styles.

\section{Research Puzzles}

I have chosen to use narrative inquiry methodology, which requires the researcher to frame a research puzzle rather than a specific set of research questions (Clandinin, 2013). The research puzzles that I seek to understand are:

- What are the individual stories of beginning teachers who worked with an induction coach?

- What are the common themes across the narratives of beginning teachers?

- What do the retrospective stories of beginning teachers who participated in the Induction Program tell us about working with their induction coach?

\section{Definitions of Terms}

For the purpose of this study, I will use the following definitions:

- Induction coaches: Fully released (from classroom teaching responsibilities) veteran teachers with at least six years experience who completed required induction coach training provided by The New Teacher Center, and who were hired by the Rhode Island Department of Education to support fifteen to seventeen first year teachers.

- Beginning Teacher: A Rhode Island Department of Education (RIDE) certified teacher who has not previously started and ended a school year in the same classroom. 
- Coaching/Mentoring: Coaching and mentoring are used interchangeably in the research literature. In discussing coaching/mentoring, I have appropriated the terminology referred to by the researchers cited. RIDE used the term "coaching" as a way to distinguish the induction program from the previous programs that were referred to as "mentoring." They defined "coaching" as supporting the mentee in acquiring and refining the skills and knowledge required for enhanced performance in the classroom.

- Narrative: For the purpose of my research I used the word narrative as defined by Andrews, Squire, and Tamboukou (2013), "individualized, internal representations of phenomena-events, thoughts and feelings" (p. 5).

\section{Organization of Dissertation}

I have divided this dissertation into five chapters. Chapter lintroduces the statement of the problem, purpose of the study and research puzzles that focus my investigation. Chapter 2 provides an overview of the literature that pertains to the theoretical framework of the study, as well as the previous research in related fields to coaching, beginning teachers, and teacher development. Chapter 3 provides a detailed overview of the methodology I have chosen, and steps I followed in conducting this research. Chapter 4 presents the findings of my research, followed by a discussion and conclusion in Chapter 5. 


\section{CHAPTER 2}

\section{REVIEW OF LITERATURE}

\section{Introduction}

When investigating beginning teachers' experiences in an induction program designed to support them in developing and honing the craft of teaching, I draw from theory and research. Figure 2.1 represents the theorists I studied in sociocultural learning theory, adult learning theory, and teacher development. I also draw from research addressing how the field supports beginning teachers with respect to induction coaching.

\section{Theoretical Framework}

\section{Sociocultural Learning Theory}

I framed this study through the lens of sociocultural learning theory, which is used to explain how individuals' cognitive development is related to social interactions and culturally organized activities (Scott \& Palincsar, 2009). Vygotsky (1978) suggested we learn through our social interactions and communications with

others: "[Vygotsky] was the first modern psychologist to suggest the mechanisms by which culture becomes a part of each person's nature" (Cole \& Scribner, 1978, p. 6). Vygotsky theorized that we learn by watching others and mimicking their actions. At an early age, children begin to imitate the way an adult in their world speaks, uses tools, and moves. As children engage in more complex actions, they have a greater need and reliance on language to complete a task, often times using speech to plan 
the task. Therefore, learning and cognitive development depend on the social context in which they occur and are heavily dependent on language: "...learning is not development; however properly organized learning results in mental development" (Vygotsky, 1978, p. 90).

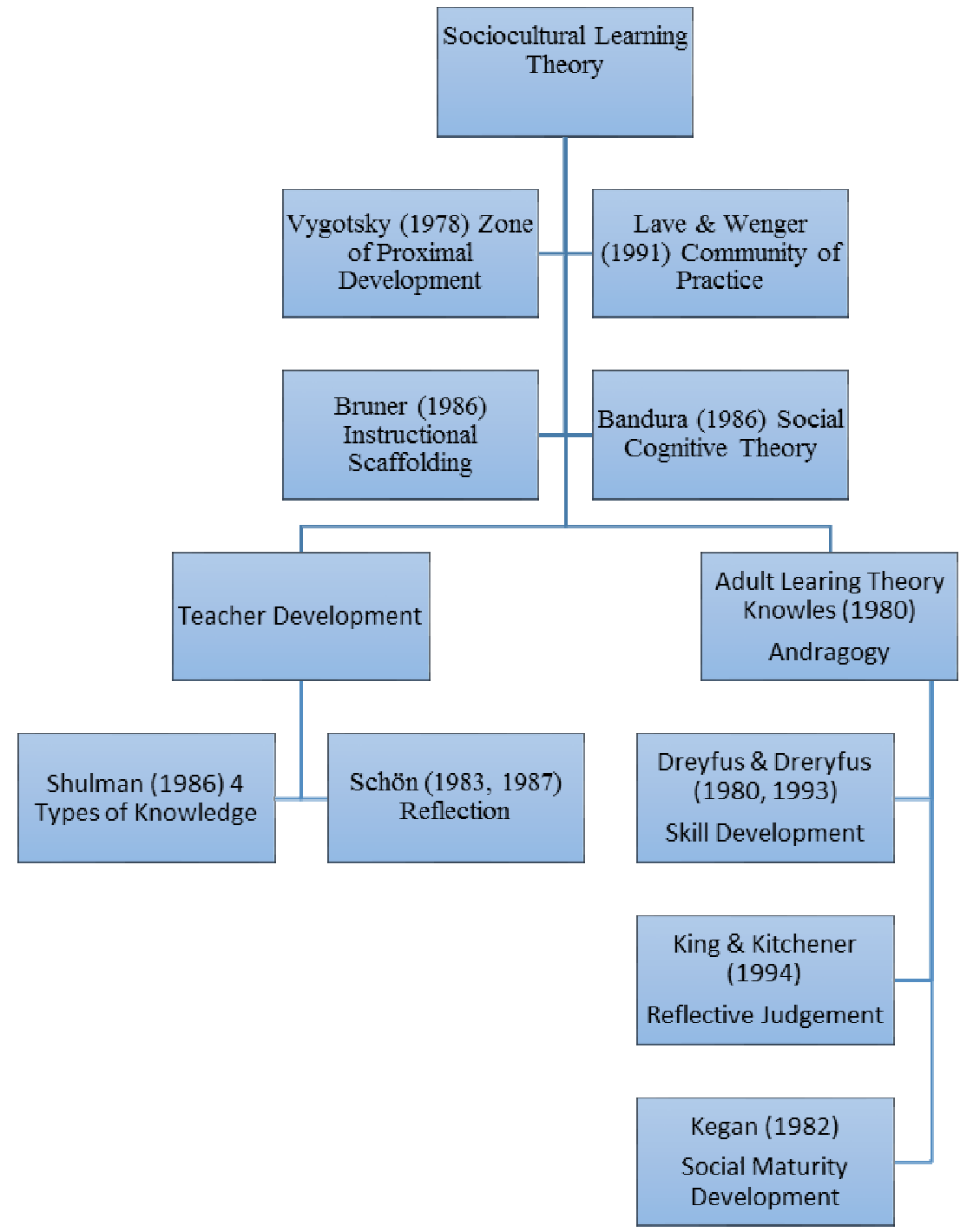

Figure 2.1. This figure represents the overview of the theoretical framework used to inform my study. 
Vygotsky believed that to assist in mental development, learning occurs through interaction with a "more knowledgeable other" (MKO). The MKO provides support by working within the novice's Zone of Proximal Development, which is "the distance between the actual development level, as determined by independent problem solving, and the level of potential development as determined through problem solving under adult guidance or in collaboration with more capable peers" (Vygotsky, 1978, p. 86). This theory supports the notion that learning precedes development. Vygotsky held that the role of the MKO is to model and co-construct knowledge alongside the learner in a social, collaborative interaction, rather than simply transmit his or her own knowledge. This occurs best when the MKO challenges the novice to develop just beyond his/her current level of skill, while supporting his/her learning through coaching with feedback.

Later, Bruner (1986) added to Vygotsky's theory of development the idea of instructional scaffolding - temporarily providing support to the learner in order to gain greater independence toward mastering the specific skill. The MKO models the task, gives advice, or guides the novice with intentional talk through each step of the process, purposely lessening the amount of support with each attempt. This gradual release of responsibility, coupled with practice at each step in the process, provides the scaffolding needed for the learner to internalize the process or skill being taught, and to perform it independently. An example of this is a parent teaching a child how to ride a bike. The parent models riding a bike for the child while using language to explain each step. Then the parent scaffolds the child's learning by holding the bike steady as the child begins to practice the movement of pedaling and gaining balance. 
The parent coaches with praise and suggestions, releasing the tight grasp gradually to let the child learn to balance. With continued practice and failures, the parent slowly releases the bike when the child keeps it steady and balanced.

Rogoff (1990) expanded on the notion of learning through scaffolded, or guided, participation. However, she believed that this interaction does not need to be face to face; rather, the teacher, librarian, classmates and parents who helped shape the writing of the research report as a cultural activity, can guide a student working on a report in isolation. This idea of learning differs greatly from Vygotsky's and Bruner's emphasis on didactic dialogue (Scott \& Palincsar, 2009). However, all of these theorists suggest that through repeated, supported practice in challenging situations, the learner becomes skilled at the targeted tasks.

Lave and Wenger (1991) further articulated sociocultural learning, focusing on adult learning through an apprenticeship, or through situated learning with an MKO. They proposed that mastery of knowledge and skill requires newcomers to engage in full participation of the practice alongside an MKO. Over an extended period, the novice observes the MKO, and then eventually completes simple tasks with guidance, with the ultimate goal of mastery. The notion of "learning by doing" is the highest level of authentic learning that can take place, and allows engagement in the sociocultural practice of the community. Lave and Wenger studied the concept of a "Community of Practice," where participants within a common craft or profession come together to share information and experience, in order to learn from each other; "Transformation occurs as participants in the activity assume increasing responsibility 
for the activity; in essence redefining membership in a community of practice, and, in fact, changing the sociocultural practice itself" (Scott \& Palincsar, 2009, p. 13).

Bandura (1986) expanded social learning theory to social cognitive theory. His work focuses on how behavior and growth are affected during social activities in context; specifically, he studied self-efficacy. He found that modeling is useful in training by increasing the learner's knowledge and understanding of new strategies, therefore, increasing the learner's self-efficacy. Bandura (1986) stated that when people observe a model performing a behavior, they remember the sequence of events and use this information to guide subsequent behaviors. He believed that people do not learn new behaviors merely by trying them and succeeding or failing; they replicate modeled behaviors based on reward or punishment. Bandura (1986) believed that "identification" occurs when the learner adopts the observed behaviors, values, beliefs, and attitudes of the model over time. Between observing the process and imitating it, the learner uses cognitive functions to mediate the process. The learner relies on mental processes to determine if the desired result was achieved or if a new response is required.

In relation to my study on how beginning teachers learn in the first years of the profession, it is critical to understand sociocultural learning theory. Beginning teachers learn the trade through social interaction with an MKO in the context of a classroom. They begin by watching an MKO interact with students and then mimic those interactions themselves. Having an MKO to work alongside the novice teachers allows instructional scaffolding to occur as Bruner suggests, supporting the beginning teacher to gain independence as they become more skilled. While student teaching is a 
structured learning environment for growth to occur, I will discuss research that supports the notion that a student teaching placement is not merely enough time to learn all the skills necessary to become a qualified teacher.

\section{Adult Learning Theory}

While the basic process of learning through social interactions is the same for adults and children, Knowles (1980) identified the difference in teaching adults to learn (andragogy), and teaching children to learn (pedagogy). Using pedagogy, the teacher is responsible for determining what the child will learn, how it will be learned, when it will be learned, and if it has been learned (Knowles, 1990). In andragogy, Knowles focused on the needs of adults: the need to know, the learner's self-concept, the role of the learner's experience, their readiness to learn, and their orientation to learning, and motivation. Knowles stressed that adults seek knowledge in subject matter that is relevant to their lives and/or work, and they bring with them prior knowledge and values. Engaging in a problem-centered, hands-on situation, rather than listening to a lecture, is a more powerful approach for adult learners (Knowles, 1990).

When an adult is learning a new skill, a continuum of learning development occurs before that skill is mastered. Dreyfus and Dreyfus (1980) suggested a model of skill development that ranges from novice to expertise. As a novice, the learner is inflexible, relying on rules and procedures to guide his or her thinking. The advanced beginner lacks a sense of what is truly important and responsibility for his or her actions, but is beginning to understand when to break rules and when to follow. As competent, the learner has rational goals and sets plans for achieving them. The learner 
makes conscious choices and has an emotional connection to successes and failures. As proficient, the learner relies on both intuition and an ability to analyze a situation. As an expert, the person is able to react in the moment effortlessly. Through repeated experience coping with real situations, the novice is able to move through the skill development stages with the support of an MKO. The novice learns through reflection on the trails and errors they experiences along the way.

Peno \& Silva Mangiante (2012) added to the Dreyfus and Dreyfus (1980) model of skill development with their Purposeful Ongoing Mentoring Model (POMM). Peno and Silva Mangiante (2012) stated that in order to support growth along the novice to expert skill model, an MKO must recognize where a learner is developmentally, set goals with them, and provide them with necessary scaffolding and reflection opportunities (Schön, 1983, 1987) to help them develop to the next level of practice (Vygotsky, 1978).

Kegan's (1982) theory of development also stresses the importance of resolving problems and discovering meaning in the context of experience. Kegan believes that from birth to adulthood, we develop along a continuum of social maturity. In the incorporative stage, infants rely on reflexes, followed by the impulsive stage where toddlers react to punishment and impulses. The next stage, known as imperial, occurs when a child is a concrete thinker and his or her needs and interests are central; however, the child has no sense of consequences for his or her actions. In the interpersonal stage, the teenager begins to grapple with personal needs and emotions, in contrast to the next stage of institutional where there is clear authorship and identity often related to the institution or context. This institutional stage is where 
many adults stop in social maturity, and where morals are based on what society values. Not every adult obtains the final stage of interindividual. In this stage, the individual is in charge of his or her identity, and any conflict becomes internal rather than external. The individual begins to realize that there is more than one way to be fair or honest, and can see things from different perspectives. Working alongside others can move the adult to the final stage where they are self-authored, or able to work on their own, and have personal theories that guide them. Later, Kegan (1994) dealt with the demands of everyday life, specifically discussing the difficulties that result from presenting challenging expectations to a person who does not have the support to accomplish the task. He believes that placing demands on someone who is not ready, or does not have the support needed, is ineffective.

In additional support of these problem-solving phases, King and Kitchener (1994) developed the Reflective Judgment Model that identifies seven developmental stages for responding to ill-structured problems. The seven stages are grouped into three levels: preflective thinking, quasireflective thinking, and reflective thinking. In prereflective thinking, knowledge is certain with one correct answer for all questions, often gained through the word of an authority figure. With quasireflective thinking comes the understanding that uncertainty is expected and that knowledge is constructed: this stage is indicative of the majority of college age students. As one moves up in the developmental sequence, he or she becomes more adept at handling situations in the moment. The final stage leads to reflective thinking, a process of reasonable inquiry, including the ability to judge evidence in order to support a decision. King and Kitchener (1994) believe that institutions of higher education are 
effective in promoting growth toward reflective thinking; however, unless given opportunities to interact with different points of view or become immersed in new experiences, all college students may not reach the higher levels of reasoning.

In connection to my research, it is important to use the lens of adult learning theory in order to understand the needs of beginning teachers once they finish a teacher preparation program. While the work of Dreyfus and Dreyfus (1980) indicates that beginning teachers are novices along their model of skill development, that is, often inflexible in their thinking with a strong reliance of the rules they learned preservice, the reality of the profession is that they are most often working alone in a classroom facing a bevy of ill-structured problems at any given moment in the day. Therefore, the provision of a mentor/coach is vital to novice teachers' continued development as they navigate new situations they may not have encountered preservice.

\section{Teacher Development}

For this study, it was essential that I look at adult learning theory with respect to teachers. Teaching offers a unique situation as teachers are faced with ill-structured problems on a daily basis and they must learn to react in the moment (King \& Kitchener, 1994). Schön $(1983,1987)$ helped us understand that, because teaching presents many ill-structured problems, teaching is an art that requires knowledge far exceeding merely professional knowledge. Over time, teachers develop the reflective habits of mind that allow them to be successful with each new group of students in a variety of situations. Once teachers recognize a unique situation, they must rely on reflective practices, prior experiences, critical problem solving skills, and the art of 
improvisation. Schön (1987) and Dewey (1938) agreed that one fully develops the required teaching skills by primarily using a learning-by-doing method. Schön (1987) referred to a reflective practicum in which beginning teachers are supported by an advanced practitioner in the process of learning in action and immersion in the culture of the community. As teachers progress, they begin to reflect-on-action, or think back on how their actions led to the outcome of a given situation. This eventually leads to a more spontaneous knowing-in-action, which involves making decisions based on experience in the field. Eventually, a higher level of knowing comes into play when the practitioner can reflect-in-action, using trial and error. When a novice works with an advanced practitioner in the practicum, there must be a reciprocal reflection-inaction as the novice and MKO interact in the cycle of showing and telling followed by interpretation and experimentation. This support from a MKO allows the novice to continue to develop the four types of knowledge that Shulman (1986) observed are necessary in the classroom setting, which I will discuss next.

Teachers must not only learn to navigate ill-structured problems, they must also learn content, teaching strategies, and child development. Shulman (1986) suggested that teachers must develop four different types of knowledge to be effective in the classroom. The first is subject matter content knowledge. While this type of knowledge develops during undergraduate preparation and encompasses facts and concepts specific to each teacher's certification, all teachers must learn to go beyond explaining the basic structure of the content to their students and instead design experiences for students to explore the "why" of the subject matter (Shulman, 1986). The second type of knowledge is pedagogical content knowledge (PCK) or the "how" 
of teaching. Teachers must develop strategies to use in the classroom to engage learners, such as questioning procedures, project-based learning, and classroom structures. The foundation for this type of knowledge is typically established during pre-service education and is later refined through experience. Curricular knowledge is the third type that Shulman (1986) recognized. Teachers must have a basic awareness of a variety of instructional programs, curriculums, and standards during teacher preparation programs, which are further solidified through experience and exposure in the classroom. Shulman's (1986) fourth type of knowledge is that of learners and their diverse characteristics. In order for teachers to be successful in the classroom, they must understand the developmental sequence of learning and have a clear grasp of the age group they are teaching. While a basic understanding of child development is gained in teacher preparation, through experience and reflection teachers learn to provide for the specific needs of various learning styles and levels of development. Shulman (1986) believed these four types of teacher knowledge should be developed simultaneously and recursively as teachers are required to adapt and deliver new curriculum to new students each year. He also suggested that there are three types of propositional knowledge in teaching that relate to the four types of knowledge about teaching. These three types of propositions are principles, maxims, and norms. Teachers are expected to know what research suggests is best practice in terms of teaching and learning (principles), as well as those ideas that are not confirmed by research but are accumulated wisdom of practice (maxims). For example, a principle of teaching that has been researched is the importance of repeated readings for comprehension, while a maxim might be the often heard "never smile until 
Christmas." The norms of teaching "guide the work of a teacher, not because they are true in scientific terms, or because they work in practical terms, but because they are morally or ethically right" (Shulman, 1986, p. 11). An example of a norm of teaching is not to embarrass a child in front of peers.

Framing my research in teacher development allows me to understand the complexities of the profession and all that is required of a beginning teacher. The refection that Schön $(1983,1987)$ refers to, and the four types of knowledge that teachers must develop according to Shulman (1986), support the notion that a teacher's learning does not end once a certification has been granted.

\section{Supporting Beginning Teacher Development}

If we situate teacher development in terms of what Shulman (1986), Schön (1987), Dreyfus and Dreyfus (1980), King and Kitchener (1994), and Kegan (1982) suggest, then we should never expect that teachers are ready for the classroom after a pre-service teaching program. Novice teachers may take two or three years to make the full professional transition from a university classroom to teaching in their own classroom effectively (Menchaca, 2003). Berliner (2004) also underscored that it takes two to three years for the average teacher to reach the advanced beginner stage (Dreyfus \& Dreyfus, 1980). Even after approximately five years, very few teachers move beyond the proficient stage on the novice to expert skill model (Dreyfus \& Dreyfus, 1980). Constant reflection, sharing, and growth that are appropriate to the level of expertise are required in order for the skills to develop. Because of this, Berliner noted, “...pre-service education may not be the most appropriate place to teach some things, and therefore, we may have to extend our programs of teacher 
education for some time after our students have entered practice" (Berliner, 1988, p. 27). He suggested it is, therefore, ineffective to expose pre-service teachers to complex learning theories, as they are incapable at that time in their development of understanding the implications that will occur in the field. He also noted that a person can obtain one level of development in a particular context, but when faced with a new situation, the expertise may not transfer (Berliner, 1988). For example, a teacher may become an expert at teaching sixth grade science, but if he or she transition to a second grade classroom, that level of skill needs redeveloping in the new context. Berliner (1988) warned about those who come into education through an alternative certification route because often they have limited classroom experience and a lack of pedagogical knowledge.

Neither theory nor research suggests that beginning teachers are able to react easily in the moment to the many, complex issues that inevitably arise in a classroom on a daily basis (Ingersoll \& Smith, 2004). Teaching is inherently an ill-structured problem, as teachers face new situations with new complexities every single day. Beginning teachers are not expected to be at a stage of reacting instantaneously to these issues. Yet, we often leave them alone to fend for themselves, and expect that they can solve problems and make the right decisions in the moment (Dyal \& Sewell, 2004). An opportunity to reflect on these uncomfortable and foreign situations would be key to the development of a teacher who can spontaneously react and elicit a positive outcome (Schön, 1987). If beginning teachers are making decisions based on rules and curriculum, they are not able to react in the moment to the needs of the 
students by adjusting curriculum and managing behavior (Hieber, Gallimore, \& Stigler, 2002).

Kegan's (1982) theory highlighted the need for adults (teachers) to work with an $\mathrm{MKO}$ who will engage them in reflection and teach them to develop their own theories based on specific situations. An MKO must acknowledge where a person is on this continuum. "What is most important for us to know in understanding another, is not the other's experience, but what the experience means to him or her..." (Kegan, 1982, p. 113). As individuals work through problems and experience a variety of social settings, they gain awareness in "meaning making" and they move through the stages of competency. For example, a beginner teacher might not view a behavior problem in the classroom as an issue with student engagement. An MKO must listen to how the beginner teacher interprets the experience and react accordingly, while guiding them to see beyond the behavior to the root of the problem. Through all of this research it is clear that beginning teachers are not developmentally prepared for all the demands of the profession.

\section{Induction Coaching}

Research suggests that coaching is an effective way to support the learning of beginning teachers (Ingersoll \& Strong, 2011). Darling-Hammond (1997) suggested that the research supports that quality induction programs pay for themselves with reduced teacher attrition and improved student learning. However, research has also shown that specific components are needed for an induction coaching program to be successful (Ingersoll \& Strong, 2011). In order to be effective, a trained induction coach must spend extensive time in the beginning teacher's classroom, embedded in 
the school culture (Ingersoll \& Strong, 2011). In a study using student test data, Fletcher, Strong, and Villar (2008), showed that coaches working with teachers over a period of two years, rather than just one, led to greater impact on student learning. The training and careful selection of induction coaches also plays a pivotal role in beginning teachers' success. Fletcher and Strong (2009) suggested that the amount of training that mentors receive had a direct impact on their ability to change the instructional practices of the mentee. Additionally, other vital components of an induction program have been identified, such as respect of beginning teachers' practices, induction to school and school culture, clear goal setting, and flexibility in practice (Olebe, 2005). This speaks directly to the need for induction coaches to be trained in reflective practice as well as in the needs of adult learners. It also introduces the importance of induction coaches becoming part of the school culture (Kardos, Johnson, Peske, Kauffman, \& Liu, 2001). This component of a successful induction program would seem to suggest that induction coaches should be matched with beginning teachers with similar certification. However, there is disagreement about this in the literature. Rockoff (2008) found little evidence that teacher or student outcomes improve when a coach matches a teacher's subject area or grade. In contrast, Long (2010) suggests the key to a successful process of matching beginning teachers to suitable coaches is based on similar professional content areas, learning styles, age, gender and culture, as well as personality variables. Bianchini and Benner (2009) concluded that having a coach in the same field is essential for deep knowledge to be shared and developed. In a five-year longitudinal study started in the 2007-2008 school year, conducted by Gray and Taie (2015), the percentage of beginning teachers 
who were currently teaching in each subsequent year was larger among those who were assigned a first-year mentor than among those not assigned a first year mentor. This suggests that teacher retention rates may improve when mentor support is provided.

Despite our best attempts to adequately prepare teachers in teacher preparation programs, many teachers learn through a "trial by fire" method with their students (Dyal \& Sewell, 2002). Research suggests teachers' first independent experience in a classroom setting is a transition from students of teaching, to teachers of students (Ingersoll \& Smith, 2004). A recurring phenomenon is that beginning teachers report feeling isolated at the onset of their career (Ingersoll \& Smith, 2004). Those who accept a new teaching position in a school either fail or succeed on their own with little help from the school community (Ingersoll \& Smith, 2004). Like doctors in a medical residency, beginning teachers need the support of a more knowledgeable other to support them in their development. McNulty and Fox (2010) suggested that forming alliances with fellow teachers in order to establish a support system is a key component of a beginning teacher's success. However, relying informally on a gradelevel colleague in the room next-door puts an undue burden on a beginning teacher who may already be overwhelmed by the expectations of the profession (McNulty \& Fox, 2010).

Since the school reforms of the 1980s, there has been a focus on the need to provide greater and more formalized support for new teachers. Hiebert, Gallimore, and Stigler (2002) explored the need for a long-term initiative of professional development in education that is linked to the curriculum, focused on student learning, school- 
based, and collaborative. Induction coaching is one specific way to support beginning teachers directly in their classrooms and scaffold their development as educators. Ingersoll and Strong (2011) noted:

The theory behind induction holds that teaching is complex work, preemployment teacher preparation is rarely sufficient to provide all of the knowledge and skills necessary to successful teaching and a significant portion can only be acquired while on the job. (p. 4)

An induction coach is essentially a "teacher of teachers" (Moir, 2003, p. 4).

These trained coaches, released from their classrooms, use their expertise in the field to guide beginning teachers in their development. The objective of the induction coach is to continuously engage the beginning teacher in the cycle on inquiry, which the data tells us involves goal setting, data collection, reflection, and adjustments (Moir, 2003).

Induction coaches can use theories of adult learning, as well as the Dreyfus and Dreyfus (1980) model of skill development to better support beginning teachers. In their Purposeful Ongoing Mentoring Model (POMM), Peno and Silva Mangiante (2012) stated that in order to support teachers along the novice to expert skill model (Dreyfus \& Dreyfus, 1980) mentors need to recognize where teachers are developmentally, set goals with them, use scaffolding techniques as described in Vygotsky's (1978) Zone of Proximal Development, and provide opportunities for reflection on their performance (Schön, 1987). If coaches work within this system of potential development, they are able to guide the beginner to develop a higher level of skill (Peno \& Silva Mangiante, 2012). 
According to Gordon (1990), coaches should transition gradually from a directive approach, which includes telling beginners what to do (because novices follow the rules), to a collaborative approach, which includes working together to problem-solve as the beginning teachers become more reflective. Then coaches transition to a nondirective facilitation style as learners begin to react in the moment. This style includes asking questions and encouraging independence (Gordon, 1990). Glickman (2002) suggests coaches use specific language to lead teachers to autonomy, and provides specific sentence stems for each stage of coaching. Examples of sentence stems include: "What would it look like if...?"; or "What I hear you saying is..." Glickman (2002) outlines three levels of coaching language mirror Gordon's coaching levels: directive, collaborative, and facilitative. These three levels of coaching language that Glickman (2002) suggests allow coaches to react to novices in a developmentally appropriate way as teachers grow in their practice.

Alternative certification programs present an area of concern in teacher induction. While these programs may develop a solid base of understanding regarding content matter, they lack the pedagogy practice needed for teachers to effectively deliver the instruction (Unruh \& Holt, 2010). Many states have accepted alternatives to certification in order to fill the increasing demands of teacher vacancies. Induction coaching can provide consistent support to all beginning teachers, not only to improve student learning, but also to retain novice teachers and maintain an effective work force (Unruh \& Holt, 2010). This may be particularly important in the case of teachers with alternative certification. 


\section{Impact of Coaching on Teacher Efficacy}

Shaughnessy (2004) defined teachers' self-efficacy as “their perceptions about their own capabilities to foster students' learning and engagement" (as cited in Unruh \& Holt, 2010, p. 5). Bandura's (1986) research showed that high-perceived selfefficacy leads teachers and students to set higher goals and increases the likelihood that the goals will be achieved. In a study on the effects of coaching on novice teachers' self-efficacy, Bruce and Ross (2008) found that mentoring encouraged teachers to enhance goal setting, take risks, and implement challenging teaching strategies. Ultimately, peer coaching enabled these teachers to move their practice towards standards-based methods, had positive effects on teacher self-efficacy, and caused participants to reflect more explicitly (Bruce \& Ross, 2008). This quantitative research focused on the effects of peer coaching with twelve mathematics teachers in grades three and six. Bruce and Ross (2008) came to the conclusion that "individuals who feel that they will be successful on a given task are more likely to be so because they adopt challenging goals, try harder to achieve them, persist despite setbacks, and develop coping mechanisms for managing their emotional states" (p. 347). The study analyzed the impact of positive and constructive feedback from a respected peer, and found that mentoring encouraged teachers to enhance goal setting, take risks, and implement challenging teaching strategies. Ultimately, peer coaching enabled teachers to move their practice towards standards-based methods, had positive effects on teacher self-efficacy, and caused participants to reflect more explicitly. This research suggested the value of a coach working with a beginning teacher to develop effective 
teaching practices, provide a positive induction into the field, and help improve selfefficacy (Bruce \& Ross, 2008).

Feiman-Nemser and Parker (1992) concluded that a fully-released mentor was most effective in improving teaching practice as identified by observations in the field. A fully-released mentor is a teacher who has been relieved of their own classroom responsibilities in order to coach full time. In a survey study, Kapadia, Coca, and Easton (2007) found that novice teachers in an induction group which included receiving coaching support and attending additional workshops, reported higher levels in induction support, positive teaching experiences, and retention than teachers who were not part of an induction program. Algozzine, Gretes, Queen, and CowanHathcock (2007), using mixed methods to study of third-year teachers, found that the majority indicated induction program activities were effective in providing support for them to be successful in the classroom.

Although these studies on induction coaching are informative, they do not provide detailed narrative descriptions of teachers' perceptions of their first year in terms of self-identity and the relationship with their induction coaches.

\section{Chapter Summary}

This chapter discussed the theory and research lens that I used to conduct my research. Knowledge of the ideas of sociocultural learning theory, adult learning theory, teacher development, and induction coaching provides a critical foundation for analyzing the narratives of beginning teachers and the efficacy of induction coaches. In Chapter 3, I will fully explain the methodology I used to carry out this research. 


\section{CHAPTER 3}

\section{METHODOLOGY}

\section{Introduction}

After reading the current research on teacher induction, it became clear that it is important to bring to light the stories of beginning teachers' experiences. I researched several methodologies before deciding to utilize narrative analysis. I clearly explain my decision in the research design section of this chapter. This chapter also presents the role of the researcher, selection of participants, data collection, and the data analysis techniques used to address my research puzzles.

\section{Research Design}

Much of the existing research about induction coaching uses survey design. While Likert-type scales intended to capture beginning teachers' satisfaction with induction coaching, retention explanations, and specific components of induction programs is important, these quantitative studies provide only surface level information. They do not lend themselves to capturing teachers' stories about their experience in the first year of classroom teaching. Because my research questions focus on gaining greater insight into teachers' experiences, qualitative methodology is more appropriate. As Merriam (2009) points out, "Having an interest in knowing more about one's practice, and indeed improving one's practice, leads to asking researchable questions, some of which are best approached through a qualitative 
research design" (p. 1). According to Merriam (2009), "Qualitative researchers are interested in understanding how people interpret their worlds, and what meaning they attribute to their experience" (p. 5).

I spent a great deal of time determining which method of qualitative research would best fit the question I wanted to answer: What was the experience of beginning teachers? One possible approach, phenomenology, is the study of people's experience and how they make sense of that experience by relaying how they remember it, feel about it, and describe it when they talk with others (Patton, 2002). While reading about phenomenology I was drawn to a form of this research known as heuristic inquiry which, "brings to the fore the personal experience and insights of the researcher" (Patton, 2002, p. 107). I worried about the access I had to the teachers I wanted to study, and if I would be given the time to immerse into their world in order to completely understand this phenomenon. I also looked into the field of grounded theory, which focuses on, "the process of generating theory rather than a particular theoretical content" (Patton, 2002, p. 125). Grounded theory, developed by Glaser and Strauss (1967), offers specific methods and coding procedures for uncovering a theory. I was concerned about the limited time period in which I was interested - the first year of a teacher's experience. Was this enough of an overall experience in teaching for me to capture significant patterns that change over time? My ability to study this experience in depth was also a concern when considering case study. I knew I was not able to immerse myself in the lives of those I was studying. I also worried that, because the program was over and the teachers were no longer in their first year, 
I would not be able to capture the experience as required by case study. I then came upon the methodology of narrative inquiry.

\section{Narrative Inquiry}

According to Clandinin (2013), "Narrative inquiry is an approach to the study of human lives conceived as a way of honoring lived experience as a source of important knowledge and understanding" (p. 17). Narrative analysis allows for a systematic study of personal experiences and meaning, using the story told as the source of the investigation. People tell stories, or narratives, to make sense of their world and life experiences (Creswell, 2009). The stories told are reconstructions of events based on the subject's interpretation or "truth" (Fraenkel, Wallen \& Hyun, 2012), and are socially constructed experiences between the teller and the listener (Vygotsky, 1978). For the sake of clarity, I use the terms story and narrative interchangeably throughout to refer to these first-person accounts of experiences:

The term narrative carries many meanings and is used in a variety of ways by different disciplines, often synonymously with story (...) the narrative scholar (pays) analytic attention to how the facts got assembled that way. For whom was this story constructed, how was it made and for what purpose? What cultural discourses does it draw on - take for granted? What does it accomplish? (Riessman \& Speedy, 2007, p.428-429)

According to Noddings and Withrell (1991), stories "provide us with a picture of real people in real situations, struggling with real problems. They banish the indifference often generated by samples, treatments, and faceless subjects" (p. 280). This methodology involves using first person narratives of research participants as data, 
often referred to as field text (Clandinin, 2013). Interpretation of these data occurs on three levels; the content of what is said (ideational), how something is said (textual), and the context of the roles of the speaker and listener (interpersonal) (Reismann, 1993).

There are many different foci within narrative research. The first approach views a narrative as an entire life story and uses multiple sources such as interviews, observation, and documents (Denzin, 1989). In a second approach, the narrative is a brief, organized, topically specific story that includes characters, setting, and plot in order to reconstruct facts and events in a person's past (Labov, 1982). A third approach views narrative as including sections of talk, or extended accounts of lives in context, that arise over the course of an interview as a way for the teller to make meaning of the experience (Riessman, 2003). These sections of talk can be broken down into two types of narratives, big and small, which will be explained further in a later section. The fourth, linguistic approach to narrative research is what Gee (2001) calls discourse analysis. This approach focuses on how the narrative is told, specifically looking at the language, intonation, pitch, and pauses, again as a way to make meaning of the experience. While various researchers may use a different view of a narrative, "all require [the researcher] to construct texts for further analysis, that is, select and organize documents, compose field notes, and/or choose sections of interview transcripts for close inspection” (Riessman, 2003, p. 2). Narrative researchers also use a wide variety of analyses.

Thematic analysis. Thematic analysis of narratives focuses on "what" is said, rather than "how it is said" (Reissman, 2003). Similar to grounded theorists, narrative 
researchers gather many stories and inductively create conceptual groupings from the data. "A typology of narratives organized by theme is the typical representational strategy, with case studies or vignettes providing illustrations" (Reisssman, 2003, p. 2). The thematic approach allows the researcher to theorize across multiple cases, analyzing common themes across participants and events they relay. Often times the thematic analysis is conducted on what Bamberg and Georgakopoulou (2008) refer to as "small stories":

Part of the validity of analyzing small stories for purposes of identity research lies in the ways in which this approach opens us up and urges us to scrutinize the inconsistencies, contradictions, moments of trouble and tension, and the tellers' constant navigation and finessing between different versions of selfhood in local contexts (p. 16)

Bamberg and Georgakopoulou (2008) refer to small stories as an umbrella term for narrative activities that do not follow the traditional structure of big stories. These small stories include small incidents, elaborations on a topic, explanations, or even tellings on ongoing events.

Structural analysis. Structural analysis of narratives studies the way the story is told. Here the focus is on language and the organization of the narrative. Labov's (1982) approach is to identify the components of the big story, which are abstract (summary or focus of the story), orientation (time, place, characters, and situation), plot (sequence of events with a turning point), evaluation (commentary from the narrator), resolution (outcome of the plot), and coda (the lesson of the story). Often times, structural analysis is used for a few cases to build theories that include 
language, and structure that can be missed in thematic analysis (Riessman, 2003). For example if I were to only look at the themes that participants mentioned in their stories, I would miss the meaning behind how they told their stories, including how they positioned themselves in the plot.

Interactional analysis. Interactional analysis emphasizes the interactions between the teller and listener of the story (Riessman, 2003). The focus here is on the co-construction of the story through the interview process where the two participants are engaged in a conversation. It is important to realize that the story is told in a specific context, to a specific person (researcher), and at a specific time and place. One must honor that the story could change if told in a different context. Therefore, the role of the researcher and the way he or she interprets and analyzes the story is critical in the field of narrative analysis.

Performative analysis. In this type of analysis, "Storytelling is seen as a performance — by a 'self' with a past—who involves, persuades, and (perhaps) moves an audience through language and gesture, 'doing' rather than telling alone" (Riessman, 2003). This requires the researcher to look at the way the speakers position themselves throughout the narrative, the presentation of 'self.' Davies and Harre (1990) discuss the idea of positioning as a way of understanding personhood, recognizing that once an individual takes up a particular position, he or she sees the world from the vantage point of that position. They also acknowledge that an individual can take up a variety of positions in various storylines, "in telling a fragment of his or her autobiography a speaker assign parts and characters in the episodes described, both to themselves and to other people, including those taking part 
in the conversation" (Davis \& Harre, 1990, p. 7). Here again, it is vital to look at the role the researcher is playing in the interview from the viewpoint of the participant.

I focus my study on the narratives teachers tell about their first year(s) in the field of education. Certainly, teachers remember their first year in the classroom, but how they choose to tell their story is key to their experience. I used the experiencecentered approach to making meaning of a narrative (Riessman, 1993; Denzin, 1989), rather than the event-focused approach (Labov, 1982). To do this, I used all four types of analysis: thematic, structural, interactional, and performative. Capturing each story allowed me to gain insight into the experience of a first year teacher and the role the induction coach plays in this experience. McKamey (2013) states, "Narrative researchers argue that stories capture the complexity of experience in ways that other methods cannot" (p. 6). McKamey brought together the narrative of several individuals to identify major themes and commonalities across the narratives to expand the understanding of the experience she studied. While my aim is to tell the individual stories of beginning teachers, I also wanted to share the commonalities of these stories as way of synthesizing the experiences of a first year teacher. According to Wells (2011), "Stories are told by someone, to someone else, at one or more points in time, and in a specific historical and cultural context" (p. 23). For this reason, it is critical to take into account who is telling the story, my role as the researcher, and the effect the context and historical nature of the storytelling may play in the analysis.

I have chosen narrative inquiry methodology because it allows me to use my intimate knowledge of the Induction Program in Rhode Island in the analysis of the stories captured in the interview process. As a former induction coach, I understand 
the type of relationship built between an induction coach and a beginning teacher, the tools used in coaching sessions, and the importance of building trust and respecting boundaries. As a researcher, I wanted to understand induction coaching from the beginning teacher's point of view. However, it was very apparent to me that I could not separate myself from this research completely, acting as an impartial observer. Rather, I needed to honor my role as a co-author of these stories, using my knowledge of the subject matter to enhance the research. It is through narrative analysis that I found the place where my voice had a role in the process.

\section{Context of the Study}

In 2011, the Rhode Island Department of Education (RIDE) implemented a comprehensive induction program to coach every beginning teacher in the state. The program was funded for three years by Race to the Top grant funding, which set as one of its requirements that states support beginning teachers. RIDE determined new teachers in Rhode Island's five urban core districts would receive two years of coaching (due to concerns with teacher retention in high need areas), and all other beginning teachers would receive one year of support.

To support these teachers, RIDE initially recruited seventeen teachers from across the state to be induction coaches. Induction coaches were fully released from their teaching assignments, and received 210 hours of professional development from the New Teacher Center (NTC), a non-profit organization working in teacher induction. Coaches received professional development from NTC on the researchbased practices of effective coaching in order to support beginning teachers in setting goals, analyzing student work, communicating with parents, and developing lesson 
plans, as well as any other individualized support needed. Training from NTC also included working with adults using coaching language (Glickman, 2002) and adopting a problem-centered approach directed by the beginning teacher (Knowles, 1980). Each coach worked with fifteen beginning teachers for approximately 90 minutes per week. Many coaches worked with teachers in districts outside the coaches" "home" districts, and in teaching areas outside their own certification area.

\section{The Role of the Researcher}

I had the opportunity to work as an induction coach for two years (2011-2013) and have first-hand knowledge of the development of the program. It is critical that, as I listened to the participants tell their stories, I reflected on my role as an induction coach and the way in which my story interweaved into the context being studied because, “As narrative inquirers, we become part of participants' lives and they part of ours. Therefore, our lives — and who we are and are becoming, on our and their landscapes - are also under study" (Clandinin, 2013, p. 30). Narrative analysis views the role of the researcher as an opportunity rather than a bias. As mentioned previously, interactional analysis focuses on the idea of the co-construction of narratives. In order to remain constantly aware of my role as the researcher I kept a reflexive journal, which included field notes and memos which will be described in the data collection section of this chapter.

\section{Method and Procedures}

\section{Participants}

The population for my study was the 350 teachers who received either one or two years of support from an induction coach as part of the Statewide Induction 
Program during the 2011-2012 and/or 2012-2013 school years. Although my role as induction coach is part of my study, as narrative inquiry is a co-construction between the participant and researcher, I decided to exclude from participation the beginning teachers that I coached within this two-year period (leaving a pool of 320 potential participants). I made this decision because I was concerned that beginning teachers whom I coached might not tell their stories completely and truthfully if I was conducting interviews with them.

RIDE did not keep updated contact information on the participants in the Induction Program. Therefore, I determined that the best way to access the beginning teachers in the program was to ask fellow coaches who provided support from 20112013 to forward an email from me. After gaining permission from the University of Rhode Island Institutional Review Board (IRB) (Appendix A) and the Rhode Island Department of Education (RIDE) (Appendix B), I sent an explanatory email to the sixteen other original Rhode Island Induction Coaches, and asked them to forward the email to the beginning teachers they coached in the first two years of the Program (Appendix C). The email (Appendix D) explained the nature of the study, expectations of participants, and included a copy of the consent form (Appendix E) to be signed by those interested in participating. The sixteen coaches were asked to forward the email and link to a Survey Monkey (Appendix F) to the teachers with whom they had worked. Twenty-six beginning teachers replied to the email request from the other coaches and completed the survey; two of those did not include contact information, and therefore were excluded, leaving 24 potential participants. 


\section{Purposeful Sampling}

According to Merriam (2009), "purposeful sampling is based on the assumption that the investigator wants to discover, understand, and gain insight and therefore must select a sample from which the most can be learned" (p. 77). If my goal was to capture the stories of participants in the Induction Program, I needed to represent the diversity of the participants. I created a list of attributes to represent a variety of beginning teachers to the extent possible based on school district (urban, suburban, rural), gender, age, certification area, certification route, degree, grade level, opinion of the program, and duration of participation in the program (one and two years of support). From this list I created a pre-screening tool using Survey Monkey (Appendix F), which was included in the emails sent out by coaches. After receiving completed surveys, I selected participants that matched the criteria I had identified.

I chose ten participants because I felt that I had captured all of the different categories I was looking for which might exhaust the typical profiles of all 350 beginning teachers enrolled in the program. However, of the original ten participants contacted, three did not respond to my email and phone request or changed their mind about participation. I replaced those participants with others that had a similar profile. Table 3.1 shows the final ten participants' profiles that I chose to interview. The bold categories highlighted in Table 3.1 indicate the reason why I chose a specific profile. I was pleased to be able to capture a variety of routes to teacher certification, including the traditional college/university teacher preparation route, as well as participants from The New Teacher Project (TNTP), Rhode Island Teach for America (RITFA), Career and Technical Education Certification (CTE), and those with no certification and basic 
certifications. Participants also included one part-time teacher, as well as represented a diversity of classroom placements including band, automotive, filmmaking, English, science, kindergarten, and special education.

Table 3.1

Purposeful Sampling of Participants

\begin{tabular}{|c|c|c|c|c|c|c|c|c|c|c|}
\hline Name & Gender & Age & Certification & Degree & $\begin{array}{l}\text { Location } \\
\text { of school }\end{array}$ & $\begin{array}{l}\text { Type of } \\
\text { School }\end{array}$ & Level & $\begin{array}{l}\text { Years } \\
\text { of } \\
\text { Coaching }\end{array}$ & $\begin{array}{l}\text { Gender } \\
\text { of } \\
\text { Coach }\end{array}$ & $\begin{array}{l}\text { Reflection } \\
\text { on } \\
\text { Program }\end{array}$ \\
\hline Rachael & $\mathrm{F}$ & $\begin{array}{l}20- \\
30\end{array}$ & $\begin{array}{l}\text { Early } \\
\text { Childhood/ } \\
\text { Special Ed. }\end{array}$ & BS & Rural & Public & Elem & 1 & $\mathrm{~F}$ & Satisfied \\
\hline Beth & $\mathrm{F}$ & $\begin{array}{l}20- \\
30\end{array}$ & $\begin{array}{l}\text { Early } \\
\text { Childhood } \\
\text { Special Ed. }\end{array}$ & $\begin{array}{l}\text { BA } \\
\text { MA }\end{array}$ & Urban & Charter & Elem & 1 & $\mathrm{~F}$ & Satisfied \\
\hline Shelly & $\mathrm{F}$ & $\begin{array}{l}20- \\
30\end{array}$ & $\begin{array}{l}\text { Early } \\
\text { childhood }\end{array}$ & BA & Rural & Public & Elem & 1 & $\mathrm{~F}$ & Satisfied \\
\hline Charlotte & $\mathrm{F}$ & $\begin{array}{l}20- \\
30\end{array}$ & RITFA & $\begin{array}{l}\text { BA } \\
\text { MA }\end{array}$ & Urban & Public & Mid & 2 & $\mathrm{~F}$ & Satisfied \\
\hline Jane & $\mathrm{F}$ & & $\begin{array}{l}\text { Elem. Ed. } \\
\text { Middle }\end{array}$ & BA & Rural & Public & Mid & 1 & $\mathrm{~F}$ & Satisfied \\
\hline Sarah & $\mathrm{F}$ & $\begin{array}{l}20- \\
30\end{array}$ & $\begin{array}{l}\text { Elemen. Ed } \\
\text { Middle End. }\end{array}$ & BA & Urban & Charter & Mid & 1 & $\mathrm{~F}$ & Neutral \\
\hline Mary & $\mathrm{F}$ & $41+$ & $\begin{array}{l}\text { Artist in } \\
\text { Residency }\end{array}$ & $\begin{array}{l}\text { BA } \\
\text { MA }\end{array}$ & Urban & $\begin{array}{l}\text { Public } \\
\text { Charter }\end{array}$ & High & 1 & $\mathrm{~F}$ & Satisfied \\
\hline Henry & $\mathrm{M}$ & $41+$ & CTE & BA & Urban & VoTech & High & 1 & $\mathrm{~F}$ & Satisfied \\
\hline Anne & $\mathrm{F}$ & $\begin{array}{l}31- \\
40\end{array}$ & TNTP & BS & Urban & Public & High & 1 & M & Satisfied \\
\hline Paul & M & $\begin{array}{l}20- \\
30\end{array}$ & Music Ed. & BA & Urban & Public & High & 2 & $\mathrm{~F}$ & Neutral \\
\hline
\end{tabular}

Once interviewing began, I learned that one participant, "Jane," primarily worked with a Year 2 coach, who received a different training program than the original 17 coaches. I wanted to keep coaches' training consistent to try to limit the 
variability as best I could. As a result, I eliminated "Jane" from analysis and moved forward with nine participants' interviews in the data analysis stage.

\section{Participant Consent}

The twenty-four participants understood that by responding to the survey they were giving consent to be a part of the study. This implied consent was explained clearly in the introduction of the survey (Appendix G). In the original email sent with the Survey Monkey link, participants were also given a copy of the signed consent (Appendix E) form to read, should they be chosen for an interview. I began each interview with a short statement about my research and gave participants time to ask any questions about the research and/or process (Appendix H). I then had each participant read and sign two copies of the informed consent document which included a signature to agree to be a part of the study and a signature acknowledging the use of an audio recording device (Appendix E).

\section{Data Collection}

\section{Interviews}

I emailed the ten selected participants and requested they select a time and location for our interview. Nine out of the ten participants chose to meet in a public library; the other teacher requested that the interview take place at her school. Each interview lasted approximately forty-five minutes. At the time of the interviews, in the

spring of the 2014-2015 school year, participants were relying on their memories from the 2011-2012 and/or 2012-2013 school year. The methodology of narrative inquiry often takes the position that, "the narrative constitutes reality. It is in telling that we 
make real phenomena in the stream of consciousness" (Reissman, 1993, p. 22). The interviews were recorded using an audio recording device.

I created and used an interview guide (Riessman, 1993) that included broad questions to help elicit specific stories from the participants and possible follow-up questions as needed (Appendix H). The interview guide included two specific sections. The first section included background questions about the context of the school (school culture, administration support, and colleagues). It was important at this point to capture the context of the school setting so that I could situate working with an induction coach within that context. Clandinin and Connelly (1990) refer to the context as the scene or, "place where the action occurs, where the characters are formed and live out their stories and where cultural and social context play constraining and enabling roles" (p. 8). Setting the scene is vital to understanding the narrative of the participant. I knew that in order to capture this experience I could not isolate the work of the coach from the context of the school environment.

The second section of the interview guide prompted participants to, "start at the beginning and tell me the story of working with your induction coach." During each interview, I asked follow-up questions as needed to elicit further details and narratives. At the end of each interview, I asked if the participant would be willing to answer any additional questions I had after transcription, to member check my initial thoughts on their experiences.

As a novice in interview skills, it became apparent after listening to the recordings that I often interrupted the speech of my interviewee. The majority of the time it was to clarify something, but as I continued with the interviews, this habit 
became less obtrusive. I also thought back to all the non-verbal cues that I gave the participants during the interviews; shaking my head in agreement or laughing along with them. It was impossible for me to remain completely neutral during the interviews. I knew what it felt like to be a first year teacher: the stress and chaos of the experience. I also could not hide the fact that I was an induction coach and knew the "tools" that they referred to and the lingo of education. I made sure that they knew my involvement with the program from the very first communication and repeated it again at the interview (Appendix $\mathrm{H}$ ).

\section{Field Notes}

I wrote field notes during and immediately after the interview to capture the setting, mood, and overall impression of the interview (Merriam, 2009) (Figure 3.1). Even in the experience-centered narrative approach, "researchers try to obtain a full written, aural and/or visual record of the research participants' stories," (Andrew et al., 2013, p. 53), which includes field notes that capture what the audio recording is unable to in order to recreate the condition under which the interview took place. Following the interview, I noted each participant's body language, facial expressions, and any other reflections (Bogdan \& Biklen, 2014). I collected minimal field notes during the interview to avoiding detracting my attention away from the participant; rather the notes provided a way of remembering topics or follow-up questions as a means of clarification. According to Kleinmann and Copp (1993) one should, "Put your reactions, as much as possible, into your field notes. If you felt angry about what a participant said, then write about the reaction immediately...” (p. 58). These field notes were at first kept in my reflexivity journal, which I will describe in detail in a 
later section. Eventually I embedded these notes into the final transcriptions so that I could capture the entire interview in one place. These field notes clearly illustrate my interpretation of the interview and highlight the co-constructive nature of the research methodology I have chosen.

Field Notes: 4/11/15

- old library with stained glass windows

- loud, energetic

- passionate

- a lot to say

- mentions age \& style

- old wooden table in round room

- glorious, spring day

- sat side by side

- shook hands

- lots of eye contact

- dressed in flowing clothing and dark colors

Figure 3.1. This figure is an excerpt from my field notes.

\section{Narrative Sketch}

Narrative sketches as a form of memo writing (Figure 3.2) provided a third source of data. These memos were a part of reflexivity, the process of reflecting critically on the self as a researcher (Lincoln \& Guba, 1985). My purpose for this was to reflect on my assumptions regarding the research as I analyzed the data. This memo writing helped me to make sense of data I was collecting and offered a place to work through periods of discouragement in the midst of the research (Bogdan \& Biklen, 2014). This writing was a way to make sense of the entire interview by writing a descriptive overview, which Clandinin \& Connelly (1990) refer to as a 'narrative sketch.' These memos were the start of the performative analysis of the data which I will explain in detail later. I included both direct quotes from the transcripts, as well as my interpretation of the data stating the line number from the transcript as a reference. 


\begin{tabular}{|c|c|}
\hline $\begin{array}{l}\text { Profile \#9 } \\
\text { received tw } \\
\text { "you're jus } \\
\text { deal of turn } \\
\text { their positic } \\
\text { good six m } \\
\text { (34). She h } \\
\text { how much } \\
\text { three years } \\
\text { was also go } \\
\text { psychologi }\end{array}$ & $\begin{array}{l}\text { Profile \#9 Memo-Sarah } \\
\text { "Teachers vs. Admin/ Coach \& Psychologist" } \\
\text { Teaching Fellow who taught Science in an urban high school and } \\
\text { rs of support with a male coach. She described the first year as, } \\
\text { cally treading water to stay afloat" (28). Her school was in a great } \\
\text { administration had fired all the teachers and made them reapply for } \\
\text { he states, "I was a new teacher, I was in the new program, so it took a } \\
\text { for some of the teachers to even like acknowledge my existence" } \\
\text { weeks of student teaching in the summer but still, "cannot believe } \\
\text { it is" (124). The summer started with } 20 \text { fellows and there are } 5 \text { left } \\
\text { 139). Along with the dysfunctional climate of the school, this teacher } \\
\text { rough a divorce and did say that he acted as both a coach and a } \\
\text { Positioning }\end{array}$ \\
\hline Context- & $\begin{array}{l}\text { Great deal of turmoil with all teachers being fired (30) } \\
\text { "definitely a big pull, you know, the teachers on one side, the } \\
\text { administration on the other" ( } 42,180,196,211) \\
\text { Got rid of all department heads }(53) \\
\text { Our Science Department is fantastic ( } 53) \\
\text { Being a transformation school, there is always a lot of people } \\
\text { coming and going in your classroom ( } 358) \\
\text { "The yearlong course that teaching fellows puts you through was } \\
\text { the most unhelpful program in the world" (432) }\end{array}$ \\
\hline $\begin{array}{l}\text { Induction } \\
\text { coach }\end{array}$ & $\begin{array}{l}\text { "it was nice to have someone to talk to who wasn't evaluating me } \\
\text { at all" ( } 403) \text {. } \\
\text { "combination of coach and probably a psychologist on some level" } \\
\text { (407) } \\
\text { "he was super organized" (409) } \\
\text { Year } 2 \text { had a different focus (488) } \\
\text { Meet on the weekends at Starbucks (524) } \\
\text { I need him back this year for classroom management (545) } \\
\text { "He was tantamount to the fact that I'm still a teacher. And } \\
\text { wanting to be a teacher, making it through that first year and not } \\
\text { just burning out" (608). } \\
\text { "he was really good at focusing ideas and cleaning them up and } \\
\text { then giving me the little bits of tools or outlines or templates" (638) } \\
\text { Two years was necessary-time to fine-tune (679) }\end{array}$ \\
\hline Self & $\begin{array}{l}\text { "After } 3 \text { and } 1 / 2 \text { weeks of student teaching under my belt, it was } \\
\text { terrifying" (398). } \\
\text { ADD kicked in ( } 518) \\
\text { Going through divorce ( } 488)\end{array}$ \\
\hline
\end{tabular}

Figure 3.2 This figure is an example of a narrative sketch/memo that was used to capture my first thoughts about the interview. 


\section{Data Analysis}

\section{Data Preparation}

After conducting each interview, I sent the audio to an online company, Indoswift (http://www.indoswift.com), for transcription. Once I received the transcribed interviews, I followed each transcript while listening to the original recordings to ensure accuracy, and to make any changes that were needed to clean-up the transcript in terms of acronyms, inaccuracies, and to change the names of teachers, colleagues, and schools to protect their anonymity. It was critical that I listened to each recording several times, intimately connecting to them as if I was reliving the interviews. This helped me to gain greater insight into the story of each participant, listening to the words, his or her tone, pauses, and laughter. To stay true to narrative analysis, Wells (2011) believes that it is crucial to include all of the narrator's words rather than a summarized or paraphrased, cleaned up version of the words. I developed a notational system to capture long pauses, sounds such as laughter, and interruptions (Poland, 1995) (Table 3.2).

Table 3.2

Notational System for Transcription

\begin{tabular}{ll}
\hline Situation & Notational System \\
\hline Pause & For pauses longer than 4 seconds, insert the \\
& word pause in parentheses (pause) \\
Non-verbal & Insert in parentheses the word for non-verbal \\
Communication & sound such as (laughter), (sighing), or (grunt) \\
Filler & Leave filler intact that may show pause, \\
& hesitation in speech (ex: um, ah, like, etc.)
\end{tabular}




\begin{tabular}{|c|c|}
\hline Interruptions & $\begin{array}{l}\text { Insert a hyphen where interruption occurred } \\
\text { due to other speaker or outside noise. } \\
\text { (So, I don't know the name-) }\end{array}$ \\
\hline Unintelligible Speech & $\begin{array}{l}\text { Insert parentheses and the letter } \mathrm{x} \text {, to indicate } \\
\text { each word that cannot be understood }(\mathrm{xxxxx})\end{array}$ \\
\hline Emphasis & $\begin{array}{l}\text { Use capital letters when a word is emphasized } \\
\text { with volume or pitch (NEVER) }\end{array}$ \\
\hline Elongated Sounds & Repeat sounds that are held (Nooooo) \\
\hline Paraphrasing Others & $\begin{array}{l}\text { Use quotes to indicate that a person is } \\
\text { expressing what someone else said or is } \\
\text { expressing an inner voice (I thought "I'm never } \\
\text { going to make it") }\end{array}$ \\
\hline Outside Sounds & $\begin{array}{l}\text { Insert in parentheses any outside sounds that } \\
\text { may interrupt the speaker. (Background Noise) } \\
\text { (School Bell) }\end{array}$ \\
\hline
\end{tabular}

\section{Analysis}

It is difficult in the field of narrative research to find one clear account of how to analyze data (Andrews, Squire \& Tamboukou, 2013). There has been a "recent articulation of the divisions within narrative research that has taken the form of posing 'small' against 'big' stories” (Bamberg, 2006; Freeman, 2006; Georgakopoulou, 2007 as cited in Andrews, Squire \& Tamboukou, 2013, p. 8). The "small stories" often involve repeated content or themes throughout the interview that occur naturally in the social interaction between interviewee and interviewer. In contrast, the "big stories" are biographical in nature and can be analyzed by chronological structure. Bamburg and Georgakopoulou (2008) are interested in, "how people use small stories in their interactive engagements to construct a sense of who they are, while big stories 
research analyzes the stories as representations of world and identities" (p. 6). I chose to look at both small and big stories in each individual transcription. Therefore, data analysis occurred in three stages: (a) initial coding, which included the coding of each transcription for small stories as well as big stories, (b) secondary coding, which included grouping the codes into larger themes, and (c) cross-case analysis, which involved finding common themes in stories across participants. The purpose of coding is to make sense of the data by searching for themes and patterns that the researcher finds striking, surprising, or unusual (Creswell, 2009). Following is a more detailed explanation of each stage of coding.

Stage 1: Initial coding. As was mentioned previously, narrative inquiry is divided into four types of analysis: thematic, structural, interactional, and performative. I first focused on thematic and structural analysis. To begin, I identified the big and small stories within each transcript. The first stage of coding involved coding small stories for themes (thematic) and big stories for structure (structural).

Coding small stories. I separately coded each participant's interview transcript for small stories (Bamburg \& Georgakopoulou , 2008) (Figure 3.3). I used initial coding, making notes in the margins of the transcript, which included labeling topics covered, circling repeated interesting phrases the participants used, or any questions that I had (Merriam, 2009). When labeling themes, I followed an emic strategy of using participants' words as codes and marking them with a certain color pen any time that idea showed up. Each participant told between nine and fifteen different small stories in the interview, which I originally labeled truth statements. Later in my research when I came across the definition of a small story (Bamburg \& 
Georgakopoulou , 2008), I realized that these truth statements were indeed part of the story that each participant was telling. Although these truth statements did not follow a specific storyline with a beginning, middle, and end, each statement was an explanation of the larger story of what the teacher experienced in his or her first year. It was therefore important to capture these explanations, descriptions, and brief events as small stories that held meaning (Bamburg \& Georgakopoulou, 2008). Following the initial coding, I wrote a memo (Glaser \& Strauss, 1967) or narrative sketch (Clandinin \& Connelly, 1990) for each participant capturing my initial thoughts and reflection on the interview. These memos offered me a chance to reflect on the positioning of the participant throughout the interview. I gathered data on how they positioned themselves as a beginning teacher, their role in the context of the school, as well as the position they took when working with an induction coach.

Coding big stories. I also labeled big stories when they appeared, marking the beginning, middle, and end of the story as well as the coda (Riesmann, 1987). This form of structural analysis allowed me to look further into the narrative to uncover meaning. Not every participant told a big story as a way to explain the first year teaching. I will explain this finding further in the next chapter.

Stage 2: Secondary coding. Using axial coding, I sorted, synthesized, and organized the initial codes into broader categories that made sense within each participant's transcript (Creswell, 2009). The three categories of self, context, and coach followed the structure of the interview guide and therefore can be viewed as a priori (Table 3.3). The category of self, is specific to the participants' identify as a teacher and encompasses their self-perception as a teacher, as well as the emotional 
and physical effects of being a first year teacher. The second category of context represents the teachers' perceptions of the context of school that includes administrators, colleagues, students, parents, school culture, physical setting, as well as materials including furniture and books. The final category of coach reflects the teachers' perception of the induction coach that they worked with and includes the type of support they received from the coach, the specific activities/tools used during coaching or the emotions felt by the beginning teacher in this experience. This allowed me to take a different view of the data and begin to see common themes occurring across transcripts.

\begin{tabular}{|l|l|}
\hline \multicolumn{1}{|c|}{ Sarah } \\
Initial Code= Bonding with Students Axial Code= Self
\end{tabular}

Table 3.3 
Notes from Reflexivity Journal

\begin{tabular}{ll}
\hline Initial Code & Axial Code \\
\hline Baptism by Fire & Self \\
School Supports & Context \\
RIDE Evaluation & Context \\
Age difference/lack of & Self \\
connections & \\
Positive Coach & Coach \\
Emotional Support & Coach \\
Reflection & Coach \\
Confidentiality & Coach \\
Another set of eyes & Coach \\
Still Communicating & Coach \\
\hline
\end{tabular}

Stage 3: Cross-case analysis. My next step was to analyze the data across transcripts. To do this based on the three categories mentioned above (context, self and coach), I wrote memos that captured common themes across participants. My goal here was to bring together commonalities among the stories (Josselson, 2006). To do this I had to make decisions regarding which piece of narrative to include that would support the theme that was emerging from the data. Clandinin and Connelly (2000) refer to this as restorying the narrative for the purpose of broadening or generalizing. After grouping like excerpts of the transcripts together, based on the three categories, I reflected on the data that each person offered.

At this time, I was finding that the participants spoke a great deal about the types of support they received from the induction coach. I wanted to capture this information in a way to highlight the commonalties of the experience of working with 
a coach. Therefore, I kept track of the types of support the beginning teacher received from his/her induction coach in a tally chart, using the words of the beginning teacher as my headings. I then collapsed those headings into four larger categories: emotional support, classroom management, pedagogical support, and reflection on practice. I totaled the number of teachers and the number of instances the type of support was mentioned for each original heading as well as the larger categories.

\section{Trustworthiness}

Due to the nature of my study, it was critical that I uphold high ethical standards in the research process. In order to accomplish this, I used a variety of different methods to insure trustworthiness of the study (Lincoln \& Guba, 1986) (Table 3.4). The trustworthiness of a qualitative study is established in four areas: credibility, transferability, confirmability, and dependability (Lincoln \& Guba, 1986). Credibility refers to the internal consistency of the research in order to insure rigor in the research process. Transferability is the ability to generalize the research to other contexts, while confirmability deals with the neutrality of the researcher to the extent that is possible. Finally, dependability is the way in which the research is carried out with consistency. These methods occurred simultaneously throughout the research process. 
Table 3.4

Strategies for Promoting Validity and Reliability (Merriam, 2009, p. 229)

\begin{tabular}{|c|c|}
\hline Strategy & Description \\
\hline $\begin{array}{l}\text { Member Checks } \\
\text { (Confirmability) }\end{array}$ & $\begin{array}{l}\text { Taking data and tentative interpretations back to the } \\
\text { participants to seek confirmation. }\end{array}$ \\
\hline $\begin{array}{l}\text { Triangulation } \\
\text { (Credibility) }\end{array}$ & $\begin{array}{l}\text { Using multiple sources of data or data collection } \\
\text { methods to confirm emergent findings (Interview, Field } \\
\text { Notes, Memos) }\end{array}$ \\
\hline $\begin{array}{l}\text { Researcher's position or } \\
\text { reflexivity } \\
\text { (Confirmabiltiy) }\end{array}$ & $\begin{array}{l}\text { Critical self-reflection by the researcher regarding } \\
\text { assumptions, worldview, biases, theoretical orientation, } \\
\text { and relationship to the study that may affect the } \\
\text { investigation (Reflexivity Journal) }\end{array}$ \\
\hline $\begin{array}{l}\text { Adequate engagement in } \\
\text { data collection } \\
\text { (Dependability) }\end{array}$ & $\begin{array}{l}\text { Adequate time spent collecting data such that the data } \\
\text { became "saturated"- including a variety of participant } \\
\text { profiles }\end{array}$ \\
\hline $\begin{array}{l}\text { Peer Review/Examination } \\
\text { (Dependability) }\end{array}$ & $\begin{array}{l}\text { Discussion with colleagues regarding the process of the } \\
\text { study, congruency of emerging finding with the raw } \\
\text { data, and tentative interpretations }\end{array}$ \\
\hline $\begin{array}{l}\text { Audit Trail } \\
\text { (Confirmability) }\end{array}$ & $\begin{array}{l}\text { A detailed account of the methods, procedures, and } \\
\text { decision points in carrying out the study (Reflexivity } \\
\text { Journal) }\end{array}$ \\
\hline $\begin{array}{l}\text { Rich, thick descriptions } \\
\text { (Transferability) }\end{array}$ & $\begin{array}{l}\text { Providing enough description to contextualize the study } \\
\text { such that readers will be able to determine the extent to } \\
\text { which their situations match the research context, and, } \\
\text { hence, whether findings can be transferred. }\end{array}$ \\
\hline $\begin{array}{l}\text { Maximum Variation } \\
\text { (Transferability) }\end{array}$ & $\begin{array}{l}\text { Purposefully seeking variation and diversity in sample } \\
\text { selection to allow for a greater range of application of } \\
\text { the findings by consumers of the research. (Purposeful } \\
\text { Sampling) }\end{array}$ \\
\hline
\end{tabular}




\section{Reflexivity Journal}

It is important in narrative methodology that the researcher captures the data collection process, as well as any feelings, judgments, or questions that arise (Lincoln \& Guba, 1985). I kept a reflexivity journal from the beginning stages of my data collection to serve as an audit trail, keeping track of the participant selection process, field notes during interviewing, memos, and stages of data analysis (Figure 3.4). At first this journal was in the shape of an actual paper and pencil journal, going with me everywhere-research sessions, and meetings with professors and colleagues. I carried a case of colored pens to circle and group ideas. Then, I started to keep the journal electronically in the form of memos. I tried to capture my thinking about themes that emerged. I cut and pasted clips of transcripts and intertwined the participants' words with my own, making sense of my classifications and groupings. Flipping through the pages of my purple, embossed-leather journal is like traveling back in time to join myself on this journey of reflection. I reworked my research questions many times, kept track of articles that I wanted to look up, researchers associated with narrative inquiry, and questions I had about the work I was doing. This journal would become the source of the interactional analysis of my research as I began to understand my role as a co-constructor of the narratives each participant told. 


\begin{tabular}{|c|c|}
\hline \multicolumn{2}{|c|}{ Reflexivity Journal } \\
\hline $4 / 9 / 15$ & $\begin{array}{l}\text { This was a very difficult interview. I am } \\
\text { discouraged by the lack of feedback and } \\
\text { narratives she told. She had a hard time } \\
\text { remembering anything specific. She even } \\
\text { brought notes to the interview on the } \\
\text { interview guide I had provided in the } \\
\text { email. } \\
\text { After the tape recorder was off she talked } \\
\text { about a personal issue with her assigned } \\
\text { TA. The TA treated her like a daughter. } \\
\text { The coach role-played the situation with } \\
\text { her after she observed their interaction. } \\
\text { The coached helped a lot and she was able } \\
\text { to talk with the TA about overstepping her } \\
\text { boundaries. When she came back from } \\
\text { break, things were different. She talked } \\
\text { about how public school is very different } \\
\text { from where she student taught. }\end{array}$ \\
\hline $4 / 21 / 15$ & $\begin{array}{l}\text { This was an interesting interview. It was } \\
\text { probably the longest interview of all. I felt } \\
\text { like she had a clear agenda of what she } \\
\text { wanted to talk about. Her endorsement of } \\
\text { the program was clear from the start. Did } \\
\text { she think I was analyzing the program? } \\
\text { Her concerns about the RIDE Evaluation } \\
\text { System were strong and persistent. I } \\
\text { noticed the many times that she compared } \\
\text { the Induction Program with the Evaluation } \\
\text { System. What statement was she trying to } \\
\text { make here? }\end{array}$ \\
\hline
\end{tabular}

\section{Peer Review}

I met separately with two colleagues to discuss the process of the study and to confirm emergent findings (Merriam, 2009). Both of the colleagues were also $\mathrm{PhD}$ candidates and members of my cohort who were familiar with my research and had a clear understanding of research design and process. To begin, I reviewed the 
background of each participant with my colleagues, including the participant's age, grade level, and experience. I briefly described my emic coding, explaining how I conducted the initial analysis. Both colleagues independently read over each participant's transcript and reviewed my coding and notes. They pointed out additional examples of previously identified codes and asked questions about the process that allowed me to clarify my thinking about the work. I took notes and made changes to the codes that were necessary. The final step of the review was a discussion over each participant's memo. I also met with each colleague after stage two and three of the analysis was complete. At this meeting, I reviewed my secondary codes as well as my cross-case analysis.

\section{Member Checking}

Member checking is an essential component of narrative research in order to be sure that I accurately portray the story of each participant. According to Merriam (2009) "the process involved in member checks is to take your primary analysis back to some of the participants and ask whether your interpretation "rings true"” (p. 217). I sent each participant an email explaining my reason for contacting them, and requesting that they review the memo and provide feedback (Appendix I). In the memo, I summarized the major findings in their data, using their language whenever possible. I sent a follow-up email after two weeks if I did not receive a response. All of the participants responded, agreed with my capturing of their experience, and had only minor details to add that did not change my initial analysis. 


\section{Chapter Summary}

I used a narrative analysis approached to examine the stories of nine beginning teachers. I interviewed each participant using an interview guide. After transcribing the interviews, I conducted a multi-stage analysis. First, I coded the interviews thematically for small stories and structurally for large stories. Then, I grouped the initial codes into three focused codes. A cross-case analysis was then conducted, looking for common themes within the three focus codes. The findings from these analyses are presented in Chapter 4. 


\section{CHAPTER 4}

\section{FINDINGS}

\section{Introduction}

In this chapter, I discuss my findings. There are several layers to the analysis of the data (see Figure 4.1). The first layer involves the individual, small story, thematic analysis of each participant, which also includes a perfomative analysis. The second area of findings relates to the cross-case, small story thematic analysis that is further broken down into three main categories of findings: self, context, and coach. Finally, the big story structural analysis provides further insight into the lived experiences of beginning teachers.

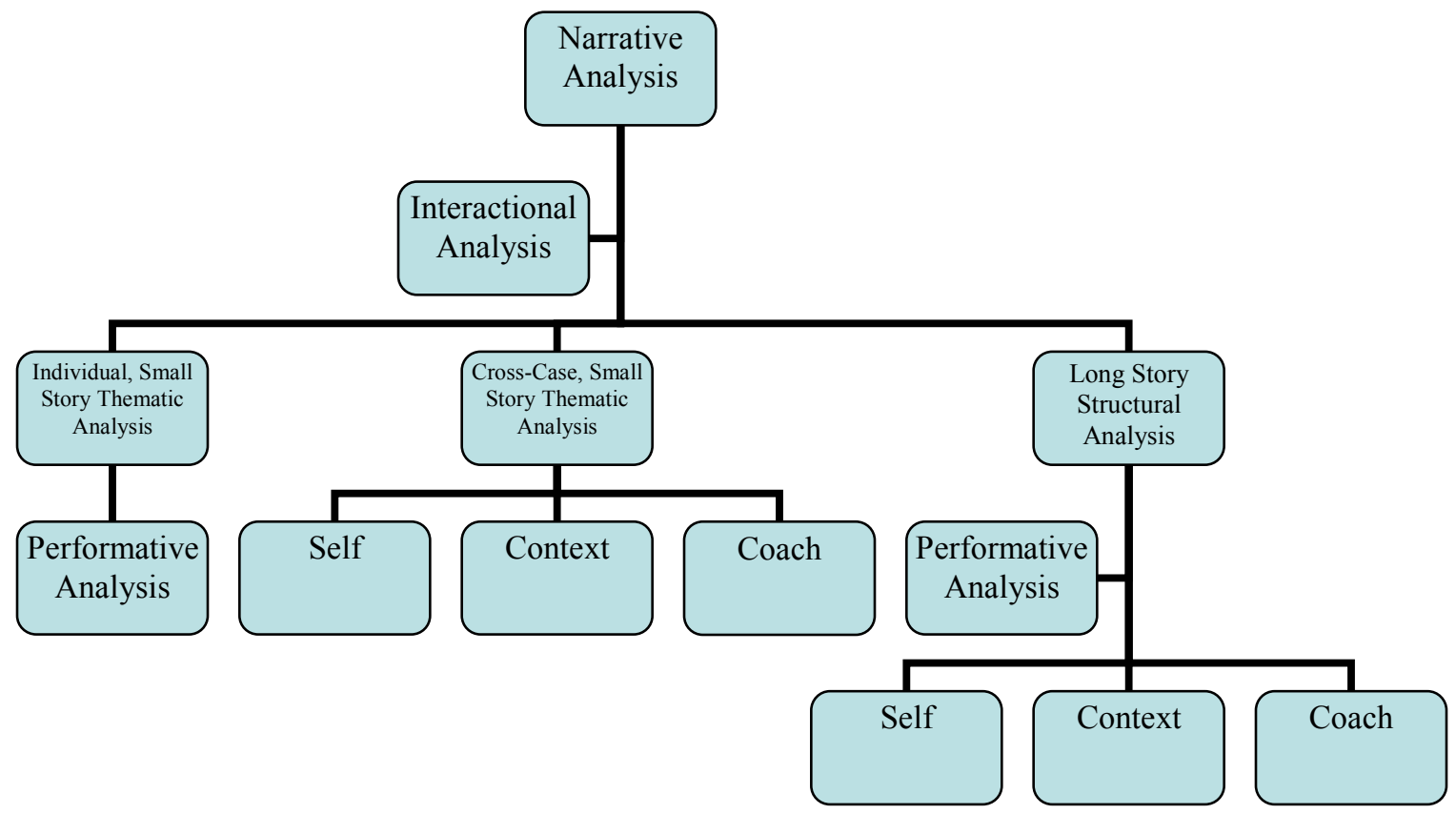

Figure 4.1. This is an overview of the narrative analysis conducted. 
When using interview data, I have used the exact language of the beginning teachers rather than paraphrase their words. I have kept the timestamp from the interview within the data to indicate the time in the interview that the statement occurred. To further indicate the sequence, I included the line numbers from the original transcription.

\section{Individual, Small Story Thematic Analysis Findings}

In narrative analysis, it is important to stay true to the individual stories of each participant (Riessman \& Speedy, 2007). In order to relay each story as I came to know it, I created participant profiles, which are my recreation of the time and place of the interview and provide a brief summary of the highlights of each participant's story. I have included my own thoughts, reactions, and observations as the co-constructor of each narrative. Kleinmann and Copp (1993) believe that, "taking a process approach to writing and bringing our feelings into the analysis will change our written product...researchers would weave their feelings into the analysis rather than relegate them to be beginning or end of the story" (p. 54). The memos or narrative sketches that are included in this section were member-checked by each participant; therefore, I wanted to keep these summaries intact, so I did not edit post-hoc for typographical errors. As Clandinin and Connelly (1980) suggest, "Because we know that a sense of the entire inquiry is useful context for readers, a descriptive overview is required. A 'narrative sketch,' something like a character sketch except that it applies to the overall inquiry, is useful" (p. 11). I am starting this chapter with the individual profile or narrative sketch so that the reader can come to know these teachers as individuals with specific stories to tell. 


\section{Profile \#1: Rachael}

Rachael and I met in a public library. We both rushed in ten minutes late thinking the other was waiting. We sat in a quiet study room with glass walls. Rachel spoke very quietly. In our introduction, I came to realize that her second year placement was in my home district (not in the school I was working in at that time) and I had even taught her brother as a former fourth grade student. Rachael had previously taken notes on the interview guide that I sent her ahead of time, and she often referred to her notes as we spoke. She did not have a lot to say, which made me very discouraged. I began to wonder if she was comfortable sharing with me because of our connections.

In an interesting turn of events, after I shut the tape-recorder off, Rachael continued talking. She told the story of her assigned teacher assistant treating Rachel like a daughter, due to the teacher assistant being older, and Rachel's lack of experience. She spoke about the role the coach played in her dealing with this situation. The coach brought it to her attention after an observation towards the start of the school year. They talked the issue through on several occasions and brainstormed ways of dealing with the problem. Eventually, Rachael was able to talk with the teacher assistant about overstepping her boundaries, and when they came back from winter break, the dynamics were better.

Memo: Rachael overview. Rachael had just completed college and worked part-time in a pre-school position. She was very nervous (193) at first and saw her principal as a savior in the new environment she found herself in, "My principal had to sneak me in because the wax, the floor was still wet, you 
know, we got yelled at by the custodian" (lines 36-37). She felt isolated in her first year, "I pretty much stayed in my own preschool bubble" (91), partly due to her part-time status and that she was the only pre-school teacher. At first, she did not know what to expect from the coach (152). She viewed the coach as "helpful”, but felt that she, "couldn't utilize her as much as, you know, somebody that was full-time" (247). She noted that she still sets up her room the same way she did when she worked with the coach (225) and even wishes she had her back now (248).

\section{Profile \#2: Beth}

Beth seemed very nervous and kept her coat on throughout the interview as we sat side by side in a study room at a public library. She could not remember many specific stories and she apologized often. She was very friendly and polite with limited eye contact during the interview.

Memo: Beth overview. Beth provided a unique perspective as she spent her first years teaching in a mayoral academy. She reported that as a first year teacher she had, "a lot of support" (21), she went on to state, "I feel like they do have a lot in place there, not necessarily like all helpful, some helpful" (316-317). She said the first year was a blur (337), “There's a lot of collaboration, a lot of professional development, and a lot of meeting type things" (60-61). At first, she struggled with her co-teaching partner, "I felt like I was kind of like still a student teacher" (27-28), and "it was really like a tough situation getting used to co-teaching" (24). While she was nervous that first year (22), "I actually knew what I was doing" (36). She appreciated that 
the coach was an outside support that understood the culture of the school, "I looked forward to meeting with her every single week whenever she came and scheduling those meeting with her because it was just a time for me to get out of like the Centerville world, if you know what Centerville is like" (295-296). In talking about the coach she stated, "She was someone to talk to, I mean I was in tears basically my first year because of like the co-teaching situation that was going on" (168-169) and "I think what (the coach) put in place for us as like a foundation to like really think through our problems and just talk more" (264-265). The coach helped her to build a relationship with her coteacher and reflect on her practice. She stated, "now that I am thinking about it, I really wish I had her this year because this is my first year actually alone" (311-312).

\section{Profile \#3: Shelly}

Shelly and I met in a public library on the Tuesday of school vacation week. I reflected on her dedication to the profession and interest in my research knowing she was taking time away from a well-deserved break from school. We shook hands when we first met and sat across from each other at a small table. While Shelly seemed very comfortable talking open and honestly, I was surprised at how chatty she was after the recording stopped. I wondered if she was uncomfortable having the conversation recorded.

Memo: Shelly overview. Shelly claims in her very first statement, "My first year was baptism by fire. It was a horrendous year to be just frank (laughter) about it" (22-23). Among other things, she had five days to set up a 
kindergarten classroom without proper tables, chairs, or curriculum materials. She mentions several times throughout the interview that she did not have a strong connection with other teachers due to various reasons (73, 88-93). At

first, she was unsure of what the role of the coach would be (104), but admits that the coach became an emotional support (117-123); Shelly refers to the long hours that they spent together, and that they still communicate today. (127). She reflects several times that the coach gave her another perspective, "I could really look at each student, see what she collected and just having a second set of eyes to take the time to do that for me" (151-152). To this day, she uses the journal that she started with her coach, "So there was a lot of emphasis on reflection and looking back, and I definitely reflect a lot more now, and I still have my journal for that first year that I use..." (275-277).

\section{Profile \#4: Charlotte}

Charlotte was very friendly and made a lot of eye contact throughout the interview. We sat at a quiet, sunny table in a public library. She talked a great deal about the tension in her building between the new staff, trained by Rhode Island Teach for America (RITFA), and the older staff. The principal was very demanding of the new teachers' time and even hosted several weekend professional development sessions that Charlotte felt obliged to attend. The problem with these meetings was the only participants were new teachers, who had many questions without anyone there to provide the answers. She was not assigned an induction coach until October because she was considered a long-term substitute. 
Memo: Charlotte overview. Charlotte was an urban, middle school teacher who received two years of support. She has an MA in English Literature and earned her teaching certification through the Rhode Island Teach for America Program. She describes her first year as a "roller coaster" (24) and she felt "suffocated" (30) with the limiting nature of the scripted curriculum. When asked about her principal she replied that he "was demanding especially with new teachers" (82). She gained confidence when she began to make the curriculum her own and moved out of the "dungeon" of the basement classroom. After that move, she found support from a colleague, and they would leave the building to get coffee and talk during their unassigned period (116). Her coach, "emotionally supported" (153) her at first, and she referred to her as a "genie" that had everything she needed (197), "I think she just basically wanted to take everyone under her wing...there was a lot of chocolate cake" (286). She relayed that, "I would always get frustrated and (the coach) was always like immediately there and like, okay, but like these are all the things that you did well...she was like see, and I can't see those things because I had been in the moment" (338). She stated that in regards to induction, "the second year was just as needed as the first. It was certainly different, the demand is different" (302).

\section{Profile \#6: Sarah}

Sarah was waiting inside for me for twenty minutes as I waited outside for her. She did not seem to mind the confusion as she was sitting busying herself with correcting papers when I finally went inside to check for her. We sat side by side in a 
window cubical in a public library. It was very warm in the library and I worried that she might be as uncomfortable as I was. Sarah was very interested in learning more about a $\mathrm{PhD}$ program and asked me many questions about my experience. Throughout the interview, she made comments that she was worried about sounding harsh and seemed to be trying to be politically correct with her answers. She spoke about the new Induction Program in her school that uses coaches from within the school, "the coaches aren't people who were very successful in the classroom, I think that's the nicest way you can say that" (379-380).

Memo: Sarah overview. Sarah was a middle school Humanities teacher. She worked in a charter school that emphasizes and builds relationships with students, including a charter fishing trip before classes start (54). She describes her school as the perfect place to teach, almost like a utopia where everyone works hard; "It's a place where I go and feel like everybody is working equally as hard from the front office to the principal, and it's so inspiring and just motivating to be there because you want to be as awesome as everybody around you, and I felt like that from the very beginning" (88). At first, she was very unsure of the Induction Program, "you can say as many times as you want, like I'm not here to evaluate you" (158), but by the end of the year, "I was wishing I could start over because I do feel like I wasted a lot of time at the beginning just I didn't know what to do with the support" (169). She came to appreciate that her coach was a "safe space" (195) where she knew that confidentiality would be kept (192). She looked at her coach as "a teacher who I consider a veteran and had all of these same struggles too and she got through 
them" (230) and stated that the coach became part of the school (477). Now in her school, the coaches come from within and she's not sure that it's working as well.

\section{Profile \#7: Mary}

Mary and I sat in an old library with stained glass windows. She was loud, energetic, and passionate about teaching. She had a lot to say and often commented about her age and personality. She began the interview stating, "I really liked the Induction Program and so my bias is definitely towards it. So anything that records it or documents it or encourages it to restart or continue in other places, I'm game" (2429).

Memo: Mary overview. Mary was a second-career teacher who did not have a teaching certification. She talks about not being the stereotypical teacher, "I broke a lot of ceilings when they hired me" (64). She refers to being, an, "old lady" (67) and female as well as having a very different perspective on art than her predecessor. She described the first year as though she was lost without a map (363). Throughout her interview she draws comparisons between the RIDE Induction Program and the RIDE Evaluation System, "I found that the Induction Program created the atmosphere I needed to be relaxed and to do my best and I feel that it goes against human nature to subject someone to endless assessment and evaluation because then we're not free to take risks" (465468). She talks a lot about the struggle she felt, "you spend time crying in the shower in the morning and you're wondering why did I give up my (previous job)?"(99-100). She even compares her experience with her time in the Peace 
Corp, “I told my boss that I haven’t had anything as difficult or as thrilling since the Peace Corps" (147-148). She viewed her coach as a "buffer" that was there to, "ease the bruises" (279) and she, "knew (the coach) knew what she was talking about" (328). She stated several times that she was, "open to learning" $(310,480)$ and that she was, "pigheaded" (129) and not giving up.

\section{Profile \#8: Henry}

Henry had to cancel our first appointment because his son was sick. We rescheduled for the day before Easter. We sat at a computer stall, facing each other. He wore casual clothing and made frequent eye contact. The library was busy that day and there was a lot of background noise we had to contend with. He seemed comfortable, easy-going, and smiled a lot.

Memo: Henry overview. Henry is a second-career male teacher who taught automotive classes in a Career and Tech school. He stated, "I have been working in the field for 25 years" (278), and, "I don't know anything about teaching" (283). He started teaching mid-year and "walked out of a shop and into a classroom" $(50,78)$. There was no written curriculum; this was, "uncharted waters" (120), but the long-term sub in the position stuck around for about three weeks to provide support (110). He was extremely unsure at first of the coach, a special education teacher, coming in and supporting him in an automotive class (283), "So, I kinda roll my eyes and I said, you know what? It is what it is" (290). "Once I saw her worth" (334), he was able to work with her and stated that, "She was extremely flexible" (317). When asked about his coach he stated, "It's a great relationship which we had, you know 
we're still great, great friends" (344). He describes the effect that coaching had on his growth and development as a teacher as, "leaps and bounds" (407). $\mathrm{He}$ even has a binder full of "stuff" from when they worked together that he lets people copy, but always insists that he gets it back (618). When asked if there was anything else that he could have used from the program, he replied, "a second year" (526).

\section{Profile \#9: Anne}

Anne and I met during the week of school vacation. She was very chatty, but unfortunately our conversation needed to end abruptly because someone else had reserved the private study room we were using. She was professionally dressed, which struck me as interesting because she was on school vacation. Anne was honest and open about her experience, even mentioning several times about her difficulty with focusing on a task due to Attention Deficit Disorder (ADD).

Anne spent a great deal of time talking about her certification process as a Rhode Island Teaching Fellow with The New Teacher Project. Her student teaching experience consisted of teaching summer school for three and a half weeks in an area of study she was not comfortable with. She was offered her position in an urban core high school before she finished her student teaching. Throughout the school year she took a yearlong course that in her words, "was the most unhelpful program in the world" (431-432).

Memo: Anne overview. Anne was a RI Teaching Fellow who taught Science in an urban high school and received two years of support with a male coach. She described the first year of teaching as, "you're just basically treading water 
to stay afloat" (28). Her school was in a great deal of turmoil as administration had fired all the teachers and made them reapply for their positions, "definitely a big pull, you know, the teachers on one side, the administration on the other" $(42,180,196,211)$. She states, "I was a new teacher, I was in the new program, so it took a good six months for some of the teachers to even like acknowledge my existence" (34). She said, after having three and a half weeks of student teaching in the summer, it was terrifying to start the school year (398), and still, "cannot believe how much work it is" (124). The summer started with 20 fellows and there are five left three years later (139). She commented that, "The year-long course that Teaching Fellows puts you through was the most unhelpful program in the world" (432). When asked about her coach she replied he was a, "combination of coach and probably a psychologist on some level" (407) and, "it was nice to have someone to talk to who wasn't evaluating me at all" (403). She went on to say that, "he was super organized" (409) and they would often meet on the weekends at Starbucks (524) where she could focus on the task at hand due to her ADD (518). When they worked together, "he was really good at focusing ideas and cleaning them up and then giving me the little bits of tools or outlines or templates" (638) and ,"He was tantamount to the fact that I'm still a teacher, and wanting to be a teacher, making it through that first year and not just burning out" (608). When asked about the second year of support she replied that the second year had a different focus (488) and she felt two years was necessary-time to fine-tune 
(679). She even reported that, "I need him back this year for classroom management" (545).

\section{Profile \#10: Paul}

Paul and I met in a public library on a beautiful, sunny Saturday, the first day of school vacation. He rode his bike to the library, and we both arrived in the parking lot at the same time and made our introductions. He seemed very comfortable and made lots of eye contact as we sat across from each other. Although I did not know him, we went to the same high school (at different times), college program, and he student taught in my school district.

Memo: Paul overview. Paul is a male high school band director in an urban setting. He was tasked with filling the shoes of the beloved previous band director who left without saying goodbye after 20 years (27). He states that, "it was difficult enough to get them on my side" (34) and the students repeated the phrase, "he did it this way". "It took two and a half years to really get the old system out" which lead to a very difficult transition. When asked about the school climate he stated, "It was extremely diverse" (69), and on his duty (assigned supervision), he often saw a lot of tension in the lunchroom (85). At the start of the year, he worked to get a student removed from his class, "He never physically attacked me, but there was always this anger that just came out" (40). He reports that the first year there was, "a big learning curve" (46) and he tried to find the balance with students being, "friendly, but not a friend" (51). When he first met his coach he was a bit resistant, "Why can't I get someone who's a retired music teacher or someone from the school who really 
knows the culture?" (140). The relationship with the coach grew as she went outside of her call of duty and would come to evening rehearsals to observe and even attended concerts. "She acted as a video camera really because she would tell me exactly what I was doing and I was more aware of myself, aware of things that I was doing well, and aware of things I wasn't doing as well “ (201). He also goes on to say that, he was so overwhelmed that first year that he did not take advantage of her (235), and even though there was no change in the support for the second year, "I think it was definitely helpful for the two years" (227).

\section{Performative Analysis Findings}

According to Mishler (1999) narratives are identity performances in which, "We express, display, make claims for who we are—and who we would like to be —in the stories we tell and how we tell them" (p. 19). To truly analyze these stories, it is important to look at the identity that the beginning teachers assigned themselves, as well as how they viewed their context and coach. Tables 8, Participant's Identities, illustrates the identity that each participant most clearly defined. Often times, the words I chose to portray the identity came from the beginning teachers themselveswords they mentioned several times in the interview. This is not to say that their identities were stagnant in the interview, but rather one rose to the foreground above the others in summing up the stories they told (Mishler, 1999). Often, the main identity I selected repeated several times in the story the beginning teacher told, or the identity had a significant impact on the decisions he or she made in the first year(s). 
When looking at the self-identities, it is critical to keep in mind that these identities are situated in the context of being a first year teacher.

Table 4.1.

Participants' Identities

\begin{tabular}{|c|c|c|c|}
\hline Participant & Self Identity & $\begin{array}{l}\text { Contextual } \\
\text { Identity }\end{array}$ & Coach Identity \\
\hline Rachael & $\begin{array}{l}\text { Isolated } \\
\text { (negative) }\end{array}$ & $\begin{array}{l}\text { Not valued or } \\
\text { welcomed } \\
\text { (negative) }\end{array}$ & $\begin{array}{l}\text { Helper/Mother } \\
\text { (positive) }\end{array}$ \\
\hline Beth & $\begin{array}{l}\text { Student Teacher } \\
\text { (negative) }\end{array}$ & $\begin{array}{l}\text { Suppressed } \\
\text { (negative) }\end{array}$ & $\begin{array}{l}\text { Confidant/Problem } \\
\text { Solver } \\
\text { (positive) }\end{array}$ \\
\hline Shelly & $\begin{array}{l}\text { Disconnected } \\
\text { (negative) }\end{array}$ & $\begin{array}{l}\text { Baptism by Fire } \\
\text { (negative) }\end{array}$ & $\begin{array}{l}\text { Second Set of Eyes } \\
\text { (positive) }\end{array}$ \\
\hline Charlotte & $\begin{array}{l}\text { Stifled } \\
\text { (negative) }\end{array}$ & $\begin{array}{l}\text { Caged } \\
\text { (negative) }\end{array}$ & $\begin{array}{l}\text { Genie } \\
\text { (positive) }\end{array}$ \\
\hline Sarah & $\begin{array}{l}\text { Connected } \\
\text { (positive) }\end{array}$ & $\begin{array}{l}\text { Perfect Place } \\
\text { (positive) }\end{array}$ & $\begin{array}{l}\text { Safe Space } \\
\text { (positive) }\end{array}$ \\
\hline Mary & $\begin{array}{l}\text { Pigheaded } \\
\text { (negative) }\end{array}$ & $\begin{array}{l}\text { Heart of } \\
\text { Darkness } \\
\text { (negative) }\end{array}$ & $\begin{array}{l}\text { Salve } \\
\text { (positive) }\end{array}$ \\
\hline Henry & $\begin{array}{l}\text { Outsider } \\
\text { (negative) }\end{array}$ & $\begin{array}{l}\text { Uncharted Waters } \\
\text { (negative) }\end{array}$ & $\begin{array}{l}\text { Flexible } \\
\text { (positive) }\end{array}$ \\
\hline Anne & $\begin{array}{l}\text { Distracted } \\
\text { (negative) }\end{array}$ & $\begin{array}{l}\text { Teachers vs. } \\
\text { Administration } \\
\text { (negative) }\end{array}$ & $\begin{array}{l}\text { Coach \& } \\
\text { Psychologist } \\
\text { (positive) }\end{array}$ \\
\hline Paul & $\begin{array}{l}\text { Newcomer } \\
\text { (negative) }\end{array}$ & $\begin{array}{l}\text { Diversity } \\
\text { (negative) }\end{array}$ & $\begin{array}{l}\text { Video Camera } \\
\text { (positive) }\end{array}$ \\
\hline
\end{tabular}

Most of the teacher's self-identities are negative in nature, from feeling isolated, to being stifled, and to being an outsider. This supports the research that the 
first year of teaching is a challenge for most teachers who take on the role of struggling to overcome an obstacle (Dyal \& Sewell, 2002; Ingersoll \& Smith, 2004).The majority of contextual identities are also negative — suppressed, caged, and not valued. It is interesting to contrast this negativity to the positive coach identitieshelper, confidant, and genie. To help bring this issue to the forefront, I have identified each of the identities as being either positive or negative, as I note in Table 4.1.

The one outlier in this analysis seems to be how Sarah positioned herself. She set the contextual identity of the first year as the "perfect place" and often stated that she felt "connected" to the students, faculty, administration, and coach. She describes the culture of the school:

Sarah: It's amazing, yeah (laughter). It's a place where I go and I feel like everybody is working equally as hard from the front office to the principal, (04:00) and so it's inspiring and just motivating to be there because you want to be as awesome as everybody around you and I felt like that from the very beginning. There wasn't really...maybe I fit in with them just as much I feel like they fit in with me but it's been a good fit from the start. I think it was really easy to feel comfortable and to jump in feet first and just it was like a perfect experience to start off my career. (87-93)

Sarah's positive self-identity may relate to the positive context of her first year experience. She spoke a great deal about the structure of her school and the amount of support she received as a beginning teacher. She worked on a team of four content teachers and a teaching partner who acted as a teacher assistant and followed one 
group of students throughout the day who needed extra support. There was also a math coach and literacy coach for each team, as well as an academic lead who met with the team weekly to check in on lesson plans and support the team. This structure of support does not exist in many schools, and I am left wondering if this context was the reason why Sarah had such a positive identity of self in her first year of teaching (Zembylas, 2003).

To contrast this positive contextual identity of Sarah and the effect it had on her identity of self as a first year teacher, I offer the case of Beth. Beth describes that she was "stifled" the first year due to the context she was teaching in. This had a negative effect on her identity of self as a first year teacher. While she knew she was capable in the classroom, her co-teacher treated her as a "student teacher," which cause a great deal of strife between them and led Beth to take on the self identity of feeling "suppressed."

Beth: I was obviously very nervous as my first year; however, at Centerville, it's a co-teaching model so there's a lead teacher and a fellow. I had the fellow position in my first year teaching and I got placed with a teacher who was in her mid 30s and at first it was a really like tough situation getting used to co-teaching. (0:00:59) She had a lot of experience, I had no experience minus my student teaching and she's a very great teacher, but I felt like I was kind of like still a student teacher. So, that was a little bit challenging and I feel like I didn't have as many lead roles. The first half of the year, we kind of butted heads along that (laughter) and you know she was kind of -we're best friends now, but she's kind of a 
control freak like, you know, just really clean with the classroom like if I misplace something, it has to be like, it was a little bit challenging my first year.

It became clear in my analysis that the beginning teachers' identity of self is situated in the context in which they are teaching. This relationship between self and context cannot be separated (Oyserman, Elmor \& Smith, 2012). I will talk more about this in the findings of the big stories.

\section{Cross-Case, Small Story, Thematic Findings}

When analyzing the data across cases, I grouped the codes into the three thematic categories: self, context, and coach. Each category represents a theme that I noticed across multiple cases within each category. I have included a section of the interview that supports the theme from each participant that spoke about this topic. Figure 4.2 illustrates the breakdown of themes discussed.

\section{Self}

The first set of cross-case findings deal with the beginning teachers' identity of self. It is important to pay close attention to the position that individuals take up when relaying stories about their lives as a first year teacher. These teacher self-identities provide insight in to how the beginning teachers handled the situations they were faced with. For instance, did they view themselves as a victim who had no power to control their destiny, or did they face the challenges with an empowered sense of fortitude? 


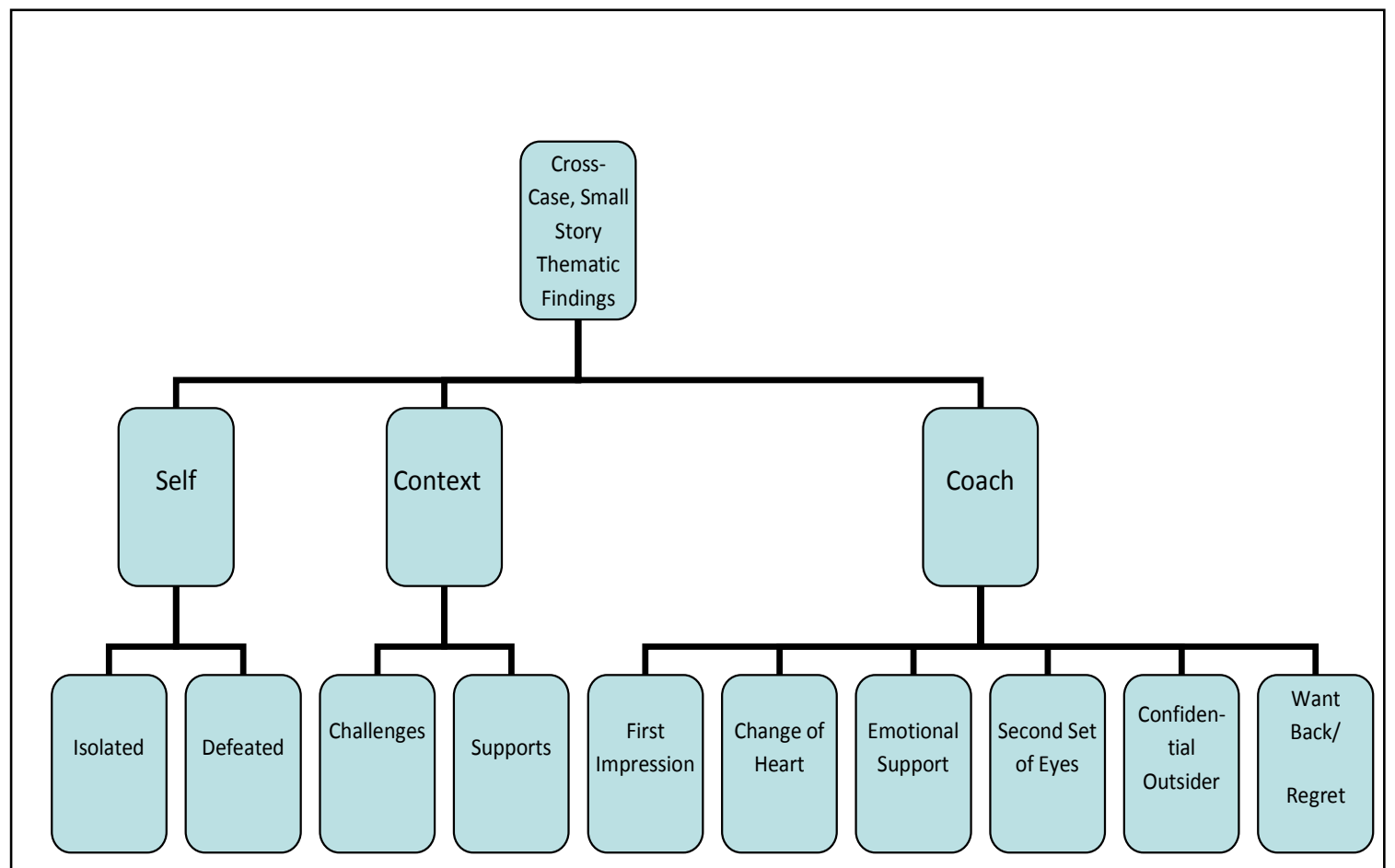

Figure 4.2. This is the overview of the cross-case, small story thematic findings.

Isolated. The feeling of isolation is often felt by those who are novices in a field (Ingersoll \& Smith, 2004). Often times it stems from simply not knowing who to reach out to and what questions to ask. This theme emerged early in the interview for most participants. For some it remained an issue throughout the first year(s); others were able to navigate themselves out of the feeling of isolation. Rachael discusses her unique position as a part time teacher who did not grow up in the small town in which she was teaching.

Rachael: $\quad$ I pretty much stayed in my own preschool bubble. Again, everyone was very friendly and willing to help me out whatever I needed but because I was part time it made it difficult to really even get to know people. 
(0:02:58) (pause) It's a small town so everybody knew everyone except kinda me (0:03:05) (91-94).

Shelly relays a story of isolation due the age difference with the staff. She was looking for someone to connect with that understood her experience.

Shelly: I have a lot of support from different teachers throughout the building but it was still difficult to kind of find peers within my colleagues because everybody is much older than I am. There was only one teacher in the school who was around my age and she is still like seven years older than I am. So, I have the support where if I just needed supplies, they would have helped out but it's more of like kind of an outlet or somebody I could go to talk to I really didn't have too much support the first year. And one (kindergarten teacher), she had just started, that was actually her first year of doing kindergarten, she had taught first grade prior to that. So she was still trying to get her feet wet with kindergarten and then the other teacher had been in kindergarten for a period of time but she ended up leaving halfway through the year. So, the other kindergarten classroom was a long term so that was not overly helpful either. (laughter) (71-93)

Henry's experience as specialized teacher working in a career and technical high school isolates him from the majority of teachers.

Henry: So, I had a little bit of, you know, going in to this room with all of these new teachers who are just like me, and I was a little bit excited about that but I'd be the different kid. (10:04) I was always going to be, you 
know, I am always the different kid. So, I'm going to walk into this room and everybody's going to be English, science, history, art. And CT is what? You're teaching what? So I always prepare myself for that. So, I go in and I sit...I walk in and look for your name tag and then of course right off the bat. Henry doesn't have a name tag.

These feeling of isolation felt by the participants, due to part-time teaching status, age difference, or specialization, mirror Ingersoll \& Smith (2004) findings in their research on why teachers leave the field.

Defeated. The notion of just making it through each day was a common theme amongst the beginning teachers' stories of their early days. Often, they are bogged down in the day-to-day survival of the first year and struggle to see the bigger picture (Ingersoll \& Smith, 2004). It can be overwhelming to the novice to rise above this struggle and often there is a moment when the beginning teacher just wants to give up. Mary, as a second career educator, questions her career path when faced with unruly students.

Mary: $\quad$ So it was one of those first years where you spend some time crying in the shower in the morning and you're wondering why did I give up my wonderful little grade school project. Is the second income really worth this? (06:00) Kids were telling me to fuck off. They were telling me that in the classroom. (98-100)

Shelly speaks about wanting to leave the profession early in the year. She questions her decision to become an educator. 
Shelly: I actually almost resigned in October in that year because I was just so overwhelmed. (110-111)

At the beginning of the year, I was like I am not supposed to be a teacher. (19:00) (331-333)

Charlotte relays how managing the day-to-day reality of teaching was overwhelming. She was not prepared for the planning and rigid curriculum.

Charlotte: Well, I think the first year is supposed to be a roller coaster, right. So, I... as you could tell with me describing all the transitions, it was very chaotic. I always sort of was just trying to figure how to do it basically like it was like how do you do this on a daily basis. I think that was most of the first year and then hitting...I remember hitting January and thinking okay I have to make this my own because I was following all these curriculums that were very limited and that's where I kind of felt suffocated, the directions of it and the kids weren't digging it. (24-30) ... I still remember how terrified I was the first day, like having like what I thought was prepared I mean like 10 minutes into the class I was like oh this is a double block, 90 minutes. I have no idea what I should say to you now, you know. (47-50)

Anne was defeated when she was asked to teach unfamiliar content and described the first as "horrible."

Anne: It was, it was I say horrible, it's, (laughter) I mean I've been a first year teacher, so it's just sheer, like you're just basically treading water to stay afloat. (27-28) 
So I struggled. I think the fact that I had to teach chemistry and I was literally every night up till 3 in the morning, trying to teach myself chemistry, crying, having panic attacks. (115-117).

Beginning teachers reported feeling defeated due to unruly students, a rigid curriculum, teaching unfamiliar content or simply being so overwhelmed that it became a question of career choice.

\section{Context}

From the very start of my research, I knew I wanted to tell the story of first year teachers. Specifically, I was interested in the story of these teachers working with an induction coach. I knew that I could not separate this experience from the context of the school in which they worked. Therefore, it was vital to ask about the context of their experience: administration, colleagues, and physical school structure (Ashforth \& Schinoff, 2016). It is in asking about this context that I would be able to situate their work with an induction coach.

Challenges. Last minute hires, no curriculum, lack of classroom supplies, negative school climate, long hours - those are just a few of the obstacles of a first year teacher. This induction into the world of teaching is not for the faint of heart (Ingersoll \& Smith, 2004; Dyal \& Sewell, 2002). As you will read later on, for many their coach was the only thing that kept them in the profession. Rachael, a late summer hire, was faced with physical challenges of a room she couldn't set up due to a newly waxed floor.

Rachael: No, I came in and everything was in boxes and they're waxing the floors. (0:01:00) My principal had to sneak me in because the wax, the 
floor was still wet, you know, we got yelled at by the custodian. A good experience. (Said with sarcasm). (35-37)

Shelly also faced physical challenges of a room with no furniture, five days before the start of school.

Shelly: $\quad$ My first year was baptism by fire. It was a horrendous year to be just frank (laughter) about it. My classroom was added the week before school started and prior to that, it was the music classroom. So I had no curriculum materials, I had no student tables, I had very little of anything to work with. In addition to that, the principal wanted to do a lot of cosmetic changes to the classroom with painting and all of that. (00:58) So, we were scrambling just to get the room to look like a kindergarten room and I had 25 kids coming in, in five days so it was a lot of work just to get the classroom up and running and then once I got my student population, they were super behavioral. I had a really tough class. It was just a crazy year, very crazy year. I kept getting materials as they came and I wouldn't, you know, it was months and November was when I got my tables for my students. So up to that point I just had a hodgepodge of whatever was hanging around the school to put the kids up. Whoever had extra chairs, I didn't have really a lot of separate workspaces for students who needed their own space so it was just, it was a lot thrown at me all at once that I was like "I don't know what to do!" 
Charlotte faced administrative demands. The expectation was to put in long hours and attend professional development as a new teacher without a family at home to take care of.

Charlotte: So the principal at the time was very much involved maybe to a point of too much sometimes. He was very demanding especially with new teachers, most likely because he knew we might have not known any better. So, I mean I remember him telling me that because I was new and I didn't have like a family or anything, you know, that he expected people like me to show up at 6 in the morning and he expected me to stay till 8 o'clock at night because that's what we should do. (06:00) He also hosted several weekend PDs that we were required to go to as new teachers even then we weren't paid and you were questioned if you didn't go to them. There was a very strange conduction of preparation. (81-89)

Anne speaks about the challenge of a negative school climate. In this case she identifies that administration and teachers were on different sides.

Anne: $\quad$ But, so I started at Willamtown High School, which had just gone through the firing of all the teachers. I was, I thought I was the first year after they got fired, but I don't think I was, I think I was the second year. So, the morale around the high school, I thought it was pretty good. But you could definitely tell, I was a new teacher, I was in this new program, so it took a good six months for some of the teachers to even like acknowledge my existence. (01:00) So I didn't really 
notice, I was pretty oblivious, your first year you're, you know you're oblivious to anything so, I know speaking, like hearing things from the teachers they said the morale was better that year than it had been, obviously to the prior year. But I still don't think it was stellar. But I didn't really notice much of anything. There was definitely that big, pull, you know, the teachers on one side, the administration on the other. (28-39)

Paul tells the story of the challenge of building relationships with students as a new teacher replacing a beloved educator who left abruptly.

Paul: First year was very difficult for me because the teacher who was in a position previous to me had been there for 20 years. He never said goodbye to the students on being a, I mean, they left in the summer. So, when I got into that position, the kids were all under this impression of who's this guy, who's this 22-year-old kid that where is dad, where is the patriarch. He was a wonderful guy, 45-year-old guy and he needed to do what he needed to do for his family, it wasn't that he did the kids or anything, it's just he had put so much work into the program and they just kept taking things away from him. (0:01:02) So, he got frustrated and left, and when I came in there was a lot of backlash. It was difficult enough just to get them on my side. Well, he did it this way, he did it this way, I heard that nonstop and being in a music program compared to being a math teacher, it's not like they just had it for one year, they had it for four. So, it was really difficult the first year. There were some students, who I remember one in particular he was a third year junior, 19 years old and there 
were several students in his situation, but he was the most vocal and he would threaten me, throw things at me. He never physically attacked me, but there was always this anger that just came out. Not a month and a half to the program, I was able to get him removed from the program because I felt it was going to go to the next level. (0:02:00) (25-42)

The beginning teachers reported challenges in the context of their first year that included lack of furniture, curriculum materials, administrative demands, a negative school climate, and difficulty with building relationships.

Support. To face the many challenges of the first year(s), beginning teachers need to be supported. Support for a first year teacher can come in the form of many different things: financial, materials, positive feedback, empathy, or a guide of how to be a teacher. Beginning teachers can also find support in many different places: principals, department chairs, colleagues, co-teachers, or district-based mentors (McNulty \& Fox, 2010). Mary felt supported by her administrators from the very start, as they sought her out specifically to fill a position.

Mary: $\quad$ So I felt supported. I felt very supported. (04:00) I'm blessed with a principal who supported this, who started the program and I'm blessed with a Dean of Arts who basically met me and wanted me in that building. (81-83)

Shelly also had the support from her principal in the form of materials and other program supports. 
Shelly: [The principal] was great. She really tried to do whatever she could to get me the materials I needed, give me the support I needed. She knew that I was in a really tough spot, so she was excellent. (53-55)

Rachel comments that feedback from her principal was helpful as well as knowing she could go to her administrator with any concerns.

Rachael: [The principal] would always pop into the classroom to just like informally see how things were going to play with the kids so see what activities we were doing, give me positive and negative feedback if I had any problems or conflicts with parents or families she was willing, you know, to help, talk with me, then and bussing was always a huge issue just because the kids were so little and they're taking the big bus $(105-110)$

Financial support from administrators is important to beginning teachers as they build their classrooms and programs. Communication and accessibility were often mentioned by beginning teachers like Paul.

Paul: $\quad$ Even though my principal wasn't visible in the school, she definitely supported me. She herself had a daughter who was a professional oboe player, which meant that she knew what it was to support music education. Constantly, I would receive e-mails of different musical activities and state things and New England's scholarship programs, very supportive. (0:07:02) Any time I had a question, she was there, fully accessible. I could walk into her office any time in my first two years never had a problem, and, as I said, always supportive with 
financial things as well. When I first got the job, they said you're going to teach a music technology program, but there's no music technology. There was a grant set up the year before I got there and nothing had been ordered. So, she was very helpful in the process of ordering all of my tech(0:07:35) and now I have a 22-computer Mac lab all with mini stations and recording studio in the school.(100-111)

Planning with a team can be a great support for beginning teachers to build their confidence and share the workload.

Beth: $\quad$ Okay. So, my first year, I had a lot of support in my first year as an educator and I was obviously very nervous as my first year; however, at Centerville it's a co-teaching model so there's a lead teacher and a fellow. (21-23)

As an educator, I felt like I had a lot of support with planning. We all planned together and the entire team collaborated together with planning and I was planning one subject with another girl in the grade and then we shared plans, which was helpful in my first year. (39-42)

Sarah also mentioned the support of her colleague, both veterans and other new teachers was helpful if she had questions or needed planning advice.

Sarah: $\quad(05: 59)$ So, there I work on a team of four content teachers and then we have a teaching partner that follows one group of students throughout the day and was kind of like a teacher's aide for...to support staff and we also have a math coach and a literacy coach for each team. So yeah, so there is no shortage of support. My first year, the math coach, the 
literacy coach were both also new hires and the ELA teacher on my team was also...so it was a good split of veterans and new folk that we could kind of come together and I'm never really afraid to ask questions anyway but I thought that it was even more of that environment because I didn't feel like the only new person who might have some questions (121-130)

Charlotte suggests that having a guide to "how to act" in the school setting was helpful to her.

Charlotte: The history teacher had been there for several years and for the most part he let me sort of just kind of watch him and he was my guide to like how the faculty maneuvered, how they got along, the school culture, expectations.(98-100)

Henry received support from colleagues and administrators who checked on him to make sure he was okay.

Henry: $\quad$ For me, it was completely, well being from industry, I'm used to a certain culture, in which one of us take care of our own, you know that kind of deal. A (03:00) little bit different, they were very helpful, making sure that I was you know okay, and at the end of the day I wasn't taped to the chair or something like that. Very supportive, the director especially, which I've gone to frequently to make sure I was okay. You know especially, the long-term sub, he stuck around for about three weeks. I now have a relationship outside of school with him. $(105-111)$ 


\section{Coach}

As an induction coach, I was curious about the experience of this program from the lens of a beginning teacher. How did they view this person walking into their classrooms? Did they embrace the coach or see the coach as a threat to their individuality and freedom of having their first teaching experience? In these findings, you will learn from the beginning teachers their first impressions of coaching, how their views of the program changed, and the types of support they valued.

First impressions. The majority of teachers interviewed were uncertain about the program at first. They did not know who this person from RIDE was coming in to "coach" them once a week. Many thought that coaching connected to the evaluation system, and that they were being evaluated; others simply felt like they had too much going on to take time to meet with someone each week. I wonder if this concern was due to the newness of the program or the reluctance any beginner feels being critiqued or having someone watch them. Perhaps there is an idea that only "bad teachers" need support. I sought to understand the lack of a culture that supports teachers and requires them to reflect on their practice in order to grow.

Shelly refers to a lack of prior notification about the program. She had no idea what to expect from the coach.

Shelly: (05:00) She came to me during that first week of craziness, getting the classroom set, introduced herself, talked to me a little bit about the program and I had no clue what she was talking about when she came in because nobody told me I would have a coach and I was like, 'oh, okay whatever.'(103-106) 
Rachel also mentions that she did not know what to expect. She alludes to the fact that the coach mentioned from the start that she was not there to evaluate her. Rachael: I guess I didn't really know what to expect when I first was told that I would have a coach. I mean she -- we went over the paperwork and stuff, she said I'm not here to evaluate you or anything like that. We're just working together and answering any questions you have and giving (0:05:54) any type of support. (152-155)

Sarah talks about her learning style and how this program did not fit her needs.

Sarah: $\quad$ And I wasn't sure what to make of it, I tend to be a very like close myself in a room and let me figure this out on my own and so the Induction Program scared me a lot because you can say as many times as you want, like I'm not here to evaluate, I'm here to help, but that was hard for me to feel through no fault of anybody's but like my own need to process things. (157-161)

Mary relays her reaction to feeling like a cat on high alert and she was not a willing participant.

Mary: I can remember the first day very clearly. And I went in there... if I were a cat my ears will be back and my tail would have been (points straight up) because I was not...I did not, NOT, want to be part of this. I thought, I have too much to do, I can't have somebody in there assessing me and all of this. I had my back against the wall when I was told to go meet her and I went down...I don't know if she picked up on that, I have no idea. (166-171) 
Paul was concerned about the lack of alignment with his coach. He was a high school music educator and she has an elementary background.

Paul: So, the first time I remember, I mean it's been a little while, when she was coming in I was a little surprised because I was partnered up with someone who was from outside the school and from an elementary education background, and at first I think I was a little bit resistant and I said how is this really going to help me, why can't I get someone maybe who's a retired music teacher or someone from the school who really knows the culture, and then only seeing them once a week for 40 minutes. I didn't feel open enough yet to be able to talk about things. $(135-141)$

Change of heart. Many of the participants had a negative view of the coach and the Induction Program at first. Was this due to a lack of publicity about the program or the fact that it came out at the same time as the RIDE Teacher Evaluation Model? Beginning teachers repeatedly told me that they had no idea who this coach was that showed up in their room the first few weeks of school. They were nervous that this person was evaluating them or that they would take all their planning time with wasteful paperwork. All of the beginning teachers that reported this reluctance of the coach at first, gave way to what I have labeled as a "change of heart", either immediately after meeting the induction coach or a few weeks in after realizing the type of support they would receive. 
Mary tells the story of her comfort level changing as soon as she met her coach. She mentions that their personalities meshed and the coach always assumed positive intentions on her part.

Mary: $\quad$... and she started talking and I immediately fell in love with this woman. She completely put me at ease. I was relaxed. I realized this was going to be a good thing just...I don't know what kind of preparation she had to prepare us for her. (11:00) I don't know what went into that but whatever did worked because I was...I was onboard 5 minutes into the conversation and I had not walked in there with that attitude at all. So I remember that day very clearly and then I was like yes, I want you here. And I can remember just really looking forward to the day that she came being very happy when she walked into the room and again it was a personality mesh as well and that's important and that's not always a guarantee, it's not always a guarantee. So I felt very, very comfortable with this person and I think she realized the importance of what a fragile situation it was. I think she had a good assessment of the student population I was working with. (12:00) I think she was aware of how, whatever mistakes I was making my intentions were sincere, my preparation was involved. (166-184)

Paul was concerned at first about the mismatch of certification with his coach, but found that getting a different perspective from someone who was an expert educator was helpful. Many beginning teachers noted that matching certifications did not really matter; good teaching, is good teaching (Rockoff, 2008). Coaches that went 
above and beyond the school day and were easily accessible to support their teachers were mentioned in many of the interviews.

Paul: Eventually, I saw that she was from the community, she understood the community, and she was a parent as well. (0:10:00) So, even though when she came into my class and I was doing something musical she might not be able to give me advice on how I can improve it. She was helpful in, for instance, the example that I remember I taught a music theory class and I remember that she wrote out a chart of (alarm goes off briefly) when I was asking certain students for answers, and she would circle who I asked more. So, different teaching strategies outside of the rehearsal process when I taught guitar class, when I taught music history, anything like that outside of that setting. She was able to offer a lot of different techniques and strategies that I can improve my teaching. Being a musician, I get so used to the rehearsal process and when you have to step outside of that, you're thinking of different learning strategies and it was difficult for me. (0:11:01) So, she was helpful with that. What was nice is she was very flexible with her schedule. I know she had maybe eight new teachers and I have rehearsals at night and occasionally she would come from 7:30 to $8: 30$ at night and observe my rehearsals. That was very helpful for me because a lot of times I'd be the only adult in the school with 75 students and one time a kid threw a water bottle across the room, hit a kid in the head. It was extremely helpful to have another adult there 
who can handle those kind of things (0:11:37). She went outside of her duties once we got to develop a relationship with each other. She would come to our concerts and she didn't have to. That really helped our relationship grow. The fact that I knew she was there to support me outside of her required 45 minutes with me. (0:12:01) (135-164)

For Henry there was also a concern about certifications matching. However, how the coach navigated this dissonance made the beginning teacher accept the support and the outside perspective.

Henry: So, Jill comes in the second day and she's like okay so, let's not sugar coat this. You're an automotive guy, I'm a special ed guy. I don't know anything about you and you don't know anything about me, but you know what, we're going to make this work. (14:03) I'm like okay. She goes as long as you're flexible and we can work on some of, bounce some ideas off each other I think this would work. And that was it. From that day forward, it just, she would give me an idea and I'd sit there and look at it and I'd go, okay, I see what you mean. But can we do it this way? And she goes yes, now I see what you're talking about. So, we were always, she goes, she put the idea in my head and she's looking, she's goes now how can you use that? So she'd put strategies or, or, you know we did the graphic organizers and I went aw yeah, this is good but can I twist this like? And she said absolutely! And it worked. And so, you know, we would kid back and forth, I would drag her into the shop and she had to put the safety glasses on and walk 
around with the clipboard and you know, it stinks in here, but her dad was in the business, so she knew exactly what she was getting into. (15:00) She was extremely flexible, she was hard at times, but it was, it needed to be hard especially with like classroom management pieces. I mean I certainly don't have angels. But the classroom management pieces, she really drove a lot of them, you've got to try a little hard line, some of these kids, they're going to push you, just to see where you're at and stuff like that. So, we've got to try that line in the sand and make sure you stick with it. She was extremely fair, extremely fair which was really helpful. You know, classroom observations were a little bit frightening at first, especially when she would give me the script, of this is what you said and I was like, you wrote down everything, didn't you. So, it was a little bit frightening at first but by the time the evaluation process came around, it was very helpful. (299-328)

Emotional support. After having a "change of heart" many beginning teachers told stories about leaning on the induction coach for emotional support. The goal of any Induction Program is not to merely provide emotional support. Yet, some teachers require this type of coaching just to get through the day, week, or school year (Stansbury \& Zimmerman, 2000). Without this emotional support, there is uncertainty as to whether the beginning teacher would have made it through the year.

Beth relays the importance of her coach having her write down her feelings and emotions as a way to combat the stress of the first year. She also speaks of the support she felt just having someone to talk to about the struggles. 
Beth: $\quad$ I have to say at the beginning of the year she was kind of like just someone to talk to for me, I mean I was in tears basically my first year because of like the co-teaching situation that was going on. So, she was a huge support for that and I still think about some of the things she says about that and how not that I am in a co-teaching situation now, but it's just helpful things to know like in a working situation. So, she gave me a lot of feedback about how to approach it and, you know, how to write things down and it actually really helped when I was the lead last year and I had a fellow under me and getting her comfortable with, you know, how to sit down and talk about things that are happening that are issues in the classroom instead of letting it build up like a marriage. (167-176)

Shelly also speaks about the emotional stress of the first year and almost leaving the profession in October. It was her coach that told her to stay with it and that things would get better.

Shelly: $\quad$ And from the get go, she was the best thing that could have happened to me that year. Her support and just her knowledge was, it was a lifesaver. We met just...originally just kind of like talking, getting to know each other and then right away I was like I need help, I almost...I actually almost resigned in October in that year because I was just so overwhelmed and she was like no, no, no don't do it and she really helped me refocus and gave me that push...like you can do it, it's 
just...it's tough. So right out of the box, we had a really good, positive strong relationship which was huge. (106-113)

She really helped me to understand what a mistake it would be if I did that not just for that year but in the future if I went to get a job again in education and they sit sit down and say okay, in October you resigned or whatever... what happened? And just the implications that would have on me in the future and also just talking to my family that this is something I always wanted to do, I always wanted to be an educator and it's a rough start but it will get better. (laughter) (361-366)

Charlotte speaks about the importance of her coach pointing out the positives when things didn't go well. The coach was there to serve as a guide pointing out the beginning teacher's strengths.

Charlotte: So, once we started working together I think a lot of times at first it was really just me letting it go and her emotionally supporting me definitely. (152-153)

Let's see I mean certainly I definitely remember the first time I met her. She walked in and she was like yeah I'm like I'm going to be the induction coach for this person, this person and I'm really trying to strive to be yours and I was like oh thank god finally someone like... and like will personally help me right now. (22:10) And, yeah, I think and a lot of times in the second year, it stands out because I would always get so frustrated and she was always like immediately there and like, okay, but wait like these are all the things that you did 
well (22:28). These are all the things that worked. It was like, see and I can't see those things because I had been in the moment. I'm like devastated that like one kid didn't get it or didn't pass it in. So, yeah I think I can't really say there was a specific moment but it was every time. $(330-340)$

Mary appreciated that there was someone there to tell her that her feeling were normal and to pick her up when she was down.

Mary: $\quad$ As I said I think it made me a better teacher, made me a more confident teacher and it made me more interested in the art form of teaching because I had someone who said look this is normal. This is going to happen. And I'm very self critical and this was a buffer. (20:00) This eased the bruises. This was a salve and yet it was also informative and it was another kind of educational process for me as well which I do not feel the RIDE process is. (276-287)

Anne even goes so far as to say that her coach acted as a psychologist who helped her make it through the first year without burning out.

Anne So he was kind of like a combination of a coach and probably a psychologist on some level. (407-408)

But no, he was tantamount to the fact that I'm still a teacher. And wanting to be a teacher, making it through that first year and not just burning out. (608-609)

A second set of eyes. Like a football player on the field, with the coach watching from the sidelines calling out plays, beginning teachers appreciated a 
"second set of eyes" in the classroom to hone their craft. There is just too much going on in any given classroom to see everything that needs to be addressed. Ultimately, this "second set of eyes", as Shelly referred to it, is there to provide the springboard for reflection. Without this catalyst, most first year teachers let the year fly by without truly reflecting (Schön, 1977, 1983).

Shelly reflected on the importance of the coach providing another view of her students in the data she collected which helped her develop behavior plans.

Shelly: (07:53) There was one interaction that was just so helpful to me because my room was so behavioral. She came in one day and all she did was sit and take notes, those students that were my biggest behaviors and every few minutes she would check off what they were doing, who was on task and just collected data for a good hour and a half of their specific behaviors. And that was huge to me because I could really look at each student, see what she collected and just having a second set of eyes to take the time to do that for me so then I could say, "oh wow, I didn't realize the student was doing this or was doing that or who are they fooling with?" Just little things that I couldn't see on my own, that really helped me when she did that because then we could really develop behavior management specific to those students with that data that I would never have been able to collect by myself. So, that was probably one of the biggest. (147-158) (20:09) Just kind of she would observe how I interacted with the students and how I handled certain behaviors, even little things like 
when the student was having an issue that I would kneel down and get eye level with them rather than like bending over them, that kind of thing. So, having her there to pick up the little things that I did and tell me, oh, that was really great how you knelt down to their eye level but next time I would use this wording rather than that and so she helped me tweak how I interacted with the students as well and not just student behavior and that was helpful also. (348-355)

Paul also discussed the importance of the coach bringing to light the things that were going well and those areas that needed improvement. The issue of equity in the classroom is one that often goes unnoticed unless there is someone there to point out the injustice in a supported way. Beginning teachers in my study reported that seeing the value in tracking data for student learning objectives was critical for their sense of reflection and purposeful lesson planning.

Paul: It made me aware. I don't feel that I videotape myself enough in my student teaching and in my early teaching and she acted as a video camera really because she would tell me exactly what I was doing, that I was more aware of myself, aware of things that I was doing well, and aware of things that I wasn't doing as well. (0:15:06) It was really helpful. I made improvements through my first and second year of things that I originally I had no idea I was doing. I mean that one that really sticks out was when I was calling students and I wasn't being fair throughout, you know, that one person keeps calling his -- raising his hand or someone getting looked over so just as being more aware of my 
surroundings and also being more diligent with deadlines when it came to SLOs (Student Learning Objectives) and PGGs (Personal Growth Goals) and all of those things, making sure that I took the time to prepare it and where a lot of teachers in the school had the attitude that well it's not going to matter why are we doing anything with this. (0:16:02) She made me care about a little more and try and get to say, if we're going to do this, we might as well get something out of it, not just fluff it off. (198-212)

Charlotte found it helpful for the coach to scribe everything that happened in a class period and then reflect after, coming up with an action plan.

Charlotte: She would come and observe and she would take like extensive notes of everything that was happening and then we would immediately sit down and go over all of it and we figured out like okay what do we need to do for this kid? What were you doing at that moment that worked that got the classes attention? Worked in a way, which is like breaking it down step by step and then immediately coming up with an action plan I could set in place the next day. (155-160)

Confidential outsider. Many beginning teachers were concerned about an "outsider" coming into their building to coach. What would this person know about the climate of our school? Our policies? Our curriculum? What was discovered in these narratives is that being an outsider was actually an advantage and strength of the program. There was also a sense of relief by many beginning teachers that the meetings, topics, and work are confidential. Beginning teachers were allowed to vent 
and show weaknesses, which is part of growing in the profession, without any judgment or worries of gossip spreading. Many of the beginning teachers mentioned the bond with the coach and lasting friendship that was formed.

Beth mentions the benefit that her coach was someone on the outside that she could go to that understood what she was going through. Many of the beginning teachers mentioned that the bond was so strong with their coach that they still communicate several years later.

Beth: I feel like she was someone who was like on the outside who I could talk to about things that maybe I couldn't go to my principal about (0:10:34) and she was just incredibly helpful. (183-185)

I think it was mainly just, I remember for me like more towards the end of the year because we became like great friends (0:18:04) and I actually have her kids go to my school now and I still talk to hear all the time, but I think it was mainly just the end of the year realizing how much she helped me that year, get through the year and I can't remember anything like specific, but it's just talking to her, sitting in the lunchroom, talking to her and really I looked forward to meeting with her every single week whenever she came and scheduling those meetings with her because it was just a time for me to get out of like the Centerville world if you know what Centerville is like, it was just a really nice chance for me to talk to someone else and kind of step back and just she was, I mean she was like a real person who gets it, who's 
like, she's super funny and just laughing with her and talking about different things I guess. (288-299)

Shelly refers to the importance of the confidential conversations with her coach and being able to feel comfortable around her.

Shelly: (17:58) I think she just from the beginning made me feel comfortable and let me know that whatever I was feeling or whatever I needed help with there. I was okay to go to her for that and the confidentiality piece that she would only go to the principal if I was onboard with it that everything I said and everything I did stayed with us and I just felt really secure in talking to her and comfortable that I could express whatever I was going through, however I needed to do it. She did hear me swear quite a bit (laughter) but so that I think just that comfort was huge right out of the box. (317-324)

Sarah talks about the need to speak with someone confidentially about her students who personally knew her students and understood her concerns. Oftentimes teachers feel like they can't talk about their students because it might be seen as gossiping or sharing confidential information.

Sarah: $\quad$ And so, those were the conversations with her that I remember the most were the ones where I said, but they can't leave me, I have to know that they're going to be okay and I have to know that like I helped them somehow and she was really good, she was almost like just a therapist and I feel like that's what I used her for the most because there were some things that came up that year as with every year and I 
couldn't...(11:02) because of confidentiality, I couldn't always talk about it with coworkers because then it's kind of was a fine line between just gossiping about kids and being protective about our jobs and so I found that she was a very safe space to have those conversations with outside of the team but she still knew the kids because she was in the building all the time and she had a love for them too so she like kind of knew where I was coming from. (187-197) Mary also mentions how important confidentiality was when working with her coach.

Mary: $\quad$ Confidentiality meant everything to me. She got out of me a lot of what was frustrating me because I knew I can trust her. I knew it wasn't going to go anywhere else. You need that. (22:00) If you can't vent your first year it was the support that was just so appreciated and I feel because I had a better attitude about my experience with that that I learned more. I was open to learning. (306-310)

Anne talks about going to her coach with questions that may seem silly or things that she could not talk about with her teammates.

Anne: $\quad$ But then I had Steve and I loved him, he was kind of like, it was nice to have somebody to talk to who wasn't evaluating me at all. And who also wasn't, and as much as my team is awesome, you know your first year you're kind of scared to ask some questions like these are really dumb questions but, and then there's some things you want to say, but you don't want to say to your team lead or whatever. (401-406) 
Want back/regret. Another ongoing theme throughout the interviews is that the beginning teachers did not realize what they had until it was gone. Many teachers reported that they did not use the coach to her full capacity for a variety of reasons: part-time status, co-teaching situations, or simply the hectic pace of the school year. Most who taught outside of the urban core and only received one year of support wished that they had a second year to dig deeper with the coach. This supports what we know of teacher development and the need to continue to work with teachers as they progress on the novice to expert skill model (Shulman, 1986; Dreyfus \& Dreyfus, 1980).

Rachael was a part-time pre-school teacher who felt that she didn't use the coach as much as she could have. Now that she is working full-time, she wishes she had her coach back to support her.

Rachael: $\quad$ No, I mean she was always there for whatever I needed her for. I know I could always call or e-mail and she'd answer (0:11:21) right away. For being part-time I felt like I couldn't utilize her as much as, you know, somebody that was full-time. I only had so many kids in my class and I only had them four days a week and two and a half hours a day. Of course, there were problems and questions I had and she was able to help with, but being full-time I think I would have benefitted a lot more (0:11:49) Like last year I kept thinking oh I wish I had her back $(245-251)$. 
Beth was in a co-teaching situation her first year and felt it was a bit challenging to manage all the meetings she had. She relays that now that she is teaching alone, she would like to have her coach back.

Beth: I think it probably would have been like more beneficial for me if I wasn't co-teaching maybe. I thought it was a little bit challenging having like I think I -- I don't think I had too many supports, but I almost just wish I had the induction coach support because it was really helpful, but like I was so focused on other things and getting things done for the school and getting things done for, the things that I had to do for them and I like truly value Sarah's things, but I feel like I was, I couldn't -- like I was working on my teaching, which was good for my first year, but now I am thinking about I really wish I had her this year because this is my first year actually alone (0:20:02) and I feel like this is my true first year of teaching by myself with my own class and I'm just like going through things like, oh, I wish I had Sarah to come in like I ask her all the time, can you just come in to be my coach this year. (304-315)

Henry also echoes the sentiment of still wishing he had a coach to support him.

Henry: At the end of the year we had to fill out a form and she's like what do you want from me? And I said another year? Just a second year? If you'd ask me today I'd go okay, a fourth year? A fifth year? (645-648)

Sarah relays the feeling that the beginning of the year was so crazy that she didn't realize she was wasting time with the coach. 
Sarah: $\quad$ But then as the year went on, I kind of came up with very specific issues that I was having and I think I got better at learning how to use her to my advantage and what to ask her and what she could help with and by the end of the year, I was wishing I could start over because I do feel like I wasted a lot of time at the beginning just because I didn't know what to do with that support. (165-169)

Paul also mentions the craziness of the first year and perhaps if he had a free period to meet with the coach he could have used the time for effectively.

Paul: $\quad$ Pedagogy really, and I think more of it was probably me than her $(0: 17: 03)$ in the second year. I feel she was there for me and I didn't take advantage of it as much because I get overwhelmed at times with everything that was going on in the school, and when I have one prep period per day and I teach five different classes that are completely different where a math teacher might be teaching math all day, but it's related. I mean I'd be jumping between two classrooms and going from jazz band to guitar class to music history to music theory. Every single one is different materials and it's nonstop. So, I think I pushed away a little bit at this process because I was always thinking about what's coming next and maybe if I had one less class that I could spend more time reflecting, I think it would have been helpful. (0:17:59) She was definitely there for me and I guess that I was - I didn't take advantage of the opportunity at times. (233-244) 


\section{Summary}

When analyzing the data across cases, the findings fell into three thematic categories: self, context, and coach. The beginning teacher's identity of self, centered on the feelings of isolation and defeat; while the reported contextual descriptions focused on challenges and supports. The common themes uncovered when the beginning teachers spoke about their induction coach were identified as first impressions, change of heart, emotional support, second-set of eyes, confidentiality, and want back/regret.

\section{Types of Coaching Support Findings}

In analyzing the category of "coach," I came to realize that there were two subcategories of findings that provided interesting data. In the section above, I looked across cases to find the common themes that participants' highlighted about working with a coach. The participants also spoke a great deal about the types of support they received from the induction coaches. Figure 4.3 illustrates the branching of two different analyses under the heading of coach.

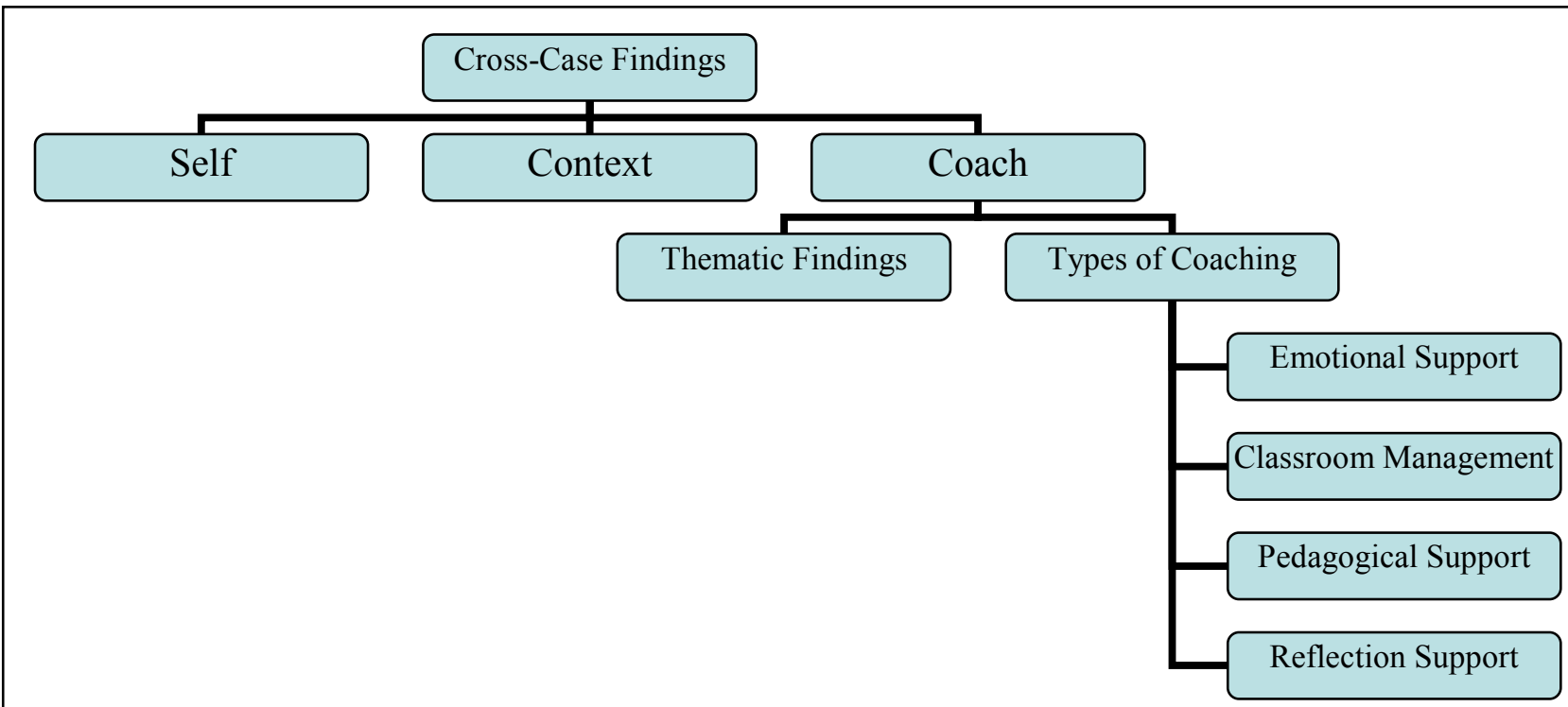

Figure 4.3. This figure represents the types of coaching support referenced by all nine beginning teachers. 
Looking at the specific types of support the beginning teachers received from his/her coach allowed me to see the bigger picture of induction. What did these new teachers need support with? What did the induction coach support them with? After coding each type of support using the participant's language and tracking the number of instances it was referenced within each transcript, I began to see larger categories of support emerge: emotional support, classroom management support, pedagogical support, and reflection support.

Emotional support was often mentioned early in the interview when the beginning teacher was explaining the start of the school year. Emotional support occurred in the form of the coach acting as a sounding board, providing a shoulder to lean on, or even giving advice. The following is an example of a section of the transcript that was coded for emotional support.

Anne: $\quad$ So we met about once a week during my unassigned. (19:59) Usually at, the way our school worked, we had blocks. So one block was like the longer unassigned, it was like the lunch block so we usually tried to do it on that day. So instead of having like 68 minutes, we'd have like 90 minutes and we kind of just go through stuff, sometimes we would actually work on unit plans, sometimes I said it was just me venting about me being frustrated or stressed or not knowing where to start or complaining about teaching fellows. (424-430)

Another area of support the beginning teachers mentioned fell into the larger category of classroom management. This category included support in terms of creating behavior systems, leveling libraries, arranging classrooms, as well as 
developing social stories. For many beginning teachers this is a critical area of need, for without classroom management in place, the work of learning cannot occur. Racheal: $\quad$ One of my kiddos had a lot of anxiety like whenever the bell would ding in the classroom and she didn't like one of the songs that we did in class Bear Hunt because she would get nervous that a real bear was coming in. (laughter) So, my coach helped me, you know, come up with different social stories for her and helped, you know, de-stress her anxiety. She also helped me come up with a reward chart from one of my kiddos that (0:06:42) had a lot of negative behaviors, came up with a motivator for him using the iPad so he earned a sticker for each part of the day and then we'd tally them up and that's how many minutes he got on the ipad(0:06:54)

The third category of support I titled pedagogical support. This category included lesson planning, rubric creation, unit development, analyzing student work, subject area research, as well as teaching strategies.

Charlotte: And often times we would...every time there is a big project or an essay, we would sit together and we would go through rubrics as well as...I can't remember what form she had. You basically, you figured out like As is Bs is Cs is Ds and then you like...

Interviewer: (12:02) Analyzing student work?

Charlotte: Yes. And then you would take it and go through and figure out what you would need for the next one. So, like okay this group needs sentence starters, the next time they do an essay. This group needs 
extension so maybe add extra analytical questions so that they can extend their knowledge. (170-180)

The following is an example of a section of transcript that was coded for reflection support, or providing the opportunity or prompts for the beginning teacher to reflect. Shelly mentions that her coach introduced her to the tool of journal writing as a means of reflection and that she still uses the tool at the time of the interview, three years later.

Shelly: $\quad$ And I used just a lot of the reflection pieces that we do with writing things down or even just stopping at some point of the day and thinking about - 'okay, how did my morning go? Which is something that you really don't find yourself doing as much as you should. So, there was a lot of emphasis on reflection and looking back and I definitely reflect a lot more now and I still have my journal from the first year that I use.

Interviewer: (15:00) You still use it?

Shelly: I do. Writing is such a huge outlet for me so that was a really great tool to use that even now I just sit there and just I'll just write out even if it's something completely ridiculous, I just feel like it's a release for me and I think that that was a really good tool to give. (272-284)

Once I indentified the four types of coaching support and the codes analyzed by each peer previewer, I tallied each category by the number of beginning teachers that referred to this type of support as well as the total number of instances it was mentioned (Table 4.2). I was looking to see what type of support was referred to the most by beginning teachers. 
Table 4.2

Types of Coaching Support

\begin{tabular}{lll}
\hline Broader Category & $\begin{array}{l}\text { Total \# of } \\
\text { teachers }\end{array}$ & $\begin{array}{l}\text { Total \# of } \\
\text { Instances }\end{array}$ \\
\hline Emotional Support & 7 teachers & 18 \\
Classroom & 7 teachers & 24 \\
Management & & \\
Pedagogy & 9 teachers & 48 \\
Reflection & 9 teaches & 58 \\
\hline
\end{tabular}

Table 4.2 shows that pedagogical support and reflection far exceeded that of emotional support. While many beginning teachers started their story talking about the emotional support they received, all nine participants mentioned many instances that fell in the pedagogical and reflection categories. Often, the year started rocky with a lot of support just dealing with day-to-day emotions and setting up the classroom or dealing with behaviors. This support was necessary and part of building the relationship between beginning teacher and coach. Once the teachers had these things under control, they were able to focus on teaching and learning. It would not have made sense for a coach to jump to reflecting on their practice, if they were barely making it through the day. It is up to the coach to make the determination of what area to coach around. Each teacher told a story about needing something different and traveling on the path at a different speed. It is also crucial to consider the other supports, outside of the coach, that they may be receiving; support from other colleagues, a principal, or school appointed mentor. Another factor in the coaching model to consider is the overall school climate that each teacher faces. Some schools are very supportive environments where new teachers can ask questions and teachers 
share ideas, other schools you will find closed doors where teaches are not comfortable working with others.

\section{Big Story, Structural Findings}

Looking at the big narratives across the transcripts allowed me another layer of findings. I have included three narratives that capture different experiences of first year teachers. Within each big story the themes of teacher identity (self), context, and coach emerge. I am using these big narratives to illustrate how connected these themes are in each of the stories and how the identities the beginning teacher assigns to self, context, and coach relate to each other. For each big narrative, a clear pattern to the story emerged including a beginning, middle, end, and coda (Reissman, 1993). I also coded for performative/identity codes when it was appropriate. Again, these codes fell into the three categories of: teacher self-identity, contextual identity, and coach identity.

\section{Big Narrative \#1: Henry's Story of Self-Identity}

The story of Henry meeting his induction coach, reminds me what it feels like to be the newcomer in any situation. He is excited and nervous at the same time. As an adult learner he brings many years of knowledge and expertise to the table (Knowles, 1980). His identity as a first-year teacher is situated in the context of the school environment as well as the perception in the education world of Career and Tech Ed teachers. I have chosen his big story to illustrate the nature of this interconnectedness, how an individual who is confident in his field can be placed in a new situation and feel entirely different. This is how Henry responded when I asked him to start at the beginning and tell me the story of working with his coach. 
Henry: $\quad$ So, this was my whole first, you know whole layout. And of course everybody in the building, they caught a little bit of a wind of it, they're like oh you're going to have somebody looking over your shoulder all day long. Great, you know so, you could see how this is a little played out.

Henry provides the background information to set the stage of his story. He is letting me know that even before he meets his coach, he is getting negative vibes from his colleagues about having someone looking over his shoulder.

Henry: $\quad$ So, I'm a little nervous, simply because, you know, Career and Tech Ed (9:42) our two buildings are separate we're always, and it's been like this for years. We kind of always thought of as the school over there and the school over there and this and this. So, I had a little bit of, you know, going in to this room with all of these new teachers who are just like me, and I was a little bit excited about that but I'd be the different kid. (10:04) I was always going to be, you know, I am always the different kid. So, I'm going to walk into this room and everybody's going to be English, science, history, art. "And CT is what?" "You're teaching what?" So I always prepare myself for that. So, I go in and I sit...I walk in and look for your name tag and then of course right off the bat. Henry doesn't have a name tag.

Henry wants me to know that Career and Technical Education Program do not really mix with the other schools historically. He is setting his self-identity as a new teacher as already being different and an outsider. In addition to all of this anxiety he 
is feeling, he is faced with the fact that he does not have a name tag and clearly doesn't belong at this state-wide orientation for new teachers.

Henry: So I'm like okay. So, I walk through the people at the front, scribble out a nametag, slap it on your chest, everybody has a nice typed one, of course the CTE guy has one of the marker ones. So, you see how this is going. So, we sit down and you know, Commissioner Gist was there, and all of these suits were there. You know kind of taken aback, so I'm watching this whole thing unfold. And then they have a point where all the induction coaches go around and they introduce themselves. (11:00) And I'm sitting there and it doesn't happen. And everybody is getting these padfolios out—Yes. So, I'm like oh okay, guess I'm not getting the support. That's okay, I'm thinking this is a complete waste of time. But I'm a little bit taken aback, so I'm standing at the table and Jill, obviously there were a lot of people who were, not in my district but you know...So yeah, they were checking, me and Jill and Emily who's, we went to high school, pretty close to each other, so I knew who she was. We, you know, we kind of grew up in the same neighborhood. So they're like, she knew, she goes, "hey", and I'm like, "hey, how's it going?" "It's going good, where's your induction coach?" So I said, you got me I don't even know where he was. 11:53 alright? So you know I was still taken a little a back, I was okay you know, probably forgotten, it's cool, it's great. (12:00) So, I said I'm not sure I'm going to get one. Okay? So I'm like cool, I might escape this whole 
thing right? And Jill is like, "Where are you teaching?" "You know, I teach at the CTC." She's like, "oh, next door." She goes, "alright," she goes, "No promises you might be mine but if my cases, if I've got enough, you know, you are probably going to be on your own." She goes, "Just keep in mind it might not happen."

Henry's feeling of being different is exacerbated by the fact that he is not assigned a coach at this meeting. To add to that, Jill states that she is coaching in his district, but he will only be picked up if she has room in her caseload, otherwise, he will be on his own. Here he is faced with the contextual identity that he is not valued as a teacher in this room of beginning teachers and important people, like the Commissioner.

Henry: All right. So, a couple of weeks go by and I hear nothing. Knock on my door (knocks on table), I look over and it's Jill and she goes, "well guess what? You're mine." Okay. So, that's kind of how that started, that's how the whole thing started. So, interesting paring. So, we sit down, we talk a little bit. She tells me her background, I tell her my background and she leaves. And you know what I'm thinking? I'm older then her, I've been working in the field for 25 years, okay? (13:00) I don't know anything about teaching. I'm not going to be the one that says I know now, I'm coming in here and I've got a half year under my belt and I know what I'm doing. No I don't. But there's some special ed 13:12 teacher? Okay. So, this is going to work out. So, I kind of roll my eyes and I said, you know what? It is what it is. So, my 
director, again being supportive, is like okay, what's going on, she was a little bit unfamiliar with the whole situation, so what's going on? And I'd tell her and she was like, okay. So, she was just keep me posted, just do what she asked you to do, she's here to support you, if it doesn't work out just take what you can from it, but you know, it's a program, that, you know it may work for you. Just give it a go, that's enough.

In the middle of his story, Henry is finally placed with an induction coach who happens to be a Special Education Teacher. His hesitation about this pairing is clearly apparent, and he wonders how she will be able to support him in an automotive class (Bianchini \& Benner, 2009).

Henry: Okay. So, Jill's a comic, comes in the second day and she's like, "okay so, let's not sugar coat this. You're an automotive guy, I'm a special ed guy. I don't know anything about you and you don't know anything about me, but you know what, we're going to make this work." (14:03) I'm like okay. She goes, “As long as you're flexible and we can work on some of, bounce some ideas off each other I think this would work." And that was it. From that day forward, it just, she would give me an idea and I'd sit there and look at it and I'd go, okay, I see what you mean. But can we do it this way? And she goes, yes, now I see what you're talking about. So, we were always, she goes, she put the idea in my head and she's looking, she goes now how can you use that? So she'd put strategies or, or, you know we did the graphic organizers and I went aw yeah, this is good but can I twist this like? And she said 
absolutely! And it worked. And so, you know, we would kid back and forth, I would drag her into the shop and she had to put the safety glasses on and walk around with the clipboard and you know, it stinks in here, but her dad was in the business, so she knew exactly what she was getting into. (15:00) She was extremely flexible, she was hard at times, but it was, it needed to be hard especially with like classroom management pieces. I mean I certainly don't have angels. But the classroom management pieces, she really drove a lot of them, you've got to try a little hard line, some of these kids, they're going to push you, just to see where you're at and stuff like that. So, we've got to try that line in the sand and make sure you stick with it. She was extremely fair, extremely fair which was really helpful. You know, classroom observations were a little bit frightening at first, especially when she would give me the script, of this is what you said and I was like, you wrote down everything, didn't you. So, it was a little bit frightening at first but by the time the evaluation process came around, it was very helpful. (16:00) Extremely helpful, because I didn't, having someone in my classroom didn't bother me so much anymore, especially being scripted, you know, I'd look at it and be, you know as usual. I know exactly what I was saying, and it was their own paper and so forth and so on and so on. It was extremely helpful, she was flexible, I was extremely flexible simply because once I saw her worth, it was, for me, it was just, I know it was going to help me in every way possible, even 
down to writing lessons plans and getting ready for the next class. Feeling like, I'm avoiding, just the little stuff, like going home or working till midnight sometimes and she likes no you stop at 9 o clock, stop at 9 o clock because you can only get so much done, you know what I mean? Just those little things that just help you out, that keep you from burning out and stuff. Yeah extremely helpful, I'll remember the first time she wrote down that, this is what you said, this is what they said. (17:07) She goes next time I want that over there and this over there. And I'm like how do I do that? So, you know, it's a great relationship, which we had, you know we're still great, great friends.

After identifying the coach as flexible, Henry finishes the story by sharing how helpful her support was to him. His coda to this story was learning to be flexible and open to the support, allowing him to benefit from the program and make a life-long friend.

\section{Big Narrative \#2: Charlotte's Story of Contextual Identity}

In this story, Charlotte tells the story of the context in her first year: the physical space, school culture, principal, and colleague support. I have chosen this story to highlight the conditions teachers are faced with. It is clear that Charlotte's teacher self-identity that I labeled, "stifled" is a direct reflection of her environment, which I labeled as "caged." When asked to tell about the setting of her first year, this is what she replied.

Charlotte: So, I started in this basement science lab (laughter) and I had all these tables that were ripped apart basically and there was what we called the 
cage. (01:50) It was basically a closet with like metal bars in the back and it was definitely not a good environment for an English classroom.

Charlotte begins her story with a physical description of the setting she was teaching in. I have called her contextual identity a "cage." I noted that she was laughing at the start of this story as she remembers her first classroom.

Charlotte: and so around November they told me I could switch to this classroom on the third floor and that's when it was almost like I started over like new rules, new start, this is how like maybe we did that before but I'm not tolerating that in this room now so it's sort of...[new school culture, okay. Well, it was interesting, so I was in the basement for that first half.] It was...I was also next to the BD room, the behavior disorder room. So, I often times (3:33) they would flee the room, they would run through my room, the locker rooms were across from me. So, there is a lot of hustle and bustle basically in the hallways and it constantly impacted my classroom because I still was trying to figure out how to contain my classroom really.

In the middle of her story, Charlotte describes her relief in starting over after she was moved upstairs and experiences a change in self-identity as she is empowered and positive, but then she immediately flashes back continuing to tell about her first classroom and how difficult a situation it was.

Charlotte: So, then moving upstairs to the eighth grade floor was a different sort of chaos. (laughter). A little bit more contained but still chaotic I think. In our school like the hallways are just always the troublesome place 
and I mean even four years now, it's still the hallways are just I don't know we don't have it figured out yet.

Here, Charlotte alludes to a school culture problem with chaos in the hallways, when she states "we" don't have it figured out yet. She is identifying as a member of the school culture when she uses the pronoun "we."

Charlotte: There was a huge turnover of teachers as well. So, there is probably like $50 \%$ of the faculty that year where new teachers mostly TFA with a few coming from other programs, I came from RITF which is basically similar, the same almost. So, you can imagine how that would change the school culture. So, there is definitely tension that was sort of built by the admin at the time to sort of have this combat between old versus new.

Charlotte continues to speak about the culture of the building and the tension between the new and old faculty. It is interesting that she starts talking about this right after mentioning that student behavior in the hallways is chaotic. Is she blaming the lack of discipline on the controversy between old and new staff?

Charlotte: Yeah, so...So the principal at the time was very much involved maybe to a point of too much sometimes. He was very demanding especially with new teachers, most likely because he knew we might have not known any better. So, I mean I remember him telling me that because I was new and I didn't have like a family or anything, you know, that he expected people like me to show up at 6 in the morning and he expected me to stay till 8 o'clock at night because that's what 
we should do. (06:00) He also hosted several weekend PDs that we were required to go to as new teachers even then we weren't paid and you were questioned if you didn't go to them. There was a very strange conduction of preparation.

Interviewer: Did you find those PDs useful?

Charlotte: Maybe an hour or two in all of them. A lot of but I think the problem there was like it was a meeting amongst a bunch of new teachers, so we were all asking the same questions and no one was really there to give us the information. I think it would have worked better if maybe we were set up with a mentor from the school.

Charlotte describes her principal as demanding of new teachers. She relays that she was expected to put in long hours and work on Saturdays because she was new and didn't have a family. The problem of bringing all new teachers together without any experienced staff to provide answers or reflect with is an interesting observation. Charlotte: and I luckily somewhat stumbled upon that because when I was moved to be a push in, the history teacher had been there for several years and for the most part he let me sort of just kind of watch him and he was my guide until like how the faculty maneuvered, how they got along, the school culture, expectations...

The science teacher who I also pushed into, she was the first year as well and we had...she had the same sixth graders and the same eighth graders. So, we shared a lot of kids and we could at least like we had the same free too. (08:00) So, I remember like every day on our 
unassigned (08:04) we would go for a walk and just like ran for the first 10 minutes, buy coffee and like walk back and talk about how everything was going to be better once we got back with coffee (laughter). But we needed like that moment to be outside just kind of let it go and we like talked out a lot of issues with kids together because we... shared the same students.

At the end of her story, Charlotte explains how she found comfort in her colleagues who were there to confide in and support her. Her coda seems to be that stepping outside of the school setting for her free period with another first-year teacher offered her the space she needed to face each day.

\section{Big Narrative \#3: Mary's Story of Coaching Identity}

In this narrative, when asked to tell the story of working with your coach, Mary tells about one occasion where she received immediate feedback from the coach who was working in the classroom. Validation is key to a novice becoming an expert in an area (Peno \& Silva Mangiante, 2012). New teachers need validation that they are handling situations in the proper way.

Mary: I remember one day a student decided to lay on the floor because she was having a bad day and I went to her and I knelt down next to her and I said is everything okay. And the kids in Springdale could have, blended doesn't begin to explain their family situations. So it could have been anything from they were losing their home to just a regular old fight with your mom. (25:03) I don't know and I'm not often told and I don't question. And so I handled it as best as I could and 
afterwards she said I handled it well and I didn't have a map to go on and it was nice to know I did the right thing. So I remember that.

Mary begins this story by setting the stage with the visual of a high school student laying on the floor. She then quickly jumps to her response of kneeling down next to the student to ask if she is okay. Mary then provides the background information that allows the listener to identify her contextual identity of an urban school with many negative influences that affect students in the school setting. She includes in her story that she is not privy to student information in her role as a teacher who needs to support these students in a classroom setting, and implies that this lack of knowledge makes it difficult to know how to handle a student and her identity of self is lost without a map. At the end of her story her coach validates her handling of the situation and she positions the coach as a guide. The coda to her story is that as a beginning teacher she was lost with how to handle student behaviors, but the coach in her room acted as a guide that validated her approach.

\section{Interactional Findings}

Researchers of culture and consciousness who use narrative are caught between the proverbial rock and a hard place. One the one hand, we strive to listen and represent those we study 'on and in their own terms.' On the other hand, we recognize that our role in shaping the ethnographic encounter is huge; that whether consciously or not, we listen and make sense of what we hear according to particular theoretical, ontological, personal, and cultural frameworks and in the context of unequal power relations (Luttrell, 2010, p. 258). 
Throughout the data gathering, analysis, and writing stages of my research, I spent a great deal of time reflecting on my role as the co-author of these narratives. Did the participants in my research tell me the version of the story that they believed I wanted to hear? From the first contact, each participant knew my role in the Induction Program. Would they have told a different story if I had been an outsider and not a former induction coach? There is no way to know the answer to this question and so I must take each story as the truth of the lived-experience of each participant with the understanding of my role as the co-author (Fraenkel, Wallen \& Hyun, 2012; Clandinin, 2013).

One finding that I discovered in the interactional analysis stage was that the three older participants (over the age of 30) spoke in longer narratives. Here, I must take ownership in my role, as it appears that I interrupted their stories less frequently than I did the younger participants (under 30). Did the younger participants view me as an authority figure and not feel as free to speak their minds, or was it that I positioned myself as the authority that needed to guide their stories with interjections and probing questions? Or, could it be that the older participants are more reflective and therefore have more of a story to tell? Two of the three older participants were second career teachers who had many other experiences in the work force to compare to their first teaching experience. For example, Mary drew on past experience to explain first year teaching:

Mary: $\quad$ One day. And I was in the heart of darkness. I was in the Democratic Republic of the Congo and it was when it was Zaire and I was really antsy and we rode a motorcycle and one day I decided to visit a town. I 
got on my motorcycle and I drove how many kilometers I don't know. And when I think back on it I went, I can't believe I did that. I mean 3000 miles away from my mother and I did that and this experience is very similar. And I told my boss that I said I haven't had anything as difficult or as thrilling since the Peace Corps. (laughter) (142-148)

Here, Mary is comparing her first year teaching to her time in the Peace Corps. Mary provided many analogies to describe her experiences. When speaking about the State Evaluation Model she draws on other comparisons:

Mary: $\quad$ Even athletes go through all kinds of meditative exercises, people massaging them, they have whole armies trying to take stress off of them because of what they have to do. No one tries to make them more stressed out. On a film set we tell them you can't yell at your actor. You will get the worst performance out of them. You must reduce stress not increase it. And even in business where this model of assessment came from you reward excellence and you don't have that with this thing that they have in place at RIDE. I can't tell you how I don't like it. Shall I say that one more time? I hate what they do at RIDE. It just doesn't work. If it worked I would do it. And induction came from RIDE.

The older participants in the research told big stories and often used metaphors to compare teaching to prior experiences. This is interesting to note looking through the lens of adult development in terms of reflection (Schön, 1987). I am left wondering if the younger teachers in my study had fully reflected on their first year 
and what they learned from the experience. This might explain why I had trouble coding for big stories and needed to go back to the research for an explanation of how to code the short stories that most of the younger teachers told. Linde (1993) believes that certain types of stories lend themselves to extended reporting. Perhaps for the older, career-changing participants the first year was more of a shock based on their previous employment experiences. I also think that the younger teachers cannot fully reflect on the experience because they are still living the narrative and have limited other work events to use as a comparison. Linde (1993) also suggests that, "The exchange of life stories is a social process, and there are social demands on the nature of a life story" (p. 7). Perhaps if I had spent more time with the participants, interviewing them over multiple sessions, they would have told me more detailed stories.

This brings me to my next finding in the interactional analysis stage. I have done extensive memo writing on this finding and have come to identity it as, "Researcher Paralysis," "Because fieldworkers know that their written productsthesis, dissertation, articles, and books — are the basis for their reputations, the fear of analysis may become paralyzing. Some field researchers get so anxious that they put aside their project for a long time or abandon it altogether"(Kleinmann \& Copp, 1993, p. 24).

After completing the interviews in April 2015 and receiving the rough transcripts back in May 2015, I sat on the data for six months, paralyzed with fear. Did I have the right data? Did I ask the right questions? What form of analysis should I use? What if I don't have enough data? What if I analyze it wrong? One interview 
only lasted 28 minutes! I was doomed! Looking back at this a year later, I am sure that this was "Researcher Paralysis." After reading the book "Emotions and Fieldwork" by Kleinmann and Copp (1993) I came to realize that my reaction to the research process was normal.

The pressure that I had put on myself had caused me to stop completely in my tracks. I could not continue for fear I would do it wrong. One of the greatest fears that I had to face was presenting data that would illuminate the Induction Program in a negative light. I was one of the founding members of this program in my State. I had spoken to school administrators, school committees, and anyone that would listen about the benefits of this program. What would happen if my data told the stories of beginning teachers that did not find value in the program? Kleinman \& Copp (1993) believe, "Our concerns for professional and emotional security influence our choices of what group or topic to study, where to study it, how long to study it, and how to tell others about it" (p. 6). I came to realize that this research was not about the Induction Program, but rather telling the stories of first-year teachers and what they face as they enter the profession. I had to put my reservations about negative feedback aside and seek the truth that came out in the stories I was told.

Is it possible to be a "good enough" researcher-that is a person who is aware that she/he has personal stakes and investments in research relationships; who does not shy away from frustrations, anxieties, and disappointments that are part of any relationship; and who seeks to understand (and is able to appreciate) the difference between one's self and another. (Luttrell, 2010, p. 273) 
Ultimately, this struggle, or "Researcher Paralysis" allowed me to find the space needed to tell these stories. While it is true that my story is embedded in the final analysis of this research, I needed to remove myself from the need to shape the findings in a certain way that would strengthen or deplete the need for induction coaching.

\section{Chapter Summary}

This chapter reviews my findings after analyzing the data. The findings are divided into four major sections: the individual, small story, thematic analysis of each participant; cross-case, small story thematic analysis; the big story structural analysis; and the interactional analysis. From these findings, I develop conclusions in Chapter 4 that will influence the field of teacher induction. 


\section{CHAPTER 5}

\section{CONCLUSION}

\section{Introduction}

Narrative research is a critical and social project, "emphasiz(ing) the inclusion of hidden and ignored perspectives — the previously silenced 'voices'—of teachers and students" (Barone, 2009, p. 595). It is in this vein that I decided to bring to light the stories of beginning teachers. I knew that by illuminating teachers' experiences, told in both big and short narratives, I could shed light on issues of beginning teachers, and use these stories to enlighten the field of education. The purpose of this study was to tell the stories of beginning teachers, specifically regarding their experiences working with induction coaches.

In this chapter, I will summarize the findings in the stories the beginning teachers told and relate them to theory and research. I will also discuss the limitations of my research, the implications these teachers' stories have for others in the field of education, and recommended directions for future research in the field of education.

\section{Summary of Findings}

The stories of these nine beginning teachers tell the tale of the peaks and valleys of the first year(s). It is clear in all of the stories that the context of their teaching placements had a profound impact on their first year(s) in the profession. 
Some teachers reported that they had support from administrators and colleagues in terms of resources, lesson planning, and overall guidance to help them navigate the start of their careers. Others felt isolated due to their physical placement in the building, the age difference between colleagues, or not having grade level partners to share ideas with. Several shared that they started the school year without a clear curriculum to teach, materials for students, or even classroom furniture. One district had a deep polarization between administration, veteran teachers, and new hires because all teachers were fired the year before. These contextual stressors had great influence on how the teachers in my study recalled their first year(s) of teaching.

Another concern that emerged during the interviews was the beginning teachers' lack of prior knowledge about the Induction Program. All of the teachers interviewed mentioned not having a clear understanding about the role of the induction coach and therefore a hesitation about inviting this person into their classrooms. Some were simply uninformed about the program and were uncertain about what to expect. Others were disappointed about working with mentors who did not have experience in their specialty. Mary discussed her initial disdain about the program and not wanting to work with a coach. She told the story of meeting her coach for the first time and feeling the dread of giving up her precious planning time. Yet despite this uncertainty, all of the teachers interviewed reconsidered their feelings about the induction coach early into the year. These teachers reported that they bonded with the induction coach and formed a lasting relationship, grateful for the coach's support throughout the first year(s). One teacher even reported that the induction 
coach must have been trained to handle her resistant attitude at the start because she immediately put the teacher at ease.

In addition to narratives of the emotional support they received from the induction coach, the nine teachers stressed the curriculum and classroom management support. For all of the beginning teachers, there seemed to be a pattern of emotional support followed by classroom management, which then allowed for the focus on pedagogical support. The beginning teachers also spoke about the importance of the induction coach providing the prompting for reflection, either through the weekly debrief sessions or through journal writing. Even two to three years after the experience, they all remembered clearly the types of specific support the induction coach provided that made them better practitioners.

All nine teachers reported that at the end of the year, they wished they had more time with the induction coach. Many regretted that they did not use the coach as much as they could have, and wanted a second year of this intense support. These teachers reported that they were so overwhelmed the first year that they did not appreciate and utilize the coach to his/her fullest. One of the teachers felt that this was due to her own part-time status and another felt it was because she was co-teaching. She wished the coach had been with her the year she had her "own" classroom.

Narrative research allows us to understand the teachers' culture as well as the identity teachers adopt in the environment. Teaching is a complex profession that often combines personal identity with professional identity. This identity is dependent on the sense of power and "agency" the teacher feels in the school setting. Bandura (1997) defines agency as the capacity to perform intentional acts or reflexive 
mediation. Often, novice teachers do not have the reflective ability to react in the moment and therefore their negative sense of agency influences their self-identities. All but one of the teachers in this study reported a negative self-identity, which directly correlated with the negative aspects of the context they were working in. For example, Charlotte's self-identity as a teacher was "stifled" appeared directly related to her context of starting the school year in the "dungeon" basement classroom and having to follow a strict, scripted curriculum. By contrast, Sarah, the one teacher with a positive self-identity, felt "connected" in a context that she described as the "perfect place" to teach. The identity the beginning teachers assumed in their first year(s) was clear in the way they told their stories.

\section{Limitations}

The nature of this qualitative study produced some limitations. In order to counteract those limitations I took many steps towards insuring Trustworthiness of the study.

\section{Generalizability}

As common with most qualitative studies, the sample size for this study was too small to allow for generalizability across a wider population. I did use purposeful sampling to select my participants, making sure they represented a variety of beginning teachers (gender, age, certification, and placement setting). I used thick description and purposeful sampling to allow for transferability of the findings. Lincoln and Guba (1985) describe thick description as a way of achieving a type of external validity. By describing a phenomenon in sufficient detail, one can begin to 
evaluate the extent to which the conclusions drawn are transferable to other times, settings, situations, and people.

Another limitation to this study is the selection of participants who all had positive or neutral experiences with the coaching. On the initial survey, I asked if the teacher was satisfied, neutral, or unsatisfied; however, only two of the nine final participants were neutral, and no one reported that they were unsatisfied. The survey went out to all participants of the program, but I did not get responses from those that might have been unsatisfied with the program. Clandinin and Connelly (2000) have coined the term "Hollywood Plot," which occurs when everything in the research turns out well in the end. I cannot assume that every beginning teacher in the Rhode Island Induction Program made a lasting bond with his/her induction coach or even had a positive experience. I can only report the findings of the nine participants that chose to tell their stories.

\section{Credibility}

In order to ensure credibility, I member-checked the original memos for correct overall interpretation of the stories by the participants.

\section{Dependability}

Two colleagues performed an inquiry audit to check for dependability of the process and product of the research (Lincoln \& Guba, 1985). The audit included checking the raw data and coding for confirmability. I kept a reflexive journal, reviewed by my colleagues, which included information such as the researcher's schedule, logistics, insights, and reasons for methodological decisions (Erlandson, Harris, Skipper, \& Allen, 1993). 


\section{Researcher Bias}

To mitigate bias, I was very careful in choosing the methodology of the study: "Narrative inquiries are always strongly autobiographical. Our research interests come out of our own narratives of experience and shape our narrative inquiry plotlines" (Clandinin \& Connelly, 2000, p. 121). This methodology allows the researcher to acknowledge how he or she interacted with the data and includes the researcher's perspective in the findings.

\section{Implications}

After analyzing the stories of the nine participants, four main implications emerged in my findings: (a) the needs of beginning teachers in the field, (b) phases of coaching in reaction to the needs of beginning teachers, (c) qualities of an induction coach valued by a beginning teacher, and (d) the need for coaches to mediate the identities of the beginning teacher.

\section{Needs of Beginning Teachers}

The needs of beginning teachers emerged clearly from these stories. If we want new teachers to be successful and stay in the profession, we must meet their needs along the way. It is critical that beginning teachers work alongside a More Knowledgeable Other (Vygotsky, 1978), or coach, who provides the beginning teacher with reflection, emotional support, pedagogical support, and classroom management guidance across multiple years as the teacher progresses along the skill model from novice to expert (Dreyfus \& Dreyfus, 1980).

More knowledgeable other. Vygotsky (1978) asserts the need for a More Knowledgeable Other (MKO) to support a novice in the field. It is clear from my 
research that learning does not stop once individuals are handed a teaching certification. Indeed, a new and more urgent phase of learning begins after certification. All of the participants reported needing the support of the coach as they honed the art of teaching in their first year(s). Learning alongside an MKO bridges the gap from "student of teaching" to "teacher of students" (Ingersoll \& Smith, 2004) by providing continuous on-site professional development. One participant, Sarah reported having this guidance of a coach allowed her to work through the struggles. It was particularly reassuring for her to know her coach had succeeded in overcoming similar challenges on the path to becoming a veteran teacher.

Reflection. Working with an induction coach allows beginning teachers to reflect on their practice amidst the chaos of the first year(s). Schön's $(1983,1987)$ work supports the idea that teachers need to learn to reflect on their practice with an MKO. In order for teachers to learn to reflect-in-action, they need the scaffolding to make this a natural, innate occurrence (Peno \& Silva Mangiante, 2012). Many beginning teachers in the study, like Shelly, reported reflection was a key part of working with a coach. Shelly still uses writing in a journal as a way of reflecting on her teaching practice.

Emotional support. At times, beginning teachers just need a shoulder to lean on and a friendly face to share their stories of woe with. This emotional support is critical at the start of the school year as well as throughout the year as new issues arise. Shelly tells the story of how she almost resigned in October, but her coach helped her to refocus and gave her the support she needed to carry on. All nine 
beginning teachers mentioned that the emotional support from the coach was essential in the first year(s).

Pedagogical support. Learning to think on your toes and adjust to the students in front of you does not always come naturally for beginning teachers. When looking at the novice to expert skill model (Dreyfus \& Dreyfus, 1980), the novice relies on rules and set plans. Kegan (1982) suggests that there is a reliance on others for theoretical understanding until novices move along the skill model to be able to reflect and develop their own theories. At the end of the year Sarah reflected on her feelings of frustration during the year for not being able to react effectively in the moment.

Based on Shulman's (1986) work, pedagogical-content knowledge (PCK) is one of the four types of knowledge that teachers need in order to be successful in the field. It is clear that teachers develop subject-matter content knowledge in teacher preparation programs, but the PCK develops only while in the field during the early years of teaching. While behavior issues often took the forefront in the beginning of the year, all beginning teachers, including Charlotte, reported that pedagogical support helped them to be successful in the classroom. Charlotte reported that in the first few months of the school year, her work with her coach focused on behavior management and then she moved onto lesson planning, grading, and assessment work.

Classroom management. Several teachers spoke about the benefit of having another set of eyes when it came to classroom behavior and room layout. When you are engrossed in the actual teaching and break down of the lesson, you often do not tune into details such as who is engaged, and who is not. This second set of eyes, or observer, can give you a snapshot of what is occurring in the classroom. The coach 
can make suggestions or simply point out those areas that need to be addressed.

Schulman (1986) refers to this as learner-knowledge or understanding the diverse needs of students. Shelly spoke of how the coach was able to collect data needed to address behavior concerns. The coach charted specific times of the day where students were struggling and the behaviors they exhibited. Shelly was then able to develop behavior plans with her coach to target the behaviors and tricky times of the day.

Multiple years of support. A study conducted by Fletcher, Strong \& Villar (2008), showed that mentoring can have the greatest impact on student learning if mentors have concentrated contact time over a period of two years rather than just one year. All of the coaches who did not receive two years of support mentioned that they would have liked another year. Beginning teachers need time to develop along the novice to expert skill model (Dreyfus \& Dreyfus, 1980) Those in urban core districts who did receive a second year of support, like Charlotte, spoke about the difference between the types of support in the second year. She reported that in the second year of induction support she was able to focus on curriculum and standards with her coach. Anne also spoke about the shift in focus to fine-tuning her skills in the classroom during the second year of support.

\section{Phases of Induction Coach Support}

Ellen Moir's (1990) research indicates phases of a first year teacher's attitudes toward teaching. Moir suggests that teachers go through several phases throughout the first year of teaching including: anticipation, survival, disillusionment, rejuvenation, reflection, and anticipation. My research supports Moir's findings in that all of the teachers interviewed appeared to go through these phases in some way. Due to the 
retrospective nature of my study, I did not track beginning teachers' feelings at specific points in the year. However all nine of the teachers' stories followed the general arc that Moir suggests in Figure 5.1. Specifically, all of the beginning teachers mentioned the phase of disillusionment that occurred in the fall, followed by a sense of rejuvenation after the winter break.

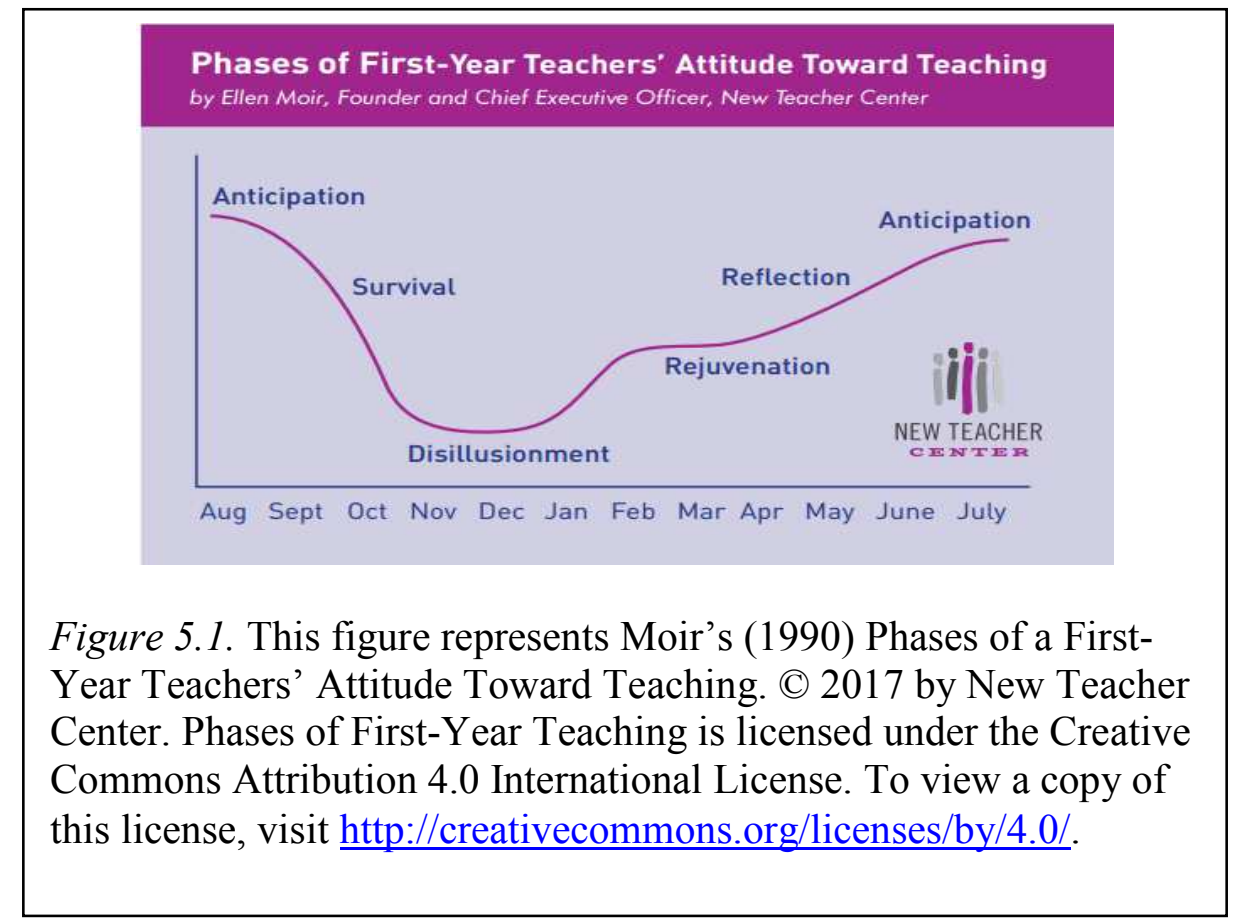

In analyzing the beginning teachers' stories, I found teachers discussed how the coaches' support tied to where they were in their own thinking about teaching. Therefore, much like Moir's phases of teaching, the beginning teachers' stories suggest how a coach responds within the first year. Figure 5.2 illustrates the phases of coaching that I observed in the situations that I studied. The beginning teachers all mentioned that the coaches were receptive to their needs as they navigated the roller coaster of their first year(s). 


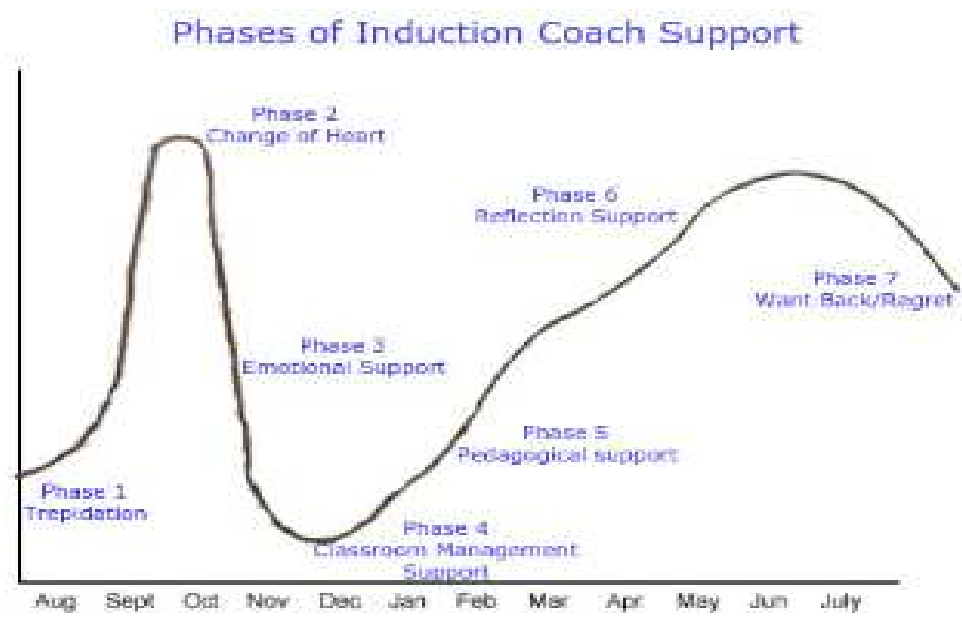

Figure 5.2. This figure shows the phases of induction coaching support that occurs during a beginning teacher's first year(s) of teaching.

Phase one: Trepidation. All nine beginning teachers talked about their initial reluctance to meet with the coach. Many had no idea what the program was all about, including the type of support they would receive. These beginning teachers felt at first that they did not have time to meet with a coach once a week and they were concerned that this person might be evaluating them in some way. Coaches reacted to the initial negative response to coaching through friendly emails and meetings to explain the program. Part of the coaches' role was to put beginning teachers at ease with this feeling of trepidation as they were anticipating their first year of teaching.

Phase two: Change of heart. The second phase of coaching I noted is the "change of heart." In most cases, the beginning teachers changed their minds about induction within the first meeting as evidenced by the continuation of Mary's story where her opinion of her coach was changed at their first meeting. The coach put her 
immediately at ease and Mary saw the worth in the program, grateful for the support. Many of the beginning teachers spoke about the coach settling their feelings of resignation about the coaching process in the very first meeting. They spoke about how the coach explained the program as non-evaluative, with no set weekly agenda. The teachers reflected that they were relieved knowing that the coach was there to provide any support that they needed facing the ill-structured problems in their classrooms. The role of the coach was to react to the feelings of trepidation and offer a space for the beginning teacher to have a change of heart about the coaching model by explaining the process and validating their feelings.

Phase three: Emotional support. The third phase of coaching coincides with the survival stage that Moir (1990) suggests. In this phase, the coach supports the emotional concerns of the beginning teacher. Emotional support at this time in the school year allows the beginning teacher to simply face each day without defeat. Teaching is not just a technical enterprise, but a highly personal and emotional profession (Nias, 1996). A teacher's personal and professional identity becomes intertwined and emotions must be acknowledged: "Teachers have to take profound personal and professional risks in their everyday teaching practices, and they need to construct defense and support mechanisms to continuously re-construct and re-affirm their identities" (Zembylas, 2003, p. 228). The feelings of inadequacy that a novice may feel can take a toll on a beginning teacher's emotional stability. Sarah relayed that the coach was almost like a therapist at the start of the year when she needed to talk about students in a confidential way with someone that knew and cared for the 
students as much as she did. Shelly spoke of how she would have resigned in October if her coach had not been there to provide emotional support.

Phase four: Classroom management support. The fourth phase, classroom management support, aligns with Moir's (1990) disillusionment phase of a first year teacher. In this stage, the beginning teacher faces managing classroom behaviors that impede teaching and learning. If the behavior management concerns continue, this can often lead to disillusionment. Charlotte's story illustrates how phase 3, "emotional support", leads into phase 4, "classroom management support" and eventually phase 5, "pedagogical support." First, the coach must support the emotional needs of the beginning teacher. Then the coach and beginning teacher address classroom management needs, followed closely by pedagogical concerns. In looking at the novice to expert skill model (Dreyfus \& Dreyfus, 1980), the novice is not able to multi-task, and needs explicit guidance for each component of the complexities of teaching. If the coach attempts to support all areas of need at once, the novice cannot handle the amount of feedback required to address every issue simultaneously.

Phase five: Pedagogical support. Phase five of coaching includes pedagogical support, which often occurs in conjunction with the rejuvenation phase of the first year (Moir, 1990). In this phase, the coach works with the beginning teacher to develop pedagogy. While this learning occurred in pre-service courses, a renewed focus is critical to address the needs of the students in the classroom (Shulman, 1986). Novice teachers can follow a lesson plan and deliver content, but have difficulty reflecting on students' needs and reacting in the moment. Working alongside a MKO helps the novice to be reflective in the moment and teach in a way that is responsive to 
the students in the classroom. Beth's story relates to this lack of confidence and the need to work with the coach to make a scripted lesson her own and to more effectively engage the students. The role of the coach is to observe the lesson and then provide feedback and data directed at the effectiveness of the lesson in terms of student learning and engagement.

Phase six: Reflection support. In order to develop on the novice to expert, skill model (Dreyfus \& Dreyfus, 1980) one must be reflective (Peno \& Silva Mangiante, 2012). Schön (1983) posits the idea that a practitioner first learns to reflect-on-action. This includes taking the time to think about the lesson or day and reflect on what went wrong and what can be done differently to produce a more positive result. Novice teachers do not inherently take the time to reflect-on-action. Working alongside a $\mathrm{MKO}$, the novice can gain the skills needed to become a reflective practitioner. Ultimately, the goal is for the teacher to be able to reflect-inaction, or think and react in the moment rather than at the end of the lesson or day (Peno \& Silva Mangiante, 2012). Beth discusses how her coach, Sarah, was able to teach her the importance of reflection-on-action and how the practice of reflection has remained with her in the form of journaling on a daily basis. The coach provides the opportunity for the beginning teacher to reflect by asking open-ended questions at each meeting, including "what's working" and "what are your challenges or concerns." Many teachers mentioned this weekly ritual in their stories, and they cited the importance of the time with the coach to reflect on their practice.

Phase seven: Want back/regret. The last phase of the coaching cycle is handling the beginning teacher's regret and feelings that they are not ready to end 
working with the coach. Many of the beginning teachers spoke of how they regretted by the end of the year not using the coach to the fullest potential. They spoke about feeling so overwhelmed in the first few months that they did not even know how to take advantage of the support. Paul tells about the struggle of having five different preps and feeling distracted by what he had to do next when he was meeting with his coach during his preparatory period. He suggests that if he, as a beginning teacher, had one less prep it would free up his schedule to be able to do the needed reflection work with the coach without the time crunch. The coach met his concern throughout the first year by meeting with him after school and observing during evening rehearsals.

Others wished they had another year of support to continue the unfinished work. In admitting that the work with the coach is unfinished after one year, the beginning teacher is acknowledging that he or she is not finished developing on the novice to expert skill model (Dreyfus \& Dreyfus, 1980). Henry related that he would have appreciated a second year of coaching support. He needed the safety of having someone to help answer questions, and he fully acknowledged that you have not mastered the craft of teaching after the first year. His coach continued to check in with him in the following years, providing ongoing support through emails and occasional visits to chat about school as he worked on her car.

Two teachers reported that they were unable to use the coach to full capacity because of their teaching assignments. One teacher was in a co-taught situation and the other, Rachael, was working part-time. Both of these teachers stated that once they had a full-time classroom on their own they wished they could have the coach back in the new setting. Again, the coach assigned to the teachers has continued to check-in 
informally to provide support in their new roles.

Anne worked with her coach for two years as part of an urban core district. When asked if the second year was necessary she replied that it was an opportunity to move beyond getting through each day to focus on the craft of teaching. The coach reacted to Anne's growth along the novice to expert skill model (Dreyfus \& Dreyfus, 1980), supporting her as she faced new ill-structured problems in the second year and improving the skills she learned in her first year.

It is clear to see in Figure 5.3 how the phases of coaching that I observed overlap with the phases that Moir (1990) presents. These phases are not linear in nature, but rather there is a general corresponding trend to how an induction coach must respond to the needs of a beginning teacher. Indeed, the induction coach could still support a behavior issue in June, and not only emotional support was given at the start of the school year, but instead there is an ebb and flow to induction coaching.

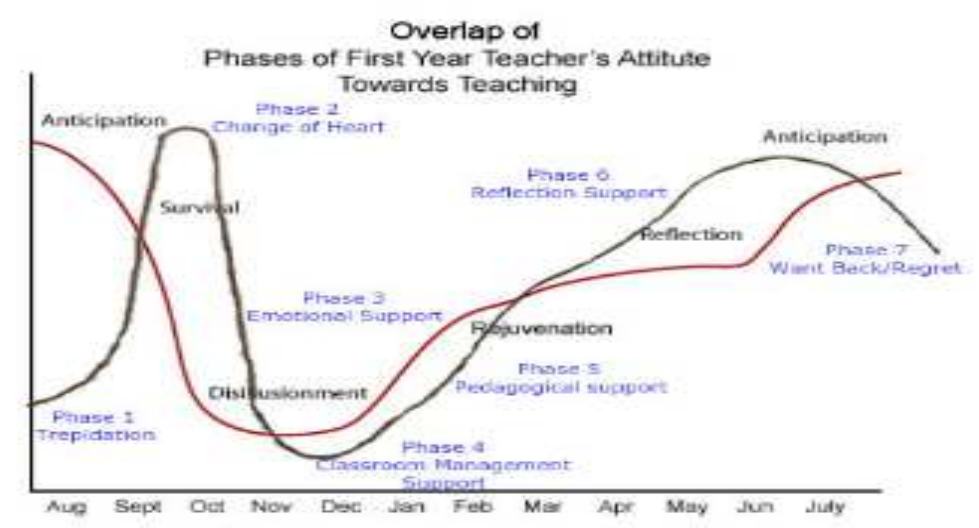

Figure 5.3. This figure represents the overlap of Moir's (1990) phases and the phases I am suggesting of how the coach reacts to the beginning teachers' needs. (C) 2017 by New Teacher Center. Phases of First-Year Teaching is licensed under the Creative Commons Attribution 4.0 International License. To view a copy of this license, visit http://creativecommons.org/licenses/by/4.0/. 


\section{Qualities of Induction Coaches}

Based on the stories told by the nine participants in this study, four key characteristics are valued in a quality induction coach: they must be flexible, keep confidentiality, be knowledgeable, and be resourceful. These traits indicate the need for a rigorous application and screening process to select coaches, as well as in-depth, on-going support during the coaching process. Just because teachers are experts in their classrooms, "[They] may not know how to make their thinking visible, explain the principles behind their practice, or break down complex teaching moves into components understandable for a beginner" (Feiman-Nemser, 2003, p. 29).

Flexible. Feiman-Nemser \& Parker (1992) compared two different models: fully-released mentors, referred to as "educational companions" and on-site mentors not released from their classrooms, called "local guides". The study concluded that the fully-released mentor approach was the most effective in improving teaching practice. The flexibility that many beginning teachers need is achievable when a coach is fullyreleased from his or her classroom teaching duties and is able to adjust his/her schedule based on the needs of beginning teachers. A fully-released coach is also able to spend time weekly in the beginning teacher's classroom getting to know the students and the teacher's methods. Dedication to the position is also required, as many beginning teachers spoke about meeting with their coaches after school hours, on weekends, or even during evening rehearsals. Another component of flexibility has to do with the coaches' ability to react to the needs of beginning teachers. Induction coaches need regular support and training to maintain the reflective nature of the program. Careful selection of induction coaches who have a reflective nature, as well 
as initial and on-going training plays a pivotal role in the success of the program. Fletcher and Strong (2009) state that the amount of training the mentors receive has a direct impact on their ability to change instructional practices of the mentee. Most research postulates the theory that the quality of mentor training has a more direct impact on the success of the program than the amount of time spent with the beginning teacher. Part of this training includes the theory of adult learning. Coaches cannot expect to work with beginning teachers in the same way as they work with students. Understanding the needs of adult learners is important to being an effective coach. In Anne's story, she told about how the coach worked around her ADD and met with her on the weekends when she could focus rather than during the school day.

Confidential. In order to build a trusting relationship between the beginning teacher and induction coach, confidentiality must be maintained. Many beginning teachers spoke about the need to vent issues with someone that was outside of the building or district. One strength of this Rhode Island program was that it was statewide, and induction coaches often worked outside of their home district. Long (2010) suggests that external mentors have an advantage of establishing mutual trust quickly because the mentor does not have direct influence on the beginning teacher's daily work practice (p. 271). Mary spoke about the importance of confidentiality in the coaching relationship, which allowed her to be open to learn from her coach.

Knowledgeable. Based on the stories of these beginning teachers, it did not seem necessary that an induction coach possess the same certification as the beginning teacher. The research of Bianchini and Benner (2009) indicates that in order to be most effective, coaches should be paired with teachers with like certifications. I did 
not find this to be true in my research. While I did not directly ask if the certification area of the coach was a concern for the beginning teachers, I did ask what the certification of their coach was and many did not exactly know. Others clearly stated that while the certification was different and posed a concern at first, they came to realize that good teaching is good teaching and a certification match was not essential.

What did make a difference was the coach's ability to enable reflection of the lesson by the beginning teacher, and to support with implementing best practices in the classroom. Several beginning teachers commented that a different perspective was often helpful when they were planning lessons or working on classroom management. The research on the novice to expert skill model (Dreyfus \& Dreyfus, 1980) clearly states that coaches must be experts in the field of education, not necessarily in the subject matter. Henry, who taught an automotive course, was hesitant at first about how a special education teacher could support him, but learned that her expertise in teaching could be applied to his subject area.

Resourceful. These beginning teachers reported that their induction coaches were like "genies," providing research and curriculum resources, or connecting the beginning teacher to other expert colleagues. Having a statewide network of induction coaches allowed the coaches to tap into the expertise of colleagues across the state. Charlotte spoke about her coach reaching out to others in the state to provide support in a specific area. Several beginning teachers mentioned the network of coaches and expertise, specifically related to the statewide seminars that coaches provided as additional professional development. 


\section{Role of the Coach in Mediating Identities}

Another finding of my research was the role of the coach in mediating the beginning teacher's self-identity as well as context identity. According to Mishler (1999), "We express, display, make claims for who we are - and who we would like to be-in the stories we tell and how we tell them" (p. 19). The identities that are performed in the telling of narratives are socially situated in a context. Zembylas (2003) discusses how teacher identity is formed through talk, social interactions, and self-presentation. In order to support the beginning teacher, the coach acknowledges and works within the confines of the context of the teacher. It is critical to remember that, "whether the early years of teaching are a time of constructive learning or a period of coping, adjustment, and survival depends largely on the working condition and culture of teaching that the new teachers encounter" (Feiman-Nemser, 2003, p. 26). The context the teachers face include administrators, colleagues, school culture, students, parents, physical working conditions, as well as access to materials and curriculum. In order to address the teaching and learning that occurs in the classroom, the coach supports the teacher as he or she navigates the context of the school setting as well as other outside influences of the beginning teacher such as past experiences, family issues, learning styles, and other life stressors as depicted in Figure 5.4. 


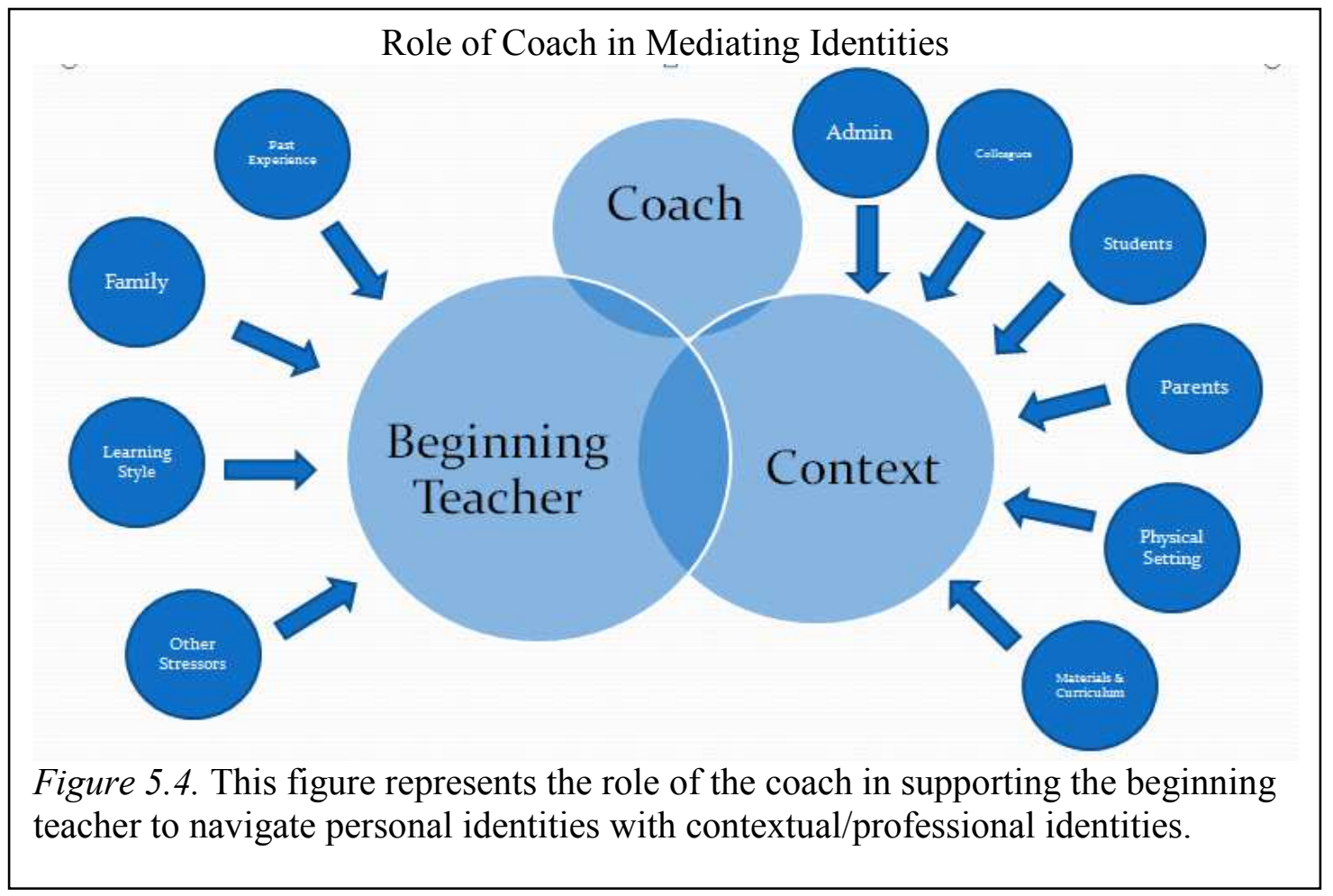

If a beginning teacher was struggling with a co-teacher or principal, the coach worked with the teacher to heal the relationship in order to move forward with the coaching work. Beth tells the story of how her coach supported her complex relationship with her co-teacher and how she was able to use those skills later in her career when she was the lead teacher in the classroom working with a novice. At first, Beth felt like a student teacher, powerless to have a voice as a co-teacher in the classroom. Her coach helped her to work with her co-teacher to find a balance of leadership and therefore empower her identity as a certified teacher in the classroom.

Another teacher, Rachael, spoke to me after the tape recorder was turned off about how her coach helped her to navigate a relationship with the teacher assistant in her room. Rachael was a young teacher right out of college working with an older, 
experienced teacher assistant who, at times, questioned her leadership in the classroom. Rachael was very intimated by the teacher assistant and sought support from the induction coach. The coach helped her to navigate her identity by role playing the situation and having Rachael talk to the teacher assistant about overstepping her boundaries. Rachael was then able to confront the assistant and change her self- identity to a leader in the classroom environment.

Induction coaches navigate the many self-identities that beginning teachers bring. This is necessary in order to meet all the needs of the beginning teacher. If these dynamics are not addressed, the coaching relationship is not fully effective. Anne spoke about how her coach worked with her learning style and ADD by meeting her on weekends at a Starbucks where she could focus on the work at hand and not the other pressures of the school day and the divorce that she was going through.

\section{Future Research}

Sarah told an interesting story of what is going on in her district now with coaching. After the statewide program ended, it was up to district to provide induction support. Many districts hired teachers from within to do this work. Sarah reported that she is unsure of the quality of the program in her school due to lack of qualifications and training of those hired. Sarah also points out the benefit in having someone outside the district do this work so that it remains confidential and allows for networking across the state.

As a follow-up to Rhode Island's Induction Program which ended in 2014, I think it would be beneficial to conduct research now in the state to see what supports are available for teachers, and if the supports are indeed moving the beginning 
teachers along the novice to expert skill model (Dreyfus \& Dreyfus, 1980). A study comparing in-district mentors like those Jane describes would provide a comparison with my current findings of out-of-district mentors.

To further investigate the needs of beginning teachers and to confirm my findings, it would be beneficial to interview induction coaches to hear their stories of working with beginning teachers. Do they mention the same needs as the beginning teachers themselves? Or do the coaches identify a different set of needs for beginning teachers? These insights from the coaches' perspective could triangulate data along with beginning teacher evaluations.

It is also critical to continue to research the impact of multiple years of induction support. While I included teachers with one and two years of support, additional research is needed to determine the appropriate number of years needed. Perhaps looking at beginning teachers' evaluations after one, two and even three years of induction support would provide insight into this question. After three years of support, is it possible to determine where a teacher is on the novice to expert skill model (Dreyfus \& Dreyfus, 1980)? Would it be possible to connect induction support with receiving tenure and showing competency through the teacher evaluation system?

\section{Chapter Summary}

In 2003 the National Commission on Teaching and America's Future stated beginning teachers need a strong residency and induction support in order to be successful in any school setting, yet three years later research shows lack of support is often cited as the main reason why teachers leave the profession too early (Andrews et al., 2006). The stories of the beginning teachers in the RI program demonstrate that 
coaching was an important part of their development and retention. The teachers clearly discussed needing support in order to grow into experts, working alongside an MKO who provided differentiated support within the context of their teaching was valuable to their learning. As the National Commission on Teaching and America's Future suggests, induction support needs to become part of our culture, something that is expected, accepted, and appreciated when you enter the field of education. As a profession we must also acknowledge that, "Keeping new teachers in teaching is not the same as helping them become good teachers...We must treat the first years of teaching as a phase in learning to teach and surround new teachers with a professional culture that supports teacher learning" (Feiman-Nemser, 2003, p. 25)

I offer the words of Charlotte to sum up my research.

Charlotte: I don't think I would have... yeah I don't know how I would have done first without her seriously. I think aside from just getting me through, she made me understand how to look into the profession but like not be defeated by the profession does that makes sense. So, I think especially just like going through the forms doing the analytic the analyzing student work, that would have taken me years to figure out how to do, but she got me there in six months. (17:09) So, she just brought like such an amazing set of skills from like 20 years of teaching that basically like she just give me like the little tidbit every week and then definitely made me the for sure a better teacher a better staff member. It was cool too because she service so many of us. It like brought part of our faculty together too because we would go on dinners and like she 
would always do some special things for her birthday so it was going to...yeah, so there was a lot of, a lot more than just inside the classroom. It was sort of a culture in itself. (253-265)

I hope this study informs the field of education of the needs of the beginning teachers and the qualities needed in an induction coach, as well as the need to change the culture of induction in the field of education. Beginning teachers need to be supported in the field as they grow along the novice to expert skill model (Dreyfus \& Dreyfus). 


\section{APPENDIX A}

\section{Approval from Internal Review Board}

\section{THE \\ UNIVERSITY \\ OF RHODE ISLAND \\ DIVISION OE RESEARCH \\ AND ECONOMIC \\ DEVELOPMENT}

OFFICE OF RESEARCH INTEGRITY

70 Lower College Rosd, sulte 2, KIngston, RI 02881 USA

p: 401.874 .4328

t: $\mathbf{4 0 1 . 8 7 4 . 4 8 1 4}$

un.eduiresearchitroilemcesiresearchintegrily

FWA: $\quad 00003132$

IRB: $\quad 00000599$

DATE: $\quad$ December 16, 2014

TO: Jodi Clark

FROM: $\quad$ University of Rhode Island IRB

STUDY TITLE: $\quad$ Teachers' Experiences of Induction Coaching: A Retrospective Narrative Inquiry

IRB REFERENCE \#: $\quad 661185-2$

LOCAL REFERENCE \#: HU1415-070

SUBMISSION TYPE: Revision

ACTION: $\quad$ APPROVED

EFFECTIVE DATE: $\quad$ December 16, 2014

EXPIRATION DATE: $\quad$ December 15, 2015

REVIEW TYPE: $\quad$ Expedited Review

REVIEW CATEGORY: Expedited review category \# 6
THINKBIG WE WE

Thank you for your submission of Revision materials for this research study. The University of Rhode Island IRB has APPROVED your submission. This approval is based on an appropriate risk/benefit ratio and a study design wherein the risks have been minimized. All research must be conducted in accordance with this approved submission.

This submission has received Expedited Review based on the applicable federal regulation 45 CFR 46 and 21 CFR $50 \& 56$.

Please note that any revision to previously approved materials must be approved by this office prior to initiation. Please use the appropriate revision forms for this procedure.

All SERIOUS and UNEXPECTED adverse events must be reported to this office. Please use the appropriate Appendix S - Event Reporting for this procedure. All FDA and sponsor reporting requirements must be followed.

Please report all NON-COMPLIANCE issues or COMPLAINTS regarding this study to this office. Please note that all research records must be retained for a minimum of five years after the project ends. 
Based on the risks, this project requires Continuing Review by this office by December 15, 2015. Please use the CONTINUING REVIEW FORM for this procedure.

If you have any general questions, please contact us by email at researchintegrity@ds.uri.edu. For study related questions, please contact us via project mail through IRBNet. Please include your study title and reference number in all correspondence with this office.

Please remember that informed consent is a process beginning with a description of the study and insurance of participant understanding followed by a signed consent form. Informed consent must continue throughout the study via a dialogue between the researcher and research participant. Federal regulations require each participant receive a copy of the signed consent document unless the signature requirement has been waived by the IRB.

Andre- A Rumak

Andrea Rusnock, Ph.D

IRB Chair 
APPENDIX B

\section{Approval from Rhode Island Department of Education}

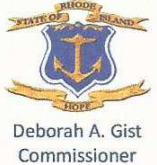

Dtate of Rhode Island and Providence Plantations DEPARTMENT OF EDUCATION

Shepard Building

255 Westminster Stree

Commissione

Providence, Rhode Island 02903-3400

October 29,2014

To whom it may concern:

I, Commissioner Deborah A. Gist, on behalf of the Rhode Island Department of Elementary and Secondary Education give approval for Jodi L. Clark to ask former Rhode Island Induction Coaches from 2011-2013 to invite beginning teachers to participate in her dissertation research. I understand that all names of teachers, Induction Coaches, schools, and districts will remain anonymous.

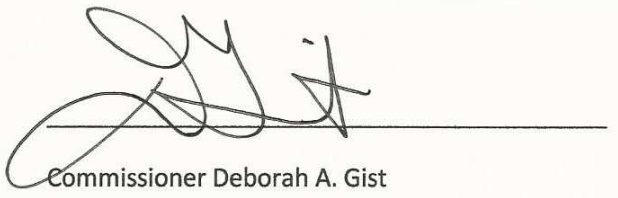




\section{APPENDIX C \\ Email to Induction Coaches}

February 22, 2015

Dear Fellow Induction Coach:

I am writing to request your professional assistance with my doctoral research at the University of Rhode Island, Teachers' Experiences of Induction Coaching: A Retrospective Narrative Inquiry. I have recently been approved by the University of Rhode Island Institutional Review Board, Commissioner Gist, and my major professor who is responsible for the study, Theresa Denney, to conduct my research on induction coaching. I am appealing to you to send the email shown below to your Beginning Teachers from both the 2011-2012 and 2012-2013 school years (first and second year of the program only). I realize that you may not have current emails for the teachers, as some may have changed schools or left the field of education. Please forward this email to as many beginning teachers as you can. They will be asked to give consent and fill out a brief background information survey using SurveyMonkey. If they are selected to participate in the study, I will arrange with them a time and location for an interview and garner a signed consent. Attached is the Interview Guide so that you may feel comfortable with the questions that will be asked. The confidentiality of all participants will be upheld and non-identifiable pseudonyms will be used to protect the identity of all beginning teachers, induction coaches, other teachers, and administrators, as well as school and districts. 


\title{
APPENDIX D
}

\author{
Email to Beginning Teachers
}

Dear Former Participant in the Rhode Island Induction Program:

My name is Jodi Clark. I am a past induction coach from the Rhode Island Induction Program. I am currently working on my $\mathrm{PhD}$ in Education at the University of Rhode Island. In order to complete my dissertation requirement, I am conducting a research study on induction coaching under the guidance of Professor Theresa Deeney, and with the approval of the URI Institutional Review Board and Commissioner Gist. I have asked my fellow induction coaches to reach out to their former beginning teachers to request your participation in my study: Teachers' Experiences of Induction Coaching: A Retrospective Narrative Inquiry. Your participation would require you to give consent and fill out the brief background information survey using the SurveyMonkey link below. If you are selected for the study, I will be contacting you to arrange a time and location of your choice to conduct a one-on-one interview and gain your written consent. The interview should last approximately one hour and will be audio-recorded. A follow-up interview may be requested to verify information.

Thank you so much for your time and interest in my doctoral research. Your participation will be greatly appreciated. I value your input as I research teachers' experiences of induction coaching.

If you are interested in participating in the voluntary research project please, complete the informed consent and survey using the link below. If you have any questions or concerns, you may email me or call (clarkjodi75@gmail.com/401-9327333).

Thank you for your time, Jodi L. Clark 


\section{APPENDIX E}

THE

Signed Consent Form

\section{UNIVERSITY \\ OF RHODE ISLAND \\ COLLEGE OF \\ HUMAN SCIENCE \\ AND SERVICES}

SCHOOL OF EDUCATION

705 Chafee Hall, Flagg Road, Kingston, R1 02881 USA $\quad$ p: $401.874 .2564 \quad f: 401.874 .5471$ uri.edu/hss/education

Project Title: Teachers' Experiences of Induction Coaching: A Retrospective Narrative Inquiry

\section{CONSENT FORM FOR RESEARCH}

You are being invited to take part in a research project described below. The student researcher, Jodi Clark, will explain the project to you in detail. You should feel free to ask questions of either Jodi Clark or the Principal Investigator, Professor Theresa Deeney.

Description of the project:

You are being invited to participate in a study of teachers' experiences of induction coaching. The purpose of this study is to understand beginning teachers' experiences with induction coaching by gaining their stories.

What will be done:

You will be asked to complete a brief on-line questionnaire asking basic background information. If you are selected to take part in the study, you will be asked to determine an agreeable time and location for a one-on-one interview with the researcher. The interview will last approximately one hour and will be audio-recorded, without using your name. During the interview, the researcher may also take notes, which will be used as part of the study. At a later day, a follow-up interview may be requested to clarify information which will last approximately 30 minutes.

Risks or discomfort:

There are no anticipated risks or discomforts associated with this study. If at any time you are uncomfortable answering a question, you may skip the question or discontinue participation in the study.

Benefits of this study:

The benefit of this study is the chance to reflect on your experiences of working with an induction coach. 


\section{Confidentiality:}

Your part in this study is confidential. All names, schools, and districts will remain protected and given pseudonyms. All audio-recorded transcripts will be secured in a locked file cabinet in a locked office (Chafee 605) on the Kingston Campus of the University of Rhode Island. Records will be kept for five years and then destroyed.

Decision to quit at any time:

The decision to take part in this study is up to you. You do not have to participate. If you decided to take part in this study, you may quit at any time. If you wish to quit, simply inform Jodi Clark (401-932-7333, clarkjodi75@gmail.com) of your decision.

\section{Rights and Complaints:}

If you are not satisfied with the way this study is conducted, you may discuss your complaints with Dr. Theresa Deeney at the University of Rhode Island (401-8742682). If you have questions about your rights as a research subject, you may contact the office of Vice President for Research and Economic Development, 70 Lower College Road, Suite 2, University of Rhode Island, Kingston, Rhode Island: (401) 874-4328.

You have read the Consent Form. Your questions have been answered. Your signature on this form means that you understand the information and you agree to participate in this study.

Signature of Participant

Typed/Printed Name
Signature of Researcher

Typed/Printed Name
Date
Date 
Your signature below indicated that you understand that your interview will be audio recorded and what you agree to that recording as specified above.

Signature of Participant

Typed/Printed Name

Date
Signature of Researcher

Typed/Printed Name

Date

Please sign both consent forms, keeping one for yourself. 


\section{APPENDIX F}

\section{SurveyMonkey Questions}

Name:

Contact Information (phone and email):

Degrees:

Certifications:

First year position: [grade, building type (elementary, middle, high), urban/suburban] Gender:

Overall satisfaction with the program (Satisfied, Neutral, Unsatisfied) 


\title{
APPENDIX G
}

\author{
Implied Consent
}

\section{Informed Consent}

Title of Project: Teachers' Experiences of Induction Coaching: A Retrospective Narrative Inquiry

Dear Participant:

You have been invited to take part in the research project described below. If you have any questions, please feel free to call Jodi Clark, or Professor Theresa Deeney, the people mainly responsible for this study.

The purpose of this study is to understand beginning teachers' experiences working with an induction coach. This study will involve filling out a questionnaire which should take approximately 15 minutes. Responses to these items will be used to determine selection in the interview process. Once the selection has occurred, all surveys will be destroyed. If selected for an interview, your identity will be protected as well as indentifying qualities.

YOU MUST BE AT LEAST 18 YEARS OLD to be in this research project.

If you decide to take part in this study, your participation will involve filling out a SurveyMonkey pertaining to your background information and experience working with an induction coach.

The possible risks or discomforts of the study are minimal, although you may feel some embarrassment answering questions about private matters. You may withdraw at any time or skip a question.

Although there are no direct benefits of the study, your answers will help determine participants for the interview selection.

Your part in this study is anonymous. That means that your answers to all questions are private. No one else can know if you participated in this study and no one else can find out what your answers were. Scientific reports will be based on group data and will not identify you or any individual as being in this project.

The decision to participate in this research project is up to you. You do not have to participate and you can refuse to answer any question.

Participation in this study is not expected to be harmful or injurious to you. However, if this study causes you any injury, you should write or call the Student Investigator, Jodi Clark at (401) 932-7333 and Faculty Investigator, Theresa Deeney at the 
University of Rhode Island at (401)874-2682.

If you have other concerns about this study or if you have questions about your rights as a research participant, you may contact the University of Rhode Island's Vice President for Research and Economic Development, 70 Lower College Road, Suite 2, URI, Kingston, RI, (401) 874-4328.

You are at least 18 years old. You have read the consent form and your questions have been answered to your satisfaction. Your filling out the survey implies your consent to participate in this study.

Thank you,

Jodi L. Clark

$\mathrm{PhD}$ Candidate

University of Rhode Island 


\section{APPENDIX H}

Interview Guide

\section{Background of Beginning Teacher:}

Gender:

Age:

Date started:

Degree:

Certifications:

Teaching Position:

School:

Teaching History:

Background of Induction Coach:

Induction coach Certification (if known):

Gender:

\section{Background Questions:}

1. Tell me about your prior experience as an educator.

2. Tell me about the school culture of the building you worked in your first year.

3. Tell me about your principal's support your first year.

4. Tell me about your colleagues' support your first year (not including induction coach).

\section{Main Question:}

Start at the beginning and tell me the story of working with your induction coach.

\section{Follow-Up/ Supporting Questions}

1. What did you do with your coach?

2. What effect did coaching have on your growth and development as a teacher?

3. Tell me about a specific interaction you had with your coach? 


\title{
APPENDIX I
}

\author{
Member Check Email to Beginning Teachers
}

Dear

As you may recall, you participated in an interview for my dissertation research titled, "Beginning Teachers Experiences with Induction Coaches". As part of your initial informed consent for this research, you agreed to answer any follow-up questions.

I know it has been a while since you have heard from me. Over the past year, I have been busy transcribing your interviews and starting to analyze the data I collected. I want to thank you again for your honesty, time, and willingness to be a part of my research. It is extremely important to me that I accurately capture your story as a first year teacher. I have put together a brief overview of some of the highlights of your interview. This is merely a snapshot of the story you told. I am looking to answer three questions through my research:

1. How does the Beginning Teacher describe his/her school environment?

2. How does the Beginning Teacher describe the work with his/her induction coach?

3. How does the Beginning Teacher describe his/her first year of teaching?

I know you are all very busy as this school year ends. At this point, I am asking you to review the brief overview of our time together. As much as possible, I tried to use your own words, and the citations you see come directly from the transcribed interview. I am asking you:

Does this resonate with what you remember about your first year of teaching and working with an induction coach? Is there anything you would like to add?

Due to the sensitive timeline of the research, I am hopeful that you will respond before June $1^{\text {st }}$.

Again, thank you for your time, and I look forward to hearing back from you.

Respectfully,

Jodi Clark 


\section{BIBLIOGRAPHY}

Algozzine, B., Gretes, J., Queen, A. J., \& Cowan-Hathcock, M. (2007). Beginning teacher's perception of their induction program experiences. The Clearing House, 80(3), 137-143.

Andrews, S.P., Gilbert, L. S. \& Martin, E. P. (2006). The first years of teaching: Disparities in perceptions of support. Action in Teacher Education, 28, 4-13.

Andrews, M., Squire, C. \& Tamboukou, M. (Eds.) (2013). Doing narrative research ( $2^{\text {nd }}$ ed.). London: Sage.

Ashforth, B. E. \& Schinoff, B. S. (2016). Identity under construction: How individuals come to define themselves in organizations. Annual Review of Organization Psychology and Organizational Behavior, 3, 111-137.

Bamberg, M. \& Georgakopoulou, A. (2008). Small stories as a new perspective in narrative and identity analysis. Talk \& Text, 28(3), 377-396.

Bandura, A. (1986). Social foundations of thought and action: A social cognitive theory. Englewood Cliffs, N.J.: Prentice-Hall.

Bandura, A. (1997). Self-efficacy: The exercise of control. New York: W. H. Freeman and Co.

Barone, T. (2009). Comments on coulter and Smith: Narrative researchers as witnesses of injustice and agents of social change? Educational Researcher, 38(9), 591-597. 
Berliner, D. C. (1988, February). The development of expertise in pedagogy. Charles W. Hunt Memorial Lecture presented at the annual meeting of the American Association of Colleges for Teacher Education, New Orleans.

Berliner, D. C. (2004). Describing the behavior and documenting the accomplishments of expert teachers. Bulletin of Science, Technology \& Society, 24, 200-212.

Bianchini, J. A. \& Benner, M. E. (2009). The role of induction in learning to teach towards equity: A study of beginning science and mathematics teachers. Science Education, 1-32.

Bogdan, R. C. \& Biklen, S. K. (2014). Qualitative research for education: An introduction to theories and methods ( $5^{\text {th }}$ ed.). New Jersey: Pearson Ed, Inc.

Bruce, C.D., \& Ross, J. A. (2008). A model for increasing performance and teacher efficacy: Teaching peer coaching in grades 3 and 6 mathematics. Canadian Journal of Education, 31(2), 346-370.

Bruner, J. (1986). Actual minds, possible worlds. Cambridge, MA: Harvard University Press.

Clandinin, D. J. (2013). Engaging in narrative inquiry. Walnut Creek, CA: Left Cost Press, Inc.

Clandinin, D. J. \& Connelly, F. M. (1990). Stories if experience and narrative inquiry. Educational Researcher, 19(5), 2-14.

Clandinin, D. J., \& Connelly, F. M. (2000). Narrative inquiry: Experience and story in qualitative research. San Francisco, CA: Jossey-Bass.

Cole, M. \& Scribner, S. (1978). Introduction. Mind in society by L.S. Vygotsky. Cambridge, MA: Harvard University Press. 
Creswell, J. W. (2009). Research design: Qualitative, quantitative, and mixed methods approaches (3rd ed.). Thousand Oaks, CA: Sage.

Darling-Hammond, L. (1997). Doing what matters most: Investing in quality teaching. New York: National Commission of Teaching and America's Future.

Davies, B. \& Harre, R. (1990). Positioning: The discursive production of selves. Journal for the Theory of Social Behaviour, 20(1), 43-63.

Denzin, N. (1989). Interpretive biography. New York: Sage.

Dewey, J. (1938). Experience and education. New York: Macmillian.

Dreyfus, H. L., \& Dreyfus, S. E. (1980). A five-stage model of the mental activities involved in directed skill acquisition. Berkeley: University of California, Berkeley, Operation Research Center.

Dyal, A., \& Sewell, S. (2002). Effective strategies to develop successful beginning teacher for $21^{\text {st }}$ century schools. Catalyst for Change, 31(2), 5-8.

Erlandson, D. A., Harris, E. L., Skipper, B. L., \& Allen, S. D. (1993). Doing naturalistic inquiry: A guide to methods. Newbury Park, CA: Sage Publications, Inc.

Feiman-Nemser, S. (2003). What new teachers need to learn. Educational Leadership, $60(8), 25-29$.

Feiman-Nemser, S., \& Parker, M. B. (1992). Los Angeles mentors: Local guides or educational companions? East Lansing, MI: National Center for Research on Teacher Learning. 
Fletcher, H. S., \& Strong, M. A. (2009). Full-release and site-based mentoring of new elementary grade teachers: An analysis of changes in student achievement. The New Educator, 5, 329-341.

Fletcher, H. S., Strong, M. A. \& Villar, A. (2008). An investigation of the effects of variations in mentor-based induction on the performance of students in California. Teachers College Record, 110(10), 2271-2289.

Fraenkel, J. R., Wallen, N. E., \& Hung, H. H. (2012). How to Design and Evaluate Research in Education ( $8^{\text {th }}$ ed.). New York: McGraw-Hill.

Gee, J. P. (2001). Identity as an analytic lens for research in education. Review of Research in Education, 25, 99-125.

Glaser, B. G. \& Strauss, A. L. (1967). The discovery of grounded theory: Strategies for qualitative research. Chicago: Aldine Publishing Co.

Glickman, C. D. (2002). Leadership for learning: How to help teachers succeed. Alexandria, VA: ASCD.

Gordon, S. P. (1990). Developmental supervision: An exploratory study of a promising model. Journal of Curriculum and Supervision, 5(4), 293-307.

Gray, L., \& Taie, S. (2015). Public School Teacher Attrition and Mobility in the First Five Years: Results from the First through Fifth Waves of the 2007-08 Beginning Teacher Longitudinal Study. First Look. NCES 2015-337.National Center for Education Statistics.

Hiebert, J., Gallimore, R., \& Stigler, J. W. (2002). A knowledge base for the teaching profession: What would it look like and how can we get one? Educational Researcher, 31(5), 3-15. 
Ingersoll, R. M., \& Smith, T. M. (2004). Do teacher induction and mentoring matter? NASSP Bulletin, 88(638), 28-40.

Ingersoll, R. \& Strong, M. (2011). The impact of induction and mentoring for beginning teachers: A critical review of the research. Review of Educational Research, 81 (2), 201-233.

Josselson, R. (2006). Narrative research and the challenge of accumulating knowledge. Narrative Inquiry, 16(1), 3-10.

Kardos S. M., Johnson S. M., Peske H. G., Kauffman D., Liu E. (2001). Counting on colleagues: New teachers encounter the professional cultures of their schools. Educational Administration Quarterly, 37(2), 250-290.

Kapadia, K., Coca, V., \& Easton, J. Q. (2007). Keeping new teachers: A first look at the influences of induction in the Chicago Public Schools. Chicago: Consortium on Chicago School Research, University of Chicago.

Kegan, R. (1982). The evolving self: Problem and process in human development. Cambridge, MA: Harvard University Press.

Kegan, R. (1994). In over our heads: the mental demands of modern life. Cambridge, MA: Harvard University Press.

King, P.M. \& Kitchener, K.S. (1994). Developing reflective judgment: Understanding and promoting intellectual growth and critical thinking in adolescents and adults. San Francisco: Jossey-Bass.

Kleinman, S. \& Copp, M. A. (1993). Emotions and fieldwork: Qualitative research methods series 28. Newbury Park: Sage Publications. 
Knowles, M. S. (1980). The modern practice of adult education: From pedagogy to andragogy. Wilton, CT: Associated Press.

Knowles, M. S. (1990). The adult learner: A neglected species. Houston, TX: Gulf Publishing Co.

Labov, W. (1982). Speech actions and reactions in personal narratives. In D. Tannen (ed.), Analyzing Discourse: Text and Talk. Washington, DC: Georgetown University Press.

Lave, J., \& Wenger, E. (1991). Situated learning: Legitimate peripheral participation. Cambridge, UK: Cambridge University Press.

Lincoln, Y. S., \& Guba, E. G. (1985). Naturalistic inquiry. Newbury Park, CA: Sage.

Linde, C. (1993). Life stories: The creation of coherence. Oxford: Oxford University Press.

Long, J. (2010). The fatal attraction of mentoring: Mentoring for retention of beginning teachers. The International Journal of Interdisciplinary Social Sciences, 5(2), 265-274.

Luttrell, W. ((2000) "Good enough" methods for ethnographic research. Harvard Educational Review, 70(4), 499-524.

Merriam, S. B. (2009). Qualitative research: A guide to design and implementation. San Francisco: Jossey-Bass.

McKamey, C. L. (2013). Ensuring success in school is about more than getting A's: layered stories. in education, 19(1). 
McNulty, C. P., \& Fox, K. R. (2010). Teacher drop-out?: Empowering induction-year teacher to create affable environments to enhance retention. Childhood Education, 86, 5-10.

Menchaca, V. D. (2003). A wake-up call for principal: Are your novice teachers leaving? Catal Change, 33(1), 25-27.

Mishler, E. G. (1999). Storyline: Craftartists' narratives of identity. Cambridge, Massachusetts: Harvard University Press.

Moir, E. (2003). Launching the next generation of teachers through quality induction. New Teacher Center at the University of California, Santa Cruz State Partners Symposium of the National Commission.

Moir, E. (1990). Phases of first year teaching [Online]. California New Teacher Project, California Department of Education (CDE). Retrieved from http:// www.newteachercenter.org/article3.html Moir, E. (2003). Launching the next generation of teachers.

National Commission on Teaching \& America's Future (US). (2003). No dream denied: a pledge to America's children. National Commission on Teaching and America's Future.

Nias, J. (1996). Think about feeling: the emotions in teaching. Cambridge Journal of Education, 26. P. 293-306.

Noddings, N. \& Witherell, C. (1991). Epilogue: Themes remembered and foreseen. In C. Witherell \& N. Noddings (Eds.), Stories lives tell: Narrative and dialogue in education (pp. 279-280). New York: Teachers College Press. 
Olebe, M. (2005). Helping new teachers enter and stay in the profession. Clearing House, 78 (4), 158-163.

Oyserman, D., Elmore, K.\& Smith, G. (2012). Self, self-concept, and identity. In Leary, M. R. \& Tangney, J. P. (Eds.) Handbook of self and identity (pp. 69104). New York: The Guildford Press.

Patton, M.Q. (2002). Qualitative research and evaluation methods ( $3^{\text {rd }}$ ed.). Thousand Oaks, CA: Sage.

Peno, K., \& Silva Mangiante, E. (2012). The journey from novice to expert: Toward a purposeful on-going mentoring model. In C. J. Boden and K. P. King (Eds.), Conversations about adult learning in a complex world. Charlotte, NC: Information Age Publishing.

Poland, B. D. (1995). Transcription quality as an aspect of rigor in qualitative research. Qualitative Inquiry, 1, 290-310.

Reissman, C.K. (1987). When gender is not enough: Women interviewing women. Gender and Society 1(2): 172-207.

Reissman, C.K. (1993). Narrative analysis. Newbury Park: Sage Publications.

Reissman, C.K. (2003). "Narrative Analysis" in M.S. Lewis-Beck, A. Bryman and T. Futing Liao, eds., The sage encyclopedia of social science research methods, 3 Vol. boxed set, Sage.

Riessman, C. K. \& Speedy J. (2007), “'Narrative Inquiry in the Psychotherapy Professions" in Handbook of narrative inquiry. Mapping a Methodology, D. J. Clandinin, ed., Thousand Oaks, California: Sage, 426-456. 
Rhode Island Department of Education (2012). Rhode Island beginning teacher induction program: 2011-2012 NTC induction survey results. Retrieved from http://www.ride.ri.gov/educatorquality/docs/mentoring/20112012_induction_report_ppt.pdf

Rockoff, J. (2008). Does mentoring reduce turnover and improve skills of new employees? Evidence from teachers in New York City. New York: NBER Working Paper.

Rogoff, B. (1990). Apprenticeship in thinking; Cognitive development in social context. New York: Oxford University Press.

Schön, D. J. (1983). The reflective practitioner: How professionals think in action. New York: Basic Books.

Schön, D. J. (1987). Educating the reflective practitioner: Toward a new design for teaching and learning in the profession. San Francisco: Jossey-Bass.

Scott, S.E. \& Palincsar, A.S. (2009). Sociocultural theory. In M. Anderman \& L. H. Anderman (Eds.) Psychology of classroom learning: An encyclopedia. Farmington Hills, MI: Gale Group.

Shulman, L. S. (1986). Those who understand: Knowledge growth in teaching. Educational Researcher, 15(2), 4-14.

Stansbury, K., \& Zimmerman, J. (2000). Lifelines to the classroom: Designing support for beginning teachers. San Francisco: WestEd.

Unruh, L., \& Holt, J. (2010). First year teaching experiences: Are they different for traditionally versus alternatively certified teachers? Action in Teacher Education, 32(3), 3-14. 
Vygotsky, L. S. (1978). Mind in society: The development of higher psychological processes. Edited by M. Cole et al., Cambridge: Harvard University Press.

Wells, K. (2011). Narrative inquiry. Oxford: Oxford University Press, Inc.

Wilkins, E. A., \& Clift, R. T. (2006). Building a network of support for new teachers. Action in Teacher Education, 28(4), 25-35.

Wong, H. K. (2003). Induction programs that keep working. Teachers Net Gazette, 3(1) Retrieved from http://teachers.net/gazette/Jan03/covera.html.

Wong, H. K. (2005). New teacher induction: The foundation for comprehensive, coherent, and sustained professional development. Teacher mentoring and induction: The state of the art and beyond. Portner (Ed). Thousand Oak, CA: Corwin Press.

Zembylas, M. (2003) Emotions and teacher identity: A poststructural perspective. Teachers and Teaching: Theory and Practice, 9(3), pp. 214-238. 